SCIREA Journal of Clinical Medicine

ISSN: 2706-8870

http://www.scirea.org/journal/CM

October 31, 2021

SCIREA

Volume 6, Issue 6, December 2021

\title{
KNOWLEDGE REGARDING METABOLIC SYNDROME AND ADHERENCE TO NCEP-ATP III \\ CLINICAL PRACTICE GUIDELINES AMONG PHYSICIANS IN NEW PROVIDENCE, THE BAHAMAS
}

\section{DR. DANIELLE STRACHAN-BOWLEG}

Department of Family Medicine, Faculty of Medical Sciences, Bahamas Campus

\section{SUBMITTAL SHEET}

Submitted in Fulfillment of the Requirement for the Degree of Doctorate of Medicine in Family Medicine

Candidate: Dr. Danielle Strachan-Bowleg

Department of Family Medicine

Faculty of Medical Sciences

University of the West Indies, School of Clinical Medicine \& Research

Nassau, Bahamas

Supervisors:

Dr. Sabriquet Pinder-Butler

Department of Family Medicine 
Family Medicine Program Director

University of the West Indies, School of Clinical Medicine \& Research

Nassau, Bahamas

Dr. Catherine Conliffe

Department of Family Medicine

University of the West Indies, School of Clinical Medicine \& Research

Nassau, Bahamas

Dr. Morton Anthony Frankson

Epidemiology \& Biostatistics

University of the West Indies, School of Clinical Medicine \& Research

Nassau, Bahamas

University of the West Indies

2020

\section{ABSTRACT}

Knowledge regarding Metabolic Syndrome and adherence to NCEP-ATP III clinical practice guidelines among physicians in New Providence, The Bahamas

Dr. Danielle Strachan-Bowleg

Background: Metabolic Syndrome is becoming an increasingly common public health problem worldwide, including in The Bahamas.

Objective: The aim of this study is to determine the knowledge of physicians in New Providence, Bahamas regarding metabolic syndrome and the adherence to NCEP-ATP III guidelines.

Methods: 110 Physicians from a wide array of specialties involved in primary care throughout the public and private sectors of New Providence, Bahamas were surveyed with a cross-sectional design using convenience sampling. Data was collected using a combined questionnaire inclusive of demographics, clinical cases, and a Modified Metabolic Syndrome 
Knowledge Level Scale (MetS-KS). IBM SPSS software was used to obtain descriptive and inferential statistics.

Results: $99.1 \%$ participants were familiar with the term Metabolic Syndrome, 88.1\% (96) treat patients with MetS, $67 \%$ of physicians identified both the correct numbers of criteria for diagnosis and comprising the NCEP-ATP III definition of metabolic syndrome. Participants had a median score of $84.0 \%$ on Metabolic Syndrome Knowledge Level scale (MetS-KS). $53.3 \%$ of physicians use the NCEP-ATP III diagnostic criteria, $56 \%$ of participants were able to successfully identify the parameters consistent with NCEP-ATP III, and $35 \%$ of participants "often" screen patients adhering to the NCEP-ATP III guidelines.

Conclusion: There is a high level of Metabolic Syndrome Knowledge among physicians in New Providence, Bahamas. Physician participants admit to 'sometimes' adhering to NCEPATP III guidelines when screening patients for MetS. Family Medicine specialty was found to have the most knowledge of and most often uses NCEP-ATP III clinical practice guidelines for MetS. As years in practice and level of training increases, knowledge level, frequency of screening, and health education increases to 'everytime'.

Keywords: metabolic syndrome; cardiovascular risk; knowledge; physician adherence, clinical practice guidelines.

\section{DEDICATION}

First and foremost I have to thank my Almighty Father, for keeping me and seeing me through the most trying four years of my medical career. His grace is sufficient and without him, I am nothing. He ordered my steps and was intentional in his path for me, for that I thank him for providing me the strength to continue to pursue his plan for my life.

I dedicate this to my Husband, my legit partner from the beginning until this very moment. I thank God for saving him for me every day. Only he intimately has seen the blood, sweat, and tears, picked me up every time I fell down and pushed me beyond my limit when I felt there was nothing left. He did this, even in his own struggle and pain. Because of him, I have made it to this point, because of him this is a victory for both of us. I thank and love him with all my heart. 
I dedicate this my two children. I did this for them, so they can have a better life, and afford them every opportunity within their reach.

I dedicate this to my mother, the real MVP. She stood in the gap selflessly and persistently. Without her love and support, this would have been physically impossible.

And last, but by no means the least, I dedicate this to my two grandmothers, Lease Strachan and Maxine Adderley, both of whom I lost along the DM journey. They were by biggest fans, my loudest cheer leaders and they loved me affectionately and unconditionally all my life and I loved them very dearly in return. A piece of me died with each of them, and I know they would have wanted nothing more than to see me continue to excel in my career and at life itself. I am, because they were.

\title{
ACKNOWLEDGEMENTS
}

I would like to thank the persons who assisted me with this research.

Dr. M. A. Frankson

Dr. Sabriquet Pinder-Butler

Dr. Catherine Conliffe

Mrs. Suja Philip - UWI SCMR Librarian

All the doctors who took time out of their busy schedules to oblige me by participating in this study.

\section{TABLE OF CONTENTS}

\author{
ABSTRACT \\ DEDICATION \\ ACKNOWLEDGEMENTS \\ LIST OF TABLES \\ LIST OF FIGURES \\ LIST OF ACRONYMS
}




\section{CHAPTER 1: INTRODUCTION}

\section{CHAPTER 2: LITERATURE REVIEW}

2.1 Metabolic Syndrome: Historical Background

2.2 Clinical criteria and Evolution of Definition

2.3 World Health Organization (WHO)

2.4 European Group for Study of Insulin Resistance (EGIR)

2.5 NCEP-ATP III

2.6 American Academy of Clinical Endocrinologists (AACE)

2.7 International Diabetes Foundation (IDF)

2.8 Comparison of thought

2.8.1 Historical criticisms

2.9 Clinical practice guideline to be assessed

2.10 Metabolic Syndrome: A Bahamian perspective

2.11 Caribbean Prevalence

2.12 Worldwide Prevalence

2.13 Metabolic Syndrome Knowledge and Physician Knowledge

2.14 Physician adherence to clinical practice guidelines

\section{CHAPTER 3: RATIONALE}

\section{CHAPTER 4: AIM}

4.1 Objectives

4.2 Hypothesis

\section{CHAPTER 5: METHODOLOGY}

5.1 Study Design and population

\subsection{Selection issues}

5.2.1 Approach

5.2.2 Selection Criteria

5.2.3 Sampling frame

5.2.4 Sampling size

5.3 Procedure and Instrument

5.4 Data collection and management 
5.5 Statistical analysis

5.6 Further ethical considerations

\section{CHAPTER 6: RESULTS}

6.1 Response rate

6.2 Patient Demographics

6.2.1 Participants' Specialty

6.3 Health Literacy in regards to MetS

6.3.1 Familiarity with MetS

6.3.2 Treat patients with MetS

6.3.3 Which physician should treat MetS

6.3.4 MetS prevalence in population

6.3.5 Total \# criteria comprising MetS

6.3.6 Number of criteria for MetS diagnosis

6.3.7 MetS Recognition of Clinical cases

6.3.8 MetS influence on prognosis

6.3.9 MetS as a risk factor for cancer

6.3.10 Metabolic Knowledge Level Scale (MetS-KS)

6.4 Physicians' experiences with Screening for MetS

6.4.1 Evaluating for MetS

6.4.2 Measuring Waist Circumference

6.4.3 Calculating BMI

6.4.4 Calculating ASCVD

6.5 Physicians' perception on health education

6.5.1 Engaging patients in health education

6.5.2 Informed of CV risk post visit

6.5.3 Recommending risk factor adjustment

6.5.3.1 Risk Factor: waist circumference

6.5.3.2 Risk Factor: blood glucose

6.5.3.3 Risk Factor: lifestyle change

6.5.3.4 Counselling on lifestyle modification

6.6 Adherence to NCEP-ATP III clinical practice guidelines

6.6.1 Criteria used for diagnosis of MetS

6.6.2 Knowledge of NCEP-ATP III parameters 
6.6.3 Screening adhering to NCEP-ATP III guidelines

6.6.4 Screening for comorbidities in isolation

\section{CHAPTER 7: DISCUSSION}

7.1 Physicians' Profile

7.2 Physicians' Health Literacy in regards to MetS

\subsection{MetS-KS}

7.4 Physicians' experiences with screening for MetS

7.5 Physicians' engage in health education

7.6 Adherence to NCEP-ATP III

7.7 Limitations

\section{CHAPTER 8: CONCLUSION}

8.1 Recommendations

\section{REFERENCES}

\section{APPENDICES}

Appendix A - Further Data Analysis

Appendix B - Survey Consent Form

Appendix C - Questionnaire

Appendix D - Questionnaire Permission Request

Appendix E - Approvals 


\section{LIST OF TABLES}

Table \#

Table Heading

Page

6.1 Participants' demographics

6.2 Total \# criteria in MetS

6.3 Number of criteria in MetS Dx

$6.4 \quad$ MetS-KS frequency correct answers (\%)

6.5 Frequency for evaluating for MetS

6.6 Recommending risk factor adjustment

6.7 Recommended risk factors to adjust

6.8 Criteria used for diagnosis of MetS

6.9 Parameters for differing clinical practice guidelines

6.10 Participants' frequency choosing parameters

\section{LIST OF FIGURES}

Figure \#

Figure Heading

Page

6.1 Participants' years since graduating medical school

6.2 Participants' place of practice

6.3 Participants' specialty

$6.4 \quad$ \# of physician participants by specialty grouping

6.5 Which physician should treat MetS

6.6 Frequency total \# Criteria comprising MetS

6.7 Correct total \# of criteria x level of training

6.8 Frequency \# of criteria in MetS Dx

6.9 Correct \# criteria included in MetS Dx x level training

6.10 Frequency scoring higher than $75 \%$ on MetS-KS

6.11 Participants' score performance on MetS-KS

6.12 Score performance on MetS-KS x level of training

6.13 Score performance on MetS-KS x specialty grouping

6.14 Frequency of evaluating for MetS

6.15 Median freq. calculating BMI x specialty grouping

6.16 Median freq. calculating ASCVD x specialty grouping

6.17 Median freq. engaging in health education $\mathrm{x}$ specialty grouping 
6.18 Median freq. thinking patients feel well informed about CV risk post visit

6.19 Frequency of recommending risk factors upon discharge

6.20 Most common risk factors recommended for adjustment

6.21 Most commonly recommended risk factors for adjustment $\mathrm{x}$ level of training

6.22 Criteria most often used to make Dx of MetS

6.23 Diagnostic Criteria most often used x specialty grouping

6.24 Freq. choosing parameters consistent with NCEP guidelines

6.25 Freq. correctly identifying category “ $\mathrm{C}$ ' specific to NCEP guidelines $\mathrm{x}$ specialty grouping

\section{LIST OF ACRONYMS}

AACE - American Association of Clinical Endocrinologists

A\&E - Accident \& Emergency

AHA/NHLBI - American Heart Association National Heart Lung Blood Institute

AMI - Acute Myocardial Infarction

ASCVD - Atherosclerotic Cardiovascular Disease

BMI - Body Mass Index

BG - Blood glucose

$\mathrm{BP}-$ Blood pressure

CVA - Cerebrovascular Accident

CVD - Cardiovascular disease

Dx - Diagnosis

EGIR - European Group for Study of Insulin Resistance

FPG - Fasting plasma glucose

FM - Family Medicine 
HDL - High Density Lipoprotein

IDF - International Diabetes Foundation

IGT - Impaired glucose tolerance

IM - Internal Medicine

IQR - Inter-Quartile Range

JNC VII - Joint National Committee VII

LDL - Low Density Lipoprotein

MetS - Metabolic Syndrome

MetS-KS - Metabolic Syndrome Knowledge Level Scale

NCEP-ATP III - National Cholesterol Education Program-Adult Treatment Panel III

O\&G - Obstetrics \& Gynaecology

PMH - Princess Margaret Hospital

PCP - Primary care physician

SHO - Senior House Officer

SR - Senior Registrar

TG - Triglycerides

WC - Waist circumference

WHO - World Health Organization

Yrs - Years 


\section{CHAPTER 1}

\section{INTRODUCTION}

Due to sedentary lifestyles and excessive calorie intake, the metabolic syndrome is becoming an increasingly common health problem in the world ${ }^{1}$, as well as in The Bahamas. This syndrome is a combination of disorders that include: obesity, insulin resistance, glucose intolerance, impaired regulation of body fat and high blood pressure. Grouping of such cardio-metabolic risk factors, which include dyslipidemia, hypertriglyceridemia, obesity and glucose metabolic disturbances in a hypertensive individual, results in an elevated risk of cardiovascular disease, type II diabetes and more importantly mortality ${ }^{2-5}$. Unfortunately, compilation of these medical illnesses birthed the concept of a syndrome that more often times than not has been found to become quite common in everyday clinical practice. Complications resulting from metabolic syndrome significantly reduces patient quality of life and represents a huge socio-economic burden ${ }^{1}$. There is currently a debate challenging the significance of diagnosing metabolic syndrome in clinical practice, rather than treating individual risk factors ${ }^{6}$. There is now convincing evidence that prevention is the most important and effective way to reduce the personal and socio-economic burden of the metabolic syndrome and its associated complications ${ }^{7}$.

This clinical phenomenon is encountered in all fronts of the medical community and the primary care management process begins with physicians in all specialties and practice pathways. The primary care setting is the cornerstone for chronic non-communicable disease management. It is posted at the forefront and serves as the gatekeeper to ensure persons avoid complications associated with diabetes, hypertension and obesity. It is also important to note that although evidence based guidelines and effective treatments exist, there is a wide therapeutic gap between guidelines and practice ${ }^{8}$ and this treatment gap is largely attributed to physician and patient adherence, in addition to health care organizations' attitudes ${ }^{8}$. With that said, the exploration into attitudes regarding physician adherence to any particular guideline in regards to the management of metabolic syndrome will be of interest. This study will aim to determine knowledge of physicians regarding metabolic syndrome, frequency of screening patients in daily practice, engagement in health education and preventative measures, and finally adherence to clinical practice guidelines, specifically the National Cholesterol Education Program-Adult Treatment Panel III. 
This type of study has never been done in The Bahamas, hence it will serve to give insight into how well the physician body is identifying the components of the syndrome, recognizing the importance of and adhering to guidelines and also contributing to assessing and therefore decreasing patient cardiovascular risk.

\section{CHAPTER 2}

\section{LITERATURE REVIEW}

For the purpose of this review an electronic search of published articles was conducted using the search engines EbscoHost, Google Scholar, Google, and West Indian Medical Journal to include data up to August 2020; using combination of key words: metabolic syndrome, cardiovascular risk, knowledge, practice, physician adherence, and clinical practice guidelines yielded approximately 294,771 articles. Search was then tailored by using specific combinations of key words to obtain more relevant articles, and this was narrowed down to 5,057 articles. Seventy-two (72) articles were found to be useful for this study.

\subsection{Metabolic Syndrome: Historical Background}

Metabolic syndrome is only now recently, within the last 30 years, an actual diagnosis because of its linkage to cardiovascular risk. Historically, before the 1980's, its clinical picture was like pieces to a puzzle that health care providers did not even know existed. Its components were evaluated in isolation and treatment was geared toward the same. It has been known by many names prior to what we know it as today. Syndrome X, being the most infamous, was first defined by Reaven in $1988^{\circ}$, and although by that point in time it had been identified, its clarity was still compromised. A year later, Kaplan's study labelled it the "deadly quartet" thereby formalizing the connection between obesity, metabolic syndrome, and cardiovascular risk ${ }^{9}$. The two most paramount features characterizing Syndrome X, was insulin resistance and hyperinsulinemia. These two factors lead to the inevitable metabolic sequelae comprising an aggregate of clinical conditions ${ }^{10}$ that will be eventually known and recognized as the Metabolic Syndrome. The metabolic syndrome is often referred to as if it were a discreet entity with a single cause however, available data suggest that it truly is a syndrome, i.e. a grouping of atherosclerotic cardiovascular disease (ASCVD) risk factors, but one that probably has more than one cause ${ }^{11}$. Regardless of the cause, the syndrome identifies individuals at an elevated risk for ASCVD ${ }^{11}$. According to the American Heart Association NHLBI Scientific statement Metabolic Syndrome (MetS) has been officially defined as "a 
constellation of interrelated risk factors of metabolic origin that appear to directly promote the development of atherosclerotic cardiovascular disease" ${ }^{11}$. The aggregate of clinical conditions include central and abdominal obesity, systemic hypertension, impaired glucose tolerance (or type 2 diabetes mellitus), and atherogenic dyslipidemia ${ }^{10}$. MetS has been described as a premorbid condition that develops in the setting of insulin resistance with factors such as poor diet, physical inactivity, obesity, and genetics all playing a contributing role ${ }^{12}$. Once these characteristics exist in tandem it can lead to a prothrombotic state and pro-inflammatory state $^{11}$. According to Harikrishnan et al, this in turn, increases the risk for development of type 2 diabetes mellitus, coronary artery disease (CAD), and other cardiovascular diseases and has been shown to independently increase all-cause mortality ${ }^{12}$.

\subsection{Metabolic Syndrome: Clinical Criteria and Evolution of the Definition}

There is no single pathogenesis that can explain or exists for the MetS phenomenon. Thus, "the syndrome could range from unrelated risk factors to risk factors linked through a common underlying mechanism"11. In the effort to introduce the MetS into clinical practice ${ }^{11}$, the point of view became institutionalized ${ }^{13}$ and with that the birth of respective organizations' definitions and criteria for diagnosis. Over the years, there have been many expert groups attempting to develop simple diagnostic criteria to be used in clinical practice to assist in the identification of patients who demonstrate multiple components of the metabolic syndrome ${ }^{11}$. The National Cholesterol Education Program's Adult treatment Panel III (NCEPATP III), the World Health Organization (WHO), the American Association of Clinical Endocrinologists (AACE), the European Group for Study of Insulin Resistance (EGIR) and the International Diabetic Federation (IDF) all have slightly different definitions however, MetS is consistently characterized by a combination of metabolic abnormalities such as insulin resistance, hyperglycemia, obesity, dyslipidemia, and hypertension, as previously defined by Wang et $\mathrm{al}^{13}$.

\subsection{World Health Organization (WHO)}

The first proposal came in 1998 from a consultation group on the definition of diabetes for the World Health Organization (WHO) ${ }^{11,14}$. Grundy et al explained it best with this quote "this group emphasized insulin resistance as the major underlying risk factor and required evidence of insulin resistance for diagnosis. This followed on the widely held belief that insulin resistance is the primary cause of the syndrome. A diagnosis of the syndrome by WHO criteria could thus be made when a patient exhibited one of several markers of insulin resistance plus 2 additional risk factors" 11 . The WHO group saw it fit to use the term 
metabolic syndrome in type 2 diabetics, acknowledging that these patients fell into the cluster category which puts them at a high risk for ASCVD $11,15,16$.

\subsection{European Group for Study of Insulin Resistance (EGIR)}

In 1999, the European Group for Study of Insulin Resistance (EGIR) proposed a modification of the WHO definition ${ }^{11}{ }^{17}$. This school of thought coined the term insulin resistance syndrome because it was assumed that insulin resistance was the primary cause and its presence was imperative for diagnosis. Most specifically, EGIR's definition, as laid out by Grundy et al, says that an elevated plasma insulin plus 2 other factors - abdominal obesity, hypertension, elevated triglycerides or reduced HDL-C, and elevated plasma glucoseconstituted a diagnosis of the insulin-resistance syndrome ${ }^{11}$. However, notably, in comparison to the WHO, EGIR focused more on abdominal obesity and therefore excluded patients with type 2 diabetes from their syndrome because insulin resistance was viewed primarily as a risk factor for diabetes ${ }^{11}$.

\subsection{National Cholesterol Education Program (NCEP) Adult Treatment Panel III (ATP} III)

In 2001, the National Cholesterol Education Program (NCEP) Adult Treatment Panel III (ATP III) introduced alternative clinical criteria for defining the metabolic syndrome ${ }^{18}$. In so doing, the purpose of ATP III identified those persons at higher long-term ASCVD risk who would benefit from clinical lifestyle intervention ${ }^{11}$. The NCEP-ATP III organization closely looked at the need to include insulin resistance as a part of the syndrome, in so doing, they recognized the cumbersome nature of trying to acquire measures of insulin resistance, and noted that investigations like glucose tolerance testing was not a part of routine clinical practice. Therefore, this body did not draw "conclusions on mechanistic pathogenesis"11. "The ATP III criteria thus required no single factor for diagnosis, but instead made the presence of 3 of 5 factors the basis for establishing the diagnosis; these were abdominal obesity (also highly correlated with insulin resistance), elevated triglycerides, reduced HDL-C, elevated blood pressure, and elevated fasting glucose (IFG or type 2 diabetes mellitus)" Although ATP III did not make any single risk factor (eg, abdominal obesity) a requirement for diagnosis, it was firm on its position that abdominal obesity is a paramount risk factor for the syndrome ${ }^{11}$. Its cut-points for abdominal obesity came from the definition in the 1998 National Institutes of Health obesity clinical guidelines ${ }^{11}{ }^{19}$; they were a waist circumference of $\geq 102 \mathrm{~cm} \mathrm{(} \geq 40$ in) for men and $\geq 88 \mathrm{~cm} \mathrm{(} \geq 35 \mathrm{in})$ for women. It would be remiss not to mention Grundy et al's detailed reasoning behind waist circumference; these WC cut-points 
represented the upper quartile of the US population. However, some ethnic groups (eg, Asians, especially South Asians) appear to be susceptible to development of the metabolic syndrome at waist circumferences below ATP III cut-points. Comparatively, ATP III, like the WHO, allowed for a diagnosis of MetS in the presence of type 2 diabetes because of the high ASCVD risk, so the combination of both T2DM with other metabolic risk factors should always be examined together because studies have proven that intervention can significantly reduce ASCVD risk ${ }^{11}$.

\subsection{American Academy of Clinical Endocrinologists (AACE)}

In 2003, the American Association of Clinical Endocrinologists (AACE) modified the ATP III criteria to refocus on insulin resistance as the primary cause of metabolic risk factors ${ }^{20,11}$. Like the EGIR, they used the name insulin resistance syndrome ${ }^{17}, 11$. There was no particular number of risk factors needed for diagnosis, but they included family history of ASCVD or type 2 diabetes mellitus. However, the "major criteria still included IGT, elevated blood pressure, reduced HDL-C, elevated triglycerides, and obesity"11. AACE's definition further implied that the diagnosis of type 2 DM meant insulin resistance syndrome could no longer $\operatorname{apply}^{11}$.

\subsection{International Diabetes Foundation (IDF)}

In 2005, the International Diabetes Foundation (IDF), which included several members of the original WHO writing body, published new criteria that again modified the ATP III definition $^{21,11}$. They recognized the ATP III definition's clinical simplicity and preferred and also acknowledged that abdominal obesity highly correlated with insulin resistance. Therefore, the IDF made abdominal obesity necessary for their clinical definition. Further explaining that when abdominal obesity is present, 2 additional factors originally listed in the ATP III definition are sufficient for diagnosis ${ }^{11}$. There is recognition and emphasis on ethnic differences. The present AHA/NHLBI statement, in contrast to IDF, maintains the ATP III criteria except for minor modifications; this decision is based on the conclusion that ATP III criteria are simple to use in a clinical setting and have the advantage of avoiding emphasis on a single cause ${ }^{11}$. Additionally, many intensive studies have been carried out to evaluate the ATP III criteria for the diagnosis of metabolic syndrome ${ }^{22,11}$ and the majority of these reports are supportive of the present structure of ATP III criteria ${ }^{11}$. With that said, continuity with the original ATP III definition, adopted worldwide in clinical practice, remains appropriate in the absence of new evidence to the contrary ${ }^{11}$. 


\subsection{Comparison of thought}

Below are two tabulated charts, for visual representation, comparing the criteria for appreciation of the slight differences. The first is courtesy of Grundy et al, "Diagnosis and Management of the Metabolic Syndrome, An American Heart Association/National Heart, Lung, and Blood Institute Scientific Statement" ${ }^{11}$, and the second table, via Joshi et al, is included more specifically for the IDF criteria, to bring attention to the central obesity component and its relation to ethnic specificities in their grouped categories ${ }^{23-26}$.

\begin{tabular}{|c|c|c|c|c|c|}
\hline Clinical Measure & WHO (1998) & EGIR & ATP III (2001) & AACE (2003) & IDF (2005) \\
\hline Insulin resistance & $\begin{array}{c}\text { IGT, IFG, T2DM, or lowered insulin } \\
\text { sensitivity* } \\
\text { plus any } 2 \text { of the following }\end{array}$ & $\begin{array}{l}\text { Plasma insulin }>75 \text { th percentile } \\
\text { plus any } 2 \text { of the following }\end{array}$ & $\begin{array}{l}\text { None, } \\
\text { but any } 3 \text { of the following } 5 \\
\text { features }\end{array}$ & $\begin{array}{l}\text { IGT or IFG } \\
\text { plus any of the } \\
\text { following based on } \\
\text { clinical judgment }\end{array}$ & None \\
\hline Body weight & $\begin{array}{c}\text { Men: waist-to-hip ratio }>0.90 \\
\text { women: waist-to-hip ratio }>0.85 \\
\text { and } / \text { or } \mathrm{BMI}>30 \mathrm{~kg} / \mathrm{m}^{2}\end{array}$ & $\begin{array}{l}\text { WC } \geq 94 \mathrm{~cm} \text { in men or } \\
\geq 80 \mathrm{~cm} \text { in women }\end{array}$ & $\begin{array}{l}W C \geq 102 \mathrm{~cm} \text { in men or } \\
\geq 88 \mathrm{~cm} \text { in woment }\end{array}$ & $\mathrm{BMI} \geq 25 \mathrm{~kg} / \mathrm{m}^{2}$ & $\begin{array}{c}\text { Increased WC (population } \\
\text { specific) } \\
\text { plus any } 2 \text { of the following }\end{array}$ \\
\hline \multirow[t]{2}{*}{ Lipid } & \multirow{2}{*}{$\begin{array}{l}\mathrm{TG} \geq 150 \mathrm{mg} / \mathrm{dL} \text { and} / o r \mathrm{HDL}-\mathrm{C} \\
<35 \mathrm{mg} / \mathrm{dL} \text { in men or }<39 \mathrm{mg} / \mathrm{dL} \\
\text { in women }\end{array}$} & \multirow{2}{*}{$\begin{array}{l}\mathrm{TG} \geq 150 \mathrm{mg} / \mathrm{dL} \text { and } / \text { or HDL-C } \\
<39 \mathrm{mg} / \mathrm{dL} \text { in men or women }\end{array}$} & $\mathrm{TG} \geq 150 \mathrm{mg} / \mathrm{dL}$ & \multirow{2}{*}{$\begin{array}{c}\mathrm{TG} \geq 150 \mathrm{mg} / \mathrm{dL} \text { and } \\
\mathrm{HDL}-\mathrm{C}<40 \mathrm{mg} / \mathrm{dL} \text { in } \\
\mathrm{men} \text { or }<50 \mathrm{mg} / \mathrm{dL} \text { in } \\
\text { women }\end{array}$} & $\mathrm{TG} \geq 150 \mathrm{mg} / \mathrm{dL}$ or on $\mathrm{TG} R x$ \\
\hline & & & $\begin{array}{l}\mathrm{HDL}-\mathrm{C}<40 \mathrm{mg} / \mathrm{dL} \text { in men or } \\
<50 \mathrm{mg} / \mathrm{dL} \text { in women }\end{array}$ & & $\begin{array}{c}\mathrm{HDL}-\mathrm{C}<40 \mathrm{mg} / \mathrm{dL} \text { in men or } \\
<50 \mathrm{mg} / \mathrm{dL} \text { in women or on } \\
\mathrm{HDL}-\mathrm{C} \text { Rx }\end{array}$ \\
\hline Blood pressure & $\geq 140 / 90 \mathrm{~mm} \mathrm{Hg}$ & $\begin{array}{c}\geq 140 / 90 \mathrm{~mm} \mathrm{Hg} \text { or on } \\
\text { hypertension } \mathrm{Rx}\end{array}$ & $\geq 130 / 85 \mathrm{~mm} \mathrm{Hg}$ & $\geq 130 / 85 \mathrm{~mm} \mathrm{Hg}$ & $\begin{array}{l}\geq 130 \mathrm{~mm} \mathrm{Hg} \text { systolic or } \\
\geq 85 \mathrm{~mm} \mathrm{Hg} \text { diastolic or on } \\
\text { hypertension Rx }\end{array}$ \\
\hline Glucose & IGT, IFG, or T2DM & IGT or IFG (but not diabetes) & $\begin{array}{l}>110 \mathrm{mg} / \mathrm{dL} \text { (includes } \\
\text { diabetes) } \ddagger\end{array}$ & $\begin{array}{l}\text { IGT or IFG (but not } \\
\text { diabetes) }\end{array}$ & 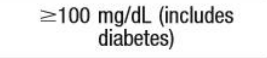 \\
\hline Other & Microalbuminuria & & & $\begin{array}{l}\text { Other features of } \\
\text { insulin resistance§ }\end{array}$ & \\
\hline
\end{tabular}

T2DM indicates type 2 diabetes mellitus; WC, waist circumference; BMl, body mass index; and TG, triglycerides. All other abbreviations as in text.

*Insulin sensitivity measured under hyperinsulinemic euglycemic conditions, glucose uptake below lowest quartile for background population under investigation. †Some male patients can develop multiple metabolic risk factors when the waist circumference is only marginally increased (eg, 94 to $102 \mathrm{~cm}$ [37 to 39 in]). Such patients may have a strong genetic contribution to insulin resistance. They should benefit from changes in lifestyle habits, similar to men with categorical increases in waist circumference.

$\ddagger$ The 2001 definition identified fasting plasma glucose of $\geq 110 \mathrm{mg} / \mathrm{dL}(6.1 \mathrm{mmol} / \mathrm{L})$ as elevated. This was modified in 2004 to be $\geq 100 \mathrm{mg} / \mathrm{dL}$ ( $5.6 \mathrm{mmol} / \mathrm{L})$, in accordance with the American Diabetes Association's updated definition of IFG. ${ }^{46,47,77}$ 
Table 1. Metabolic Syndrome Definitions by Three Different Organizations

\begin{tabular}{|c|c|c|c|}
\hline \multirow[b]{2}{*}{ MetS definition } & \multicolumn{3}{|c|}{ Organization } \\
\hline & $I D F^{\mathrm{a}}$ & $W H O^{\mathbf{b}}$ & ATPIII ${ }^{\mathrm{c}}$ \\
\hline Main components & $\begin{array}{l}\text { Central obesity: } \\
\text { For European, Eastern Mediterranean, } \\
\text { Sub-Saharan Africans, and Middle } \\
\text { Eastern, males } \geq 94 \mathrm{~cm} \text {, females } \\
\geq 80 \mathrm{~cm} \\
\text { For South Asians, Chinese, Japanese, } \\
\text { and South and Central Americans, } \\
\text { males } \geq 90 \mathrm{~cm} \text {, females } \geq 80 \mathrm{~cm}\end{array}$ & $\begin{array}{l}\text { Glucose intolerance, } \\
\text { impaired glucose } \\
\text { tolerance, or diabetes } \\
\text { and/or insulin } \\
\text { resistance }\end{array}$ & - \\
\hline $\begin{array}{l}\text { Additional } \\
\text { components }\end{array}$ & $\begin{array}{l}\text { At least two of four additional } \\
\text { components }\end{array}$ & $\begin{array}{l}\text { Two or more } \\
\text { components }\end{array}$ & $\begin{array}{l}\text { Three or more of the } \\
\text { following five } \\
\text { components }\end{array}$ \\
\hline $\begin{array}{l}\text { Raised } \\
\text { triglycerides }\end{array}$ & $\begin{array}{l}\geq 150 \mathrm{mg} / \mathrm{dL}(1.7 \mathrm{mmol} / \mathrm{L}) \text { or } \\
\text { specific treatment for this lipid } \\
\text { abnormality }\end{array}$ & $\begin{aligned} \geq & 150 \mathrm{mg} / \mathrm{dL} \\
& (1.7 \mathrm{mmol} / \mathrm{L})\end{aligned}$ & $\geq 150 \mathrm{mg} / \mathrm{dL}(1.7 \mathrm{mmol} / \mathrm{L})$ \\
\hline $\begin{array}{l}\text { Reduced HDL } \\
\text { cholesterol }\end{array}$ & $\begin{array}{l}\text { Men: }<40 \mathrm{mg} / \mathrm{dL}(1.03 \mathrm{mmol} / \mathrm{L}) \\
\text { Women: }<50 \mathrm{mg} / \mathrm{dL}(1.29 \mathrm{mmol} / \mathrm{L}) \\
\text { Or specific treatment for this lipid } \\
\text { abnormality }\end{array}$ & $\begin{array}{l}\text { Men: }<35 \mathrm{mg} / \mathrm{dL} \\
(0.9 \mathrm{mmol} / \mathrm{L}) \\
\text { Women: }<39 \mathrm{mg} / \mathrm{dL} \\
(1.0 \mathrm{mmol} / \mathrm{L})\end{array}$ & $\begin{array}{l}\text { Men: }<40 \mathrm{mg} / \mathrm{dL} \\
(1.03 \mathrm{mmol} / \mathrm{L}) \\
\text { Women: }<50 \mathrm{mg} / \mathrm{dL} \\
(1.29 \mathrm{mmol} / \mathrm{L})\end{array}$ \\
\hline $\begin{array}{l}\text { Raised blood } \\
\text { pressure }^{\mathrm{d}}\end{array}$ & $\begin{array}{l}\geq 130 / \geq 85 \mathrm{~mm} \mathrm{Hg} \text { or treatment } \\
\text { of previously diagnosed } \\
\text { hypertension }\end{array}$ & $\geq 140 / 90 \mathrm{~mm} \mathrm{Hg}$ & $\geq 130 / \geq 85 \mathrm{~mm} \mathrm{Hg}$ \\
\hline $\begin{array}{l}\text { Raised fasting } \\
\text { plasma glucose }\end{array}$ & $\begin{array}{l}\geq 100 \mathrm{mg} / \mathrm{dL}(5.6 \mathrm{mmol} / \mathrm{L}) \text { or } \\
\text { previously diagnosed type } 2 \\
\text { diabetes }\end{array}$ & - & $\geq 110 \mathrm{mg} / \mathrm{dL}(6.1 \mathrm{mmol} / \mathrm{L})$ \\
\hline Central obesity & (Main component) & $\begin{array}{l}\text { Men: waist-to-hip } \\
\text { ratio }>0.90 \\
\text { Women: waist-to-hip } \\
\text { ratio }>0.85 \\
\text { Or BMI }>30 \mathrm{~kg} / \mathrm{m}^{2}\end{array}$ & $\begin{array}{l}\text { Men: waist circumference } \\
\quad>102 \mathrm{~cm}(>40 \text { inches }) \\
\text { Women: waist circumference } \\
>88 \mathrm{~cm}(>35 \text { inches })\end{array}$ \\
\hline Microalbuminuria & - & $\begin{array}{l}\text { Urinary albumin } \\
\text { excretion rate } \\
\geq 20 \mu \mathrm{g} / \mathrm{min} \text { or } \\
\text { albumin:creatinine } \\
\text { ratio } \geq 30 \mathrm{mg} / \mathrm{g}\end{array}$ & - \\
\hline
\end{tabular}

${ }^{\mathrm{a}}$ Extracted from Alberti et al. ${ }^{6}$

${ }^{{ }^{6} \text { Extracted from World Health Organization. }}{ }^{8}$

'Extracted from Expert Panel on Detection, Evaluation, and Treatment of High Blood Cholesterol in Adults.

${ }^{\mathrm{d}}$ Values given are for systolic/diastolic blood pressure.

ATPIII, National Cholesterol Education Program's Adult Treatment Panel III; BMI, body mass index; HDL, high-density lipoprotein; IDF, International Diabetes Federation; MetS, metabolic syndrome; WHO, World Health Organization.

\subsubsection{Historical criticisms of value of metabolic syndrome vs. treating individual components}

In light of the comparison of and multiple schools of thought, it would be remiss not to mention the historical debate that has surrounded Metabolic Syndrome and its value to patient management and even more so, its role in determining cardiovascular risk. According to an article published 2013, in the American Journal of Managed Care (AJMC) by Evidence-Based Diabetes management proposed the question "Is metabolic syndrome a cluster of risk factors or a syndrome?"27. It further went on to explain that, proponents for characterizing metabolic syndrome as a syndrome believe that the evidence linking the risk factors with the development of diabetes and CVD supports the view that it is a treatable entity ${ }^{27}$. Detractors believe that metabolic syndrome is really just a clustering of risk factors, without any known underlying mechanism that associates the maladies ${ }^{27}$. Confounding the discussion is whether 
metabolic syndrome is a pre-morbid condition-whether metabolic syndrome can only be recognized before a patient is given a diagnosis of diabetes or CVD, thus excluding the population with these highly prevalent chronic conditions or on the other hand, an actual diagnosis of diabetes or CVD does not affect the underlying mechanism (eg, insulin resistance or some other factor still exists $)^{27}$. Numerous recent studies have described MetS as a premorbid condition in most instances, has been found to be more of relative risk than that of predictive value. This is demonstrated in the 20 year long prospective study done in Rotterdam, Netherlands where elderly patients were followed and the IDF, EGIR, and American Heart Association National/Heart, Lung and Blood Institute AHA/NHLBI definitions were used for MetS, as well definitions for Type II DM, stroke and cardiovascular and all-cause mortality ${ }^{28}$. This study specifically sought "to investigate whether the metabolic syndrome as a syndrome captures more of the risk for clinical endpoints than the individual components" 28 . Although large variability existed between the findings for the specific definitions with respect to clinical events and mortality, "in a relatively old population the metabolic syndrome did not show an additional predictive value on top of its individual components", it moreso served as a means for easier identification of high risk patients ${ }^{28}$.

Unwin et al noted "of importance to the clinical value of the metabolic syndrome is whether it provides more predictive information than considering its components individually, i.e. is it greater than the sum of its parts?" 29 . Review of several studies addressed this issue, and none found that considering the components together (as a syndrome) had any greater predictive value than considering them separately ${ }^{28,30}$, however, one recent study has suggested that the syndrome does provide predictive power for cardiovascular disease (CVD) events even after adjusting for its individual components ${ }^{29,30}$. The weight of evidence strongly suggests that individuals with the metabolic syndrome have a much higher risk for cardiovascular disease and diabetes than individuals without the syndrome ${ }^{29,31}$. This is hardly surprising given that the components of the syndrome are well known risk factors. The estimates of the increased risk vary from $30-400 \% 29,31$, probably mainly representing differences in the underlying populations studied and the length of follow up. In such studies it has been found that excess risk remains after adjustment for other conventional cardiovascular risk factors ${ }^{29,31}$. "Also relevant to its clinical value is whether it provides a better alternative to other approaches to predicting CVD risk, such as those based on the Framingham risk equation and made widely available for use in clinical practice. Studies addressing this issue are limited and somewhat inconsistent in their findings, but overall suggest that the metabolic syndrome performs no 
better or worse than the Framingham risk equation" ${ }^{29}$. For example, in the San Antonio Heart Study, using data on subjects free of diabetes and CVD at baseline and followed for 7-8 years, the Framingham risk equation had a higher sensitivity for predicting cardiovascular disease events than the presence of the syndrome, and adding metabolic syndrome did not improve the prediction of events ${ }^{29,32}$. Similar comparisons with alternative risk prediction scores, such as the European version (SCORE) ${ }^{29,33}$ would be worthwhile.

Wassink et al acknowledged that despite criticisms associated with MetS, its clinical relevance lies in the pathophysiology of insulin resistance and its associated metabolic changes and vascular consequences ${ }^{34}$. "Insulin resistance induces several metabolic changes, including hyperglycemia, dyslipidemia and hypertension, all leading to increased cardiovascular risk. In addition, the dysfunctional adipocyte, reflected largely by low adiponectin levels and a high TNF concentration, directly influences the vascular endothelium, causing endothelial dysfunction and atherosclerosis. Adipocyte dysfunction could therefore be regarded as the common antecedent of both insulin resistance and atherosclerosis and functions as the link between obesity and cardiovascular disease. Targeting the dysfunctional adipocyte may reduce the risk for both cardiovascular disease and the development of type 2 diabetes" ${ }^{34}$. Wassink et al further deduced that the concept of the metabolic syndrome improves understanding of the pathophysiology of insulin resistance at cellular and molecular level as well as the mechanisms by which metabolic risk factors like hypertension and dyslipidemia develop; it moves clinical practice away from the single-risk factor strategy to one that focuses on multiple risk factors and gives insight into the mechanisms by which the adipocyte influences both insulin target tissues and vasculature, improving our understanding of the link between obesity and cardio-vascular disease $^{34}$. This pathophysiological knowledge is important for applying logical therapeutic strategies. Identification of the metabolic syndrome may increase the awareness of both physicians and patients that in order to reduce the metabolic risk factors, the underlying risk factors contributing to insulin resistance should be targeted by weight reduction and exercise. Improvement of insulin sensitivity, and targeting the dysfunctional adipocyte, not only has favorable effects on the individual risk factors, but also might improve the not routinely measured risk factors associated with the metabolic syndrome ${ }^{34}$. 


\subsection{Clinical practice guideline to be assessed: NCEP ATP III}

The National Cholesterol Education Program Adult Treatment Panel III (NCEP-ATPIII) has become a staple in the defining criteria for metabolic syndrome. Since the working definition of MetS has been produced by both the NCEP and WHO, there has been a great deal of research undertaken to define its epidemiology ${ }^{1}$. However, uncertainty exists about the clinical and public health importance of the metabolic syndrome ${ }^{35}$, 36. "One way to address this uncertainty is to examine the nature of adverse events and the magnitude of the risks associated with the metabolic syndrome. Chief among these risks are all-cause mortality, cardiovascular disease, and diabetes. Although studies using nonstandard definitions of the metabolic syndrome have suggested that the risk of premature death and developing cardiovascular disease or diabetes is higher among people with the metabolic syndrome compared with those who did not have this syndrome, the risks for these outcomes associated with the new definitions of the metabolic syndrome are now emerging. Several studies have produced such risk estimates for all-cause mortality, cardiovascular disease, and diabetes" 1 . The majority of prospective studies have presented risks based on the NCEP definition ${ }^{1}$. The estimates of relative risk from studies using the WHO definition are only slightly higher than those from studies using the NCEP definition. However, two studies, Lakka et al and Hunt et al, using both the NCEP and modified WHO definitions produced estimates for all-cause mortality and cardiovascular disease associated with the metabolic syndrome. On the basis of the NCEP definition, the fixed effects estimates were 1.50 (95\% CI 1.18-1.91) for all-cause mortality and 2.71 (1.91-3.83) for cardiovascular disease ${ }^{37,38}$. The WHO definition is difficult to implement in epidemiologic studies, as evidenced by the fact that most studies had to alter $\mathrm{it}^{1}{ }^{1}$, therefore when the modified WHO was used, the fixed-effects estimates were 1.37 (1.091.74) for all-cause mortality and 1.85 (1.34-2.55) for cardiovascular disease ${ }^{37,38}$. The criteria of MetS as defined by the IDF differs only specifically by the change in waist circumference values.

In a comparison analysis journal, Harmonizing the definition of Metabolic Syndrome, the prevalence of MetS was compared using both ATP III and IDF definitions in American and German populations ${ }^{38}$. The Dallas Health Study and National Health and Nutrition Education Survey (NHANES) were the two American studies and the German being the Prospective Cardiovascular Munster Study (PROCAM). This paper identified that the IDF criteria will always generate a higher prevalence of MetS due to its specific inclusion of abdominal circumference. Prevalence rates were significantly higher in both American population studies 
using the IDF as supposed to the ATP III criteria, and also higher than those prevalence rate results in the German populations. This gives insight into the sensitivity and specificity of both criteria. The analysis also compared the predictive power for coronary events for each criteria $^{38}$. "The incidence of coronary events associated with MetS, as defined using the ATP III or the IDF criteria, were compared over a 10 -year period among the middle-aged men in the German population, a total of three percent (3.4\%) of men without MetS developed an event. A much a higher percentage $(10.7 \%)$ of the men with MetS defined by the ATP III criteria than the IDF criteria, five percent (5.5\%), had a cardiovascular event. This proved that although the prevalence of MetS was higher when the IDF criteria were used in the German sample, the IDF criteria have lower predictive power for coronary events" 39 . ATP III criteria proves to be more efficient for clinical practice purposes and has been used in most studies in assessing metabolic syndrome at any level be it incidence, prevalence, knowledge/perception or ASVCD risk. Therefore, it would be beneficiary to assess physicians' ability to diagnose MetS as defined by the NCEP ATP III.

In addition to the above, the NCEP-ATP III basis centers around its evidence based treatment algorithm and the direct benefit with early treatment of elevated blood cholesterol in the effort to decrease cardiovascular risk. Its development focused on several large randomized controlled clinical trials that have yielded extensive data in support of this theory and proves to translate into clinical practice. This in part, indicates its advantage of being used as supposed to other criteria formulated for the diagnosis of metabolic syndrome. ATP III placed major emphasis on therapeutic lifestyle changes (TLC) as an essential modality in clinical management for persons at risk for cardiovascular disease (CVD) ${ }^{40}$. ATP III's TLC approach was designed to achieve risk reduction through both LDL-C lowering and metabolic syndrome management ${ }^{40}$.

\subsection{Metabolic Syndrome: A Bahamian Perspective}

In addition to serving as a predictive tool for the development of cardiovascular disease and type 2 diabetes, MetS identification allows for the development and evaluation of targeted lifestyle interventions to combat the rising burden of non-communicable diseases ${ }^{11}$. There is concerning rise of chronic non-communicable diseases (CNCDs) worldwide, throughout the Caribbean region and most importantly reflective in our nation, The Bahamas. CNCDs have been proven as components of cardiovascular risk as well as mirror the components of metabolic syndrome. It is necessary to explore the importance of just how prevalent CNCDs are because it gives an inclination into the prevalence of metabolic syndrome. The Bahamas 
CNCD Prevalence Study and Risk Factor Survey of 2005 included one thousand four hundred and twenty-four $(1,424)$ participants surveyed from six hundred and thirty-seven (637) households, ages 15-74yrs, and reported that seventy-two percent (72\%) of participants had increased to extremely high risk of developing cardiovascular disease ${ }^{41}$. Those with increased risk, twenty percent (20\%), those with high risk, seventeen percent (17\%), those with very high risk, twenty-seven percent (27\%), and those with extremely high risk, eight percent $(8 \%)^{41}$. Reported results on lifestyle indicated seventy percent $(70 \%)$ of those surveyed were overweight or obese, at twenty-seven percent (27\%) and forty-three percent (43\%) respectively. Sixty-five percent (64.5\%) described themselves as sedentary in their leisure time, twenty-one percent $(21 \%)$ had been diagnosed with high blood pressure, twenty-six percent $(26 \%)$ of those measured had high blood pressure, seven percent $(7 \%)$ had been diagnosed with diabetes (self-reported), and twelve percent (12\%) had impaired and elevated fasting glucose on measurement ${ }^{41}$.

The STEPS survey of chronic disease risk factors in The Bahamas was carried out from June 2011 to March $2012^{42}$. The STEPS survey in The Bahamas was a population-based survey of adults aged 25-64. A stratified multi-stage cluster sample design was used to produce representative data for that age range in The Bahamas. A total of 1,654 adults participated in The Bahamas STEPS survey ${ }^{42}$. The overall response rate was $54.1 \%{ }^{42}$. In the 2012 Bahamas STEPS Survey on Hypertension, it was found that diagnosed hypertension prevalence existed in twenty-seven percent (27\%) of participants in age group 25yrs-64yrs, with sixty percent $(60 \%)$ of participants having measured elevated blood pressures but not diagnosed ${ }^{43}$. This showed a drastic ten-year (10yr) increase in prevalence, approximately seventeen percent (17.7\%), in comparison to the 2001 Bahamas Living Conditions Survey (included in all persons) that gave a prevalence rate of nine percent (9.3\%). The STEPS survey also reported that the mean body mass index (BMI) of participants was 30.5, with no difference in sex, eighty percent $(80 \%)$ were overweight, forty-nine percent $(49 \%)$ were obese, seventy-three percent (73\%) did not engage in vigorous physical activity, and ninety percent (90\%) ate less than five (5) servings of fruits and/or vegetables average daily ${ }^{43}$. Relevant findings were also reported in regards to risk factors assessed, which included current daily smokers, low level of activity, overweight (BMI $>25 \mathrm{~kg} / \mathrm{m}^{2}$ ), less than five (5) servings of fruits and vegetables per day, and elevated blood pressure (SBP $\geq 140$ and/or DBP $\geq 90 \mathrm{mmHg}$ or currently on medication for raised BP $)^{42}$. Among these risk factors, only one percent $(1.4 \%)$, inclusive of both sexes, had no risk factors, fifty-two percent (52.3\%) had three or more risk factors (ages 
$25-44 y r s)$, and sixty-nine percent (69\%) had three or more risk factors (ages $45-64 \mathrm{yrs})^{42}$. This represents a significant percentage of the Bahamian population with risk factors for cardiovascular events and disease, and without the official assessment and/or diagnosis of metabolic syndrome, and inherently without proper evaluation and counselling on lifestyle modification. There is little to no published studies on the prevalence of MetS in the Bahamas but rather studies concentrating on the individual cardiovascular risk factors. Although specific objective information is limited, it is imperative to put this into a regional perspective.

\subsection{Metabolic Syndrome: Caribbean Prevalence}

Ferguson et al, a cross-sectional analysis of a cohort study done in Spanish Town, Jamaica, used an interviewer administered questionnaire and collected vitals, anthropometric measurements, and blood investigations in one thousand eight hundred and seventy $(1,870)$ Jamaican adult participants and defined metabolic syndrome using both the IDF and AHA/NHLBI criteria to estimate prevalence. The prevalence using the IDF criteria indicated an overall prevalence of twenty-one percent (21.1\%), twenty-seven percent $(27.6 \%)$ in females and ten percent $(10.6 \%)$ in males. Using the AHA/NHLBI criteria indicated an overall prevalence of eighteen percent $(18.4 \%)$, twenty-three percent $(23 \%)$ in females and eleven percent $(11 \%)$ in males $^{44}$.

C. E. Ezenwaka et al reported significantly higher prevalence rates in Trinidad and Tobago. The cross-sectional study was conducted comparing metabolic syndrome and its components in type II diabetic patients between sister islands Trinidad and Tobago using the IDF definition. The study included four hundred and thirteen (413) type II diabetic patients, two hundred and forty-seven (247) from Trinidad, one hundred and sixty-six (166) from Tobago, which visited ten lifestyle disease clinics in primary care settings accessible on both islands ${ }^{45}$. Again, demographics, vitals and blood investigations were done and analyzed resulting in type 2 diabetic patients in the two Caribbean islands of Tobago and Trinidad had less than optimal blood glucose control, and high prevalence rates of risk factors components including generalized and central obesity, raised triglycerides, raised blood pressure and reduced HDLcholesterol. Thus, based on the new IDF definition, the prevalence of the MetS and its critical components were quantitatively higher in diabetic patients in Trinidad than Tobago ${ }^{45}$. With the IDF-based metabolic syndrome definition, Abdominal obesity +2 components: Trinidad patients had twenty-one percent $(21.5 \%)$ while Tobago patients had forty-eight percent (48.2\%); Abdominal obesity +3 components: Trinidad patients had twenty-three percent (23.5\%) while Tobago patients had nineteen percent (19.3\%); Abdominal obesity +4 
components: Trinidad patients had twenty-two percent (22\%) while Tobago patients had five percent $(5 \%)^{45}$.

In St. Lucia, a descriptive study was conducted to assess MetS risk factor prevalence, as a middle income nation. Its methodology was similar to the two previously discussed studies however, it based its findings on the definition instituted by the National Institutes of Health National Heart Lung, and Blood Institute (NIH/NHLBI). The NIH/NHLBI list five conditions as metabolic risk factors: central adiposity, high triglyceride levels, low HDL cholesterol, elevated blood pressure, and high fasting blood glucose and MetS is diagnosed if three criteria are met $^{46}$. Self-reported behavioral information on smoking, alcohol consumption, exercise, dietary habits, and demographic information, such as age, gender, address, and ethnicity ${ }^{46}$ was collected from questionnaires, biometrics were performed and blood results were gathered from participants' most recent lab reports in order to screen for MetS. Out of four hundred and ninety-nine (499) participants, thirty-six percent (36.4\%) of females and thirty-three percent $(33 \%)$ of males lead sedentary lifestyles, $31 \%$ had BMI of 25 or over indicating overweight or obese, and females demonstrated higher frequency percentages of indicators for MetS, low HDL with fifty-four percent (54.5\%), elevated random blood glucose with twentyfive percent (25.6\%), and increased waist circumference with a frequency of fifty-five percent $(55.7 \%)^{46}$.

\subsection{Worldwide Prevalence}

Studies have shown that the prevalence of MetS continues to increase globally, regardless of the definition used ${ }^{23}$. The incidence of metabolic syndrome often parallels the incidence of obesity and incidence of type 2 diabetes (one of the outcome of MetS) ${ }^{47}$. There is no specific global data on metabolic syndrome as it is harder to measure, but since MetS is about three times more common than diabetes, the global prevalence can be estimated to be about one quarter of the world population ${ }^{47}$. In other words, over a billion people in the world are now affected with metabolic syndrome ${ }^{47}$. "The prevalence of MetS in U.S. adults has been described in several reports based upon analysis of the National Health and Nutrition Examination Survey (NHANES) data. The first of these reports, based upon NHANES data from 1988-1994, estimated total age-adjusted prevalence of MetS of $23.97 \%$, using ATPIII criteria. The most recent report by Beltran-Sanchez et al. compared trends in prevalence using serial NHANES data from 1999-2000 and 2009- 2010. The authors reported a modest decrease in age-adjusted prevalence of MetS among U.S. adults, from 25.5\% in 1999-2000, to $22.9 \%$ in $2009-2010$. These results indicate that approximately one in five U.S. adults 
currently meets the criteria for MetS, and the prevalence increases with age in all racial/ethnic groups" ${ }^{\prime 4}$. During 2007-2014, the United States had an estimated overall prevalence of thirtyfour percent $(34.3 \%)$, specifically $35 \%$ in men, $33 \%$ in women, according to D. Shin et $\mathrm{al}^{49}$ indicating an increase in the prevalence of the disease since 2010. In one of the largest diabetes studies conducted in India, the Chennai Urban Rural Epidemiology Study, MetS prevalence was 23.2\% (World Health Organization criteria), 18.3\% (ATPIII criteria), and $25.8 \%$ (International Diabetes Federation criteria) $)^{23}$.

\subsection{Metabolic Syndrome Knowledge (MetSK) and Physician Knowledge}

From the information gathered in literature review thus far, it is evident that the prevalence and incidence of metabolic syndrome is a significant clinical entity and there is benefit in looking at the collective picture of the syndrome in its clinico-pathological sense. There have been studies assessing the level of knowledge of clinical staff regarding MetS and just how intricately they are putting their knowledge into practice.

Helminen et al conducted a descriptive cross-sectional study, The Heart Study 2005, in 26 randomly selected primary care health centers around Finland that represented the entire Finnish public primary care system in terms of size and location ${ }^{50}$. The purpose of the study was to survey patients in a primary care setting and assess general practitioner's (GPs) knowledge about MetS, as well as level of detection. Study participants were required to have $\mathrm{CHD}$ or at least one of its risk factors, such as previously diagnosed diabetes or metabolic syndrome, hypertension, smoking or dyslipidaemia ${ }^{50}$. Altogether 181 general practitioners collected the data during two workweeks; all the patients who visited the health center during the two weeks and met the study criteria were registered and invited to attend a health check $^{50}$. The GPs collecting the patient data were mainly senior doctors, and $67.5 \%$ of them had over 10 years of work experience ${ }^{50}$. "The GPs had answered the question about metabolic syndrome in $1173(99.4 \%)$ of the 1180 patient cases. They assessed that $28.5 \%$ of the study patients (30.7\% of the men, $27.4 \%$ of the women) had MetS according to the study criteria. However, $49.4 \%$ of the patients $(50.8 \%$ of the men, $49.6 \%$ of the women) met the study criteria of metabolic syndrome according to the measurements and records made at the nurse's appointment and the answers from the patients' questionnaires. The group of patients with MetS according to the GPs' evaluation did not quite match with the group of patients actually meeting the study criteria of the syndrome. The sensitivity of the general practitioners' diagnosis for MetS was 0.31 and the specificity was 0.73 respectively. In this study, MetS was 
poorly detected by general practitioners; the sensitivity of diagnosis was only 0.3 " 50 . This indicated that GPs did not recognize MetS in patients meeting the criteria of the syndrome ${ }^{50}$.

In previous studies researching the awareness level of MetS in medical communities, Faiz Alam et al found that only thirty-six (36) of one hundred and ninety-four (194) participants (mostly physicians), approximately eighteen percent (18.56\%) knew three out of the five criteria (3/5) for diagnosing MetS using ATP III definition, while almost all the nurses and paramedics were unaware of MetS altogether ${ }^{51}$. In the UK, over two thousand $(2,727)$ primary care physicians (PCPs) were surveyed in the Shape of the Nations survey, and nearly twothirds, or fifty-eight percent (58\%) of PCPs were aware of the CVD risk associated with abdominal obesity, and sixty-nine (69\%) reported that they would treat abdominal obesity to manage risk ${ }^{52}$. The study goes on further to divulge that few PCPs knew the threshold for waist circumference (WC) that is considered to confer significantly increased cardiometabolic risk in women or men; and that more than fifty percent $(50 \%)$ of them overestimated this threshold ${ }^{52}$. Overall, forty-five (45\%) of PCPs reported never measuring WC, and WC was only measured in seventeen percent $(17 \%)$ of patients on average ${ }^{52}$. Comparatively, a study to assess "Awareness to MetS in Hospital Health Providers" ${ }^{53 "}$ in Tel Aviv, Israel included 71\% physicians and 29\% nurses. Among physicians, the most prevalent level of experience was resident $(68.5 \%)$, and the most prevalent field of practice was internal medicine $(45.5 \%)$. The vast majority of participants (98\%) stated that they were familiar with the term metabolic syndrome, and that they treat MetS patients on a regular basis. $97 \%$ of the participants responded that MetS has an effect on patients' prognosis and $86 \%$ said that it is related to higher prevalence of cancer. Similarly, most participants said that they evaluate the presence of MetS risk factors in their patients frequently and recommend on MetS risk factors modulation upon discharge. Most of the participants knew the correct number of criteria included in MetS definition and the number of criteria needed for MetS diagnosis $(84 \%$ and $90 \%$, respectively $)^{53}$. Overall, however, the participants performed poorly with identifying MetS cases. Only 12\% were able to discriminate correctly all MetS cases from non-MetS ones. Physicians performed better compared with nurses $(15.5 \%$ made a complete accurate identification of MetS cases compared with 3\%, respectively, $\mathrm{P}=0.003$ ), however, senior physicians performed similarly as residents $(19 \%$ and $15 \%$, respectively, $p=0.4){ }^{53}$. Field of practice did not have a significant influence on the results; staff from internal medicine wards performed similarly as staff from surgical departments $(13 \%$ and $11 \%$, respectively, $\mathrm{p}=0.44)$ 53. 


\subsection{Physician adherence to clinical practice guidelines}

Echlin et al identified that in the past decade, there was a need for physician and governmental organizations to develop clinical practice guidelines (CPG) to "facilitate high quality, appropriate, and cost-effective medical care, while decreasing regional and systemic variations in practice" ${ }^{\prime 4}$. After much research, clinical practice guidelines, facilitated by evidence, provide a standardized management protocol for physicians across the globe. Studies measuring physician adherence to guidelines continue to impose an impact on daily clinical practice. Adherence referring to how well physicians follow evidence-based guidelines and how well patients follow their physician's recommendations ${ }^{8}$.

In a cross-sectional study aimed to assess the knowledge of primary health care (PHC) physicians and the extent of their adherence to the recommendations of clinical practice guidelines (Joint National Committee-7) concerning care of hypertensive patients, ${ }^{55}$ all physicians working at primary health care centers in the Aseer region (Saudi Arabia) were surveyed using a modified version of the WHO Physician Inquiry Questionnaire ${ }^{55}$. "Results indicated that PHC physicians did not fully adhere to all hypertension guidelines. It concluded that many PHC physicians in the Aseer region lack the necessary knowledge to define and to correctly diagnose hypertension, especially among diabetic patients. Most PHC physicians do not adhere to the guidelines of hypertension management ${ }^{55}$ ".

In another prospective study published in the Family Practice journal 2011, conducted a post hoc analysis of data collected by a prospective cluster randomized trial with 7041 patients diagnosed with clinical atherosclerosis requiring secondary prevention of dyslipidemia and 127 primary care physicians over an 18-month period ${ }^{8}$. Adherence was measured by physicians' and patients' actions taken according to the guidelines and correlated using multivariate logistic regressions ${ }^{8}$. The sample included 20- to 74-year-old patients with diagnoses of clinical atherosclerosis, with clinical statuses as identified by ICD coding. The dataset included 19,175 clinical statuses requiring prevention measures, 127 physicians in 36 clinics regarding 7,041 patients (2.2 clinical statuses per patient on average) ${ }^{8}$. Outcome measures were physician adherence, patient adherence and composite physician and patient adherence to the guidelines ${ }^{8}$. Each clinical status was categorized as 'implemented by the physician' if the physician acted concordantly according to the clinical status detected (referred the patient to lipid profile screening or prescribed the appropriate lipid-lowering medication, within 4 months of detecting the status $)^{8}$. Each of these clinical statuses adhered to by the physician was categorized as 'implemented by the patient' if the patient performed 
the lipid profile screening or purchased the medication within 4 weeks after referral to screening or receiving the prescription, respectively ${ }^{8}$. Composite physician and patient adherence was calculated as the multiplication of the net physician adherence and net patient adherence for the entire cohort (e.g. if the physicians adhered in $60 \%$ of the cases and the patients adhered in $50 \%$ of these $60 \%$ and then the composite adherence would be $30 \%)^{8}$. Physician adherence was greatest when screening of lipid profile was appropriate according to the guidelines, lower when pharmacotherapy up-titration was appropriate [odds ratios $(\mathrm{OR})=$ $0.411,95 \%$ confidence interval (CI) $0.371-0.454$, relative to lipid profile screening] and lowest when pharmacotherapy initiation was appropriate $(\mathrm{OR}=0.539,95 \% \mathrm{CI} 0.496-0.585)^{8}$. Patient adherence was greatest for pharmacotherapy up-titration (OR $=1.929,95 \%$ CI $1.637-$ 2.272 , relative to lipid profile screening) and lowest for pharmacotherapy initiation (OR = 0.675 , 95\% CI $0.562-0.810$, relative to lipid profile screening $)^{8}$. In total, the composite physician and patient adherence (the multiplication of physician adherence by patient adherence) was greatest for screening of lipid profile $(26.5 \%)$, somewhat lower for pharmacotherapy up-titration $(23.1 \%)$ and lowest for pharmacotherapy initiation $(13.2 \%)^{8}$.

\section{CHAPTER 3}

\section{RATIONALE}

The prevalence and incidence of chronic non-communicable diseases in conjunction with obesity has led to the advent of the "constellation of interrelated risk factors of metabolic origin" 11 known as metabolic syndrome. Metabolic Syndrome (MetS) has become a clinical heavyweight as a predictor of atherosclerotic cardiovascular morbidity and mortality. Subsequently, it plagues the clinical community resulting in both clinical and financial burden. It is imperative to ensure the medical community is clinically astute in keeping the complex phenomenon at the forefront when following their patient as a whole. This study is the first of its kind in the Bahamas, and aimed to identify just how in tune our physicians are with the disorder and will hopefully raise physician competence in metabolic syndrome. The information obtained from this study will be used make recommendations for health education and health promotion in the population. Reports of the survey will be disseminated to the Ministry of Health as well as presented at forums that aid in Continued Medical Education to enhance physician awareness and in turn optimize patient management and subsequently decrease cardiovascular risk in the population. 


\section{CHAPTER 4}

\section{AIM}

To determine the knowledge of physicians in New Providence, Bahamas regarding metabolic syndrome and the adherence to NCEP-ATP III guidelines.

\subsection{Objectives}

1. To assess health literacy of physicians in regards to metabolic syndrome

2. To assess physicians' experiences in screening for metabolic syndrome (i.e., frequency of screening vs. screening in isolation)

3. To assess the extent to which physicians perceive that they engage patients in health education about the involved cardiovascular risk

4. To assess adherence to the NCEP-ATP III clinical practice guideline

\subsection{Hypothesis}

The researchers hypothesized that there will be a low level of health literacy regarding knowledge of metabolic syndrome $(<40 \%)$. We also posit that there will be low intentionality regarding screening for the complex that makes up the syndrome; instead, approximately $85 \%$ of physicians targeted will be found to do fragmented screening for the separate components that make up the syndrome (MetS). It is also hypothesized that approximately $50 \%$ of physicians will perceive that they engage in health education about the cardiovascular risk associated with MetS. Further, the researchers anticipate that concerning adherence, $65 \%$ will be found to adhere to the NCEP ATP III criteria.

\section{CHAPTER 5}

\section{METHODOLOGY}

\subsection{Study design and population}

Design: This study employed a cross-sectional survey design conducted from September 2019 - December 2019 in New Providence, The Bahamas.

Target population: The population of physicians in The Bahamas to which findings from this study will likely be most useful pertains to those physicians inclusive of senior house staff, registrars, consultants and specialists all involved in some level of primary care working in both the private and public sector in New Providence. 
Available population: Physicians throughout New Providence listed as reflected in the Bahamas Medical Council gazette of registered practicing physicians working within the Princess Margaret Hospital, the government public clinics, as well as the private clinics.

\subsection{Selection issues}

5.2.1 Approach: A convenience sampling approach, by specialty of interest in this study, was used. The rationale for this choice was that a random sampling approach would be more time consuming since it would have required obtaining a listing of the physicians and several visits to many of the potential participants at their practice settings. At those settings, researchers in the recent past, have found that the response rate is often times unacceptably low because these physicians may be challenged with finding the time to be involved in such studies. In several instances, the physicians approached at their work site were willing to participate and did complete the survey as time allowed. It is at this stage that non-response became a particular challenge. The researcher however, found that participating hospital based physicians were much more inclined to be involved in this study by completing the survey when they were invited to as they attended their departmental meetings. Very few persons refused when the researcher used this approach. The researcher was able to capture select demographics on $30(58.8 \%)$ of the 51 non-responders and this information is provided in the results. For the remaining 21 non-responders, little was known about such characteristics because they were particularly unavailable. The sample was obtained from consenting physicians recruited from the government community clinics, private practice and the hospitals. In the event that a participant had difficulty with completion of the survey on their own (E.g. visually impaired, language barrier, illiteracy), the questionnaire was administered with assistance in a private area. Participants were informed that no incentives/direct benefits or repercussions would be gained from participation in this study. Sensitive questions of a personal nature were avoided and therefore information from this research can be disseminated to scientific conferences both locally and abroad.

\subsubsection{Selection criteria:}

- Inclusion criteria :

○ Physicians with willingness to participate

- Physicians with more than one year clinical experience

o Physicians working in all departments of medicine E.g. Family medicine, Public Health, Internal Medicine, Cardiology, General practice, Surgery, Emergency Medicine, Psychiatry and Obstetrics \& Gynaecology 
- Exclusion criteria :

- Physicians who have not completed at least one clinical year, e.g. interns will be excluded

- Physicians working in the department of Pediatrics and Anesthesia \& ICU

5.2.3 Sampling frame: The medical council's list of registered, practicing physicians in New Providence, The Bahamas was used.

5.2.4 Sample size: A minimal sample size of one hundred and ninety-six (196) physicians was calculated via Cochran's formula for determining the minimal sample size and estimating a proportion. This sample size was required in order for this study to be statistically significant. This number was based on the premise that MetS knowledge level was an estimated $40 \%$ ( $\mathrm{n} \geq$ 93 physicians), low intentionality of physician experience with MetS, inclusive of screening frequency and practice was estimated at $85 \%$ ( $\mathrm{n} \geq 196$ physicians), the extent to which physicians engage patients in health education about involved cardiovascular risk was estimated at 50\% ( $\mathrm{n} \geq 97$ physicians), and the frequency that NCEP ATP III diagnostic criteria is used/adhered to was estimated at $65 \%$ ( $\mathrm{n} \geq 88$ physicians) on adopting a $10 \%$ Type I error $\alpha$ and a $5 \%$ refusal rate.

\section{Cochran's formula: $n_{0}=\underline{t^{2} p *(1-p)} / d^{2}$$$
n^{\prime}=n_{0} /\left(1+n_{0} / N\right)
$$

Where $\mathbf{N}$ is the estimated number of Bahamian physicians registered and practicing in New Providence island, $\mathrm{n}_{0}$ is equal to the sample size, $\mathbf{t}^{2}$ is the abscissa of the normal curve that cuts off an area $\alpha$ at the tails ( $\mathbf{t}^{2}=1.96$ to represent the number of standard deviations implied for these results, including margin of error, to be reposted with a 95\% confidence interval), $\mathbf{n}$ ' is the sample size adjusted for the finite population of interest, $\mathbf{p}$ is equal to the estimated proportion of an attribute that is present in the population $(\mathrm{p}=0.40$ for MetS health literacy in physicians, $\mathrm{p}=0.85$ for low intentionality of physician experience, $\mathrm{p}=0.50$ for patient engagement in education, $\mathrm{p}=0.65$ for use of NCEP ATP III diagnostic criteria) and $\mathbf{d}^{2}$ is equal to desired level of precision $\left(\mathbf{d}^{2}=0.05\right)$ or the margin of error within which the actual proportion (p) will be reported. With factoring in a refusal rate of five percent $(5 \%)$, using the following formula, the total number of physicians needed to fill out questionnaires is two hundred and seven (207), where $\mathbf{K}=$ the proportion of participants projected to refuse to participate. 


\section{$\mathbf{n} /(\mathbf{1}-\mathrm{K})$}

\subsection{Procedure and instrument}

Potential participating physicians were visited by the DM candidate who also served as study coordinator seeing through this research project. An introductory letter/consent form prefaced the questionnaire and participants were encouraged to read it in its entirety, thereby covering the essence of the research project, all towards the participant being adequately apprised of the study. The questionnaire developed for this survey was submitted for distribution to the selected Bahamian physicians acquired from the registered listing of licensed, practicing physicians from the Bahamas Medical Council. There was implied consent inferred with physician permission to answer the questionnaire provided (See Appendix A) and it allowed participants to disinvite themselves at any time with no punitive measures. The questionnaire, adapted from both Havakuk et al questionnaire on "Awareness of MetS in hospital health providers" published in Diabetes and Metabolic Syndrome: Clinical research and reviews ${ }^{44}$, along with modified version of Atalay et al's "Metabolic Syndrome Knowledge Level Scale (MetS-KS)" published in the Indian Journal of Research ${ }^{47}$, covered physician demographics, recognition of clinical cases, self-reported knowledge of Metabolic Syndrome and subsequent measurement with the Metabolic Syndrome Knowledge Scale (MetS-KS) and frequency of and adherence to specific guideline screening, its usage and subsequent counselling. There was questionnaire review prior to packing away to avoid missing data; and it was placed in confidential packaging.

\subsection{Data collection and management}

With ethical approval and participants' completion of the study instrument, all completed questionnaires were stored in a locked file cabinet. Data was double entered into protected software. The most recent version of the Statistical Package for Social Sciences, SPSS, was the tool for which data was entered and analyzed. Electronic backup copies were also stored and saved.

\subsection{Statistical analysis}

This study was analyzed producing descriptive statistical summary measures. As such, point estimates as measures of central tendency and their accompanying measures of dispersion were obtained. Univariate measures of central tendency included the mean, median and mode for interval-ratio level data, ordinal and nominal data respectively. Accompanying these were 
the measures of dispersion and they included standard deviations/errors, interquartile ranges and full range. Bivariate and multivariate measures of association were also calculated as appropriate. These were calculated and reported for each variable of interest in this study. Tables, figures and charts were used where applicable.

Furthermore, inferential statistics were done when assessing issues such as differences in physician's level of education, specialty, knowledge of MetS, guideline adherence, and counselling practice. Specifically, student's $t$-test was used to compare the central tendency of quantitative variables by levels of dichotomously grouped variables. For grouping variables with more than two groups, an analysis of variance (ANOVA) F-test was used where they meet the mathematical requirements of equality of variants and acceptably approximate normality. Otherwise, the appropriate non-parametric statistical tests was used when there was failure to meet these assumptions. For bivariate factors that were cross-tabulated, the chisquared test of homogeneity of proportions, or of independence, was used to assess the statistical significance of any differences in the percentages observed for each category identified. The p-values were reported to indicate the statistical significance. Phi, Cramer's V, Spearman's rho and Pearson correlation coefficients were all used to assess the strength of association between pairs of variable. Steps were taken for possible confounding. Multivariate data analysis was done to allow for the creation of possibly useful predictive models concerning dependent variables of interest and conjointly controlled for possible confounding variables. The Jonckheere-Terpstra (J-T) test, a rank-based nonparametric test, was used to determine if there were statistically significant differences or trends between two or more groups of an ordinal independent variable and a continuous or ordinal dependent variable. The J-T test tested for an ordered difference in medians between distribution of scores in each group ensuring the same shape and variability with only possible difference being a shift in location.

\subsection{Further ethical considerations}

Ethical approval was granted from the Medical Ethics Committee, Public Hospitals Authority. This study was of minimal risk. Implied consent with agreement to fill out questionnaire. Confidentiality was of the utmost importance and withheld. Therefore, self-administered questionnaires without any identifiers were used. Also, to that effect, participants were assured that any reports, publications, or presentations of findings would not reveal their identity. This study will be beneficial to the scope of primary health care practice, more specifically family medicine, by increasing knowledge on the subject matter (MetS) 
subsequently affecting positive change in decreasing patient cardiovascular risk. Although guidelines are only just that, and should be tailored to the patient, this study also sought to give insight into adherence to clinical practice guidelines and possibly bring about the advent of implementation of department protocols geared towards making physicians accountable for the use of one or the other in management practices.

\section{CHAPTER 6}

\section{RESULTS}

\subsection{Response Rate}

Of the 162 physicians approached and invited to participate in this study, $20(12.3 \%)$ physicians did not return the questionnaire although agreeing to complete, $20(12.3 \%)$ physicians refused to participate due to time constraints, and $12(7.40 \%)$ questionnaires were misplaced by physicians. This gave a response rate of $\mathbf{6 8 . 3 \%}$, totaling 110 physicians that completed the questionnaire and subsequently participated in this study. Of the $51(31.7 \%)$ non-respondents, the researcher was able to capture select demographics of $30(58.8 \%)$. Concerning their sex, $18(60.0 \%)$ were male and $12(40.0 \%)$ were female. The age distribution (in categories) of these non-participants was $1(3.3 \%)<30$ years, $7(23.3 \%) 30$ 45years, $19(63.3 \%)$ 46-60years, and $3(10.0 \%)>60$ years. The distribution of their specialty were General Practice/Public Health 20 (66.7\%), Family Medicine 3 (10.0\%), Internal Medicine 4 (13.3\%), and Obstetrics \& Gynaecology 3 (10.0\%).

\subsection{Participant Demographics}

In this study, 110 adult persons participated and 104 (94.5\%) provided information on their age. Their mean $( \pm 1 \mathrm{SD})$ age was $38.6( \pm 7.6)$ years old, the youngest was 26 years old and the oldest was 69 years old (See Table 1 below).

Table 6.1: Table showing participants' demographics

\begin{tabular}{|c|c|}
\hline \multicolumn{1}{|c|}{ Characteristic } & Frequency (\%) \\
\hline Gender & $30(27.5 \%)$ \\
\hline Male & $79(72.5 \%)$ \\
\hline Female & \\
\hline Ethnicity & \\
\hline
\end{tabular}




\begin{tabular}{|c|c|}
\hline Afro-Caribbean & $95(87.2 \%)$ \\
\hline African-American & $4(3.7 \%)$ \\
\hline Caucasian & $2(1.8 \%)$ \\
\hline Asian & $3(2.8 \%)$ \\
\hline Other & $5(4.6 \%)$ \\
\hline \multicolumn{2}{|l|}{ Nationality } \\
\hline Bahamian & $102(93.6 \%)$ \\
\hline American & $1(0.9 \%)$ \\
\hline Jamaican & $1(0.9 \%)$ \\
\hline Other & $5(4.6 \%)$ \\
\hline \multicolumn{2}{|l|}{ Level of Training } \\
\hline Senior House Officer & $39(35.8 \%)$ \\
\hline Resident & $22(20.2 \%)$ \\
\hline Registrar & $12(11.0 \%)$ \\
\hline Senior Registrar & $7(6.4 \%)$ \\
\hline Consultant & $29(26.6 \%)$ \\
\hline \multicolumn{2}{|l|}{ Years since graduating Medical School } \\
\hline$<5$ yrs & $20(18.9 \%)$ \\
\hline $5-10 y r s$ & $35(33.0 \%)$ \\
\hline $11-20 \mathrm{yrs}$ & $38(35.8 \%)$ \\
\hline$>20 \mathrm{yrs}$ & $12(12.3 \%)$ \\
\hline \multicolumn{2}{|l|}{ Participants' place of practice } \\
\hline Public Sector & $66(61.7 \%)$ \\
\hline Private Sector & $14(13.1 \%)$ \\
\hline Both Public \& Private Sectors & $27(25.2 \%)$ \\
\hline \multicolumn{2}{|l|}{ Participants' Specialty } \\
\hline Family Medicine & $54(53.5 \%)$ \\
\hline Internal Medicine & $22(21.8 \%)$ \\
\hline Obstetrics \& Gynaecology & $15(13.6 \%)$ \\
\hline Public Health & $8(7.9 \%)$ \\
\hline
\end{tabular}




\begin{tabular}{|l|c|}
\hline General Practice & $6(5.9 \%)$ \\
\hline Accident \& Emergency & $1(0.9 \%)$ \\
\hline Geriatrics & $1(0.9 \%)$ \\
\hline
\end{tabular}

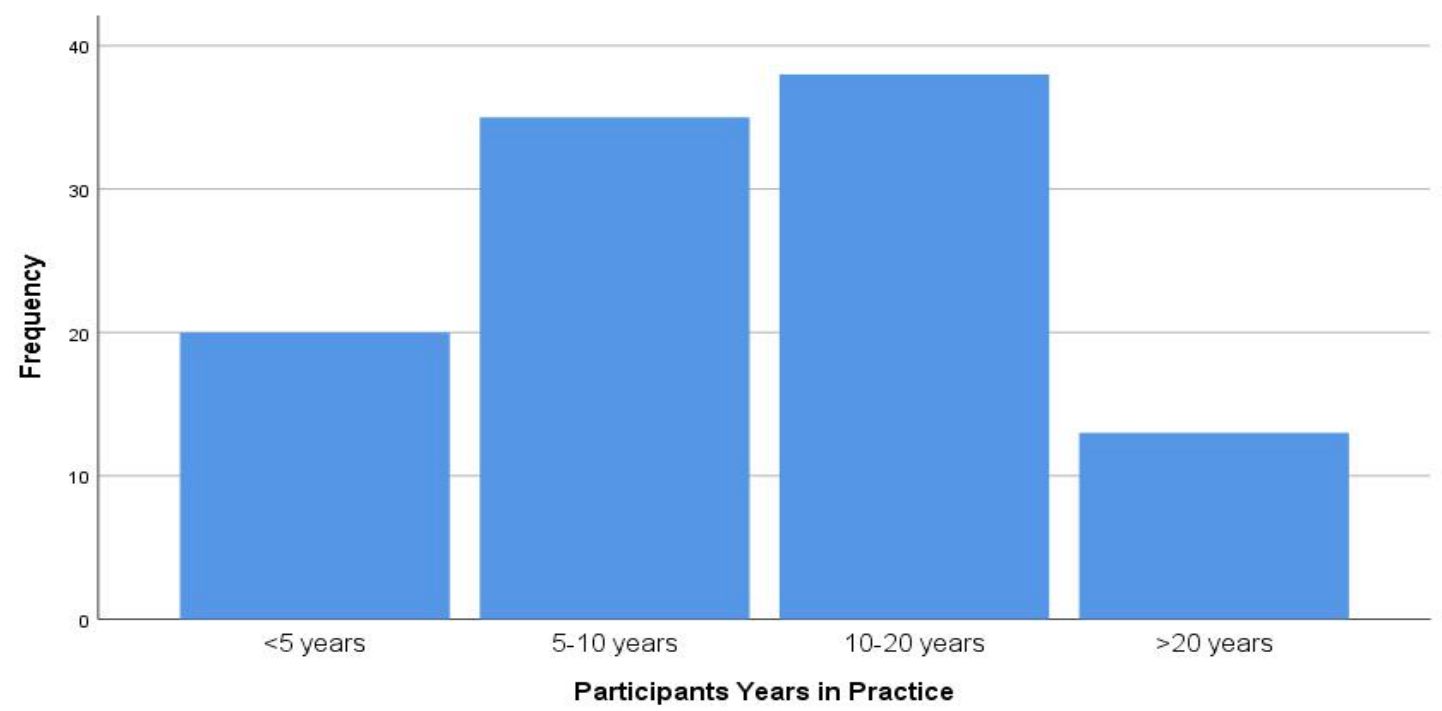

Figure 6.1: Bar graph showing participants' years since graduating medical school

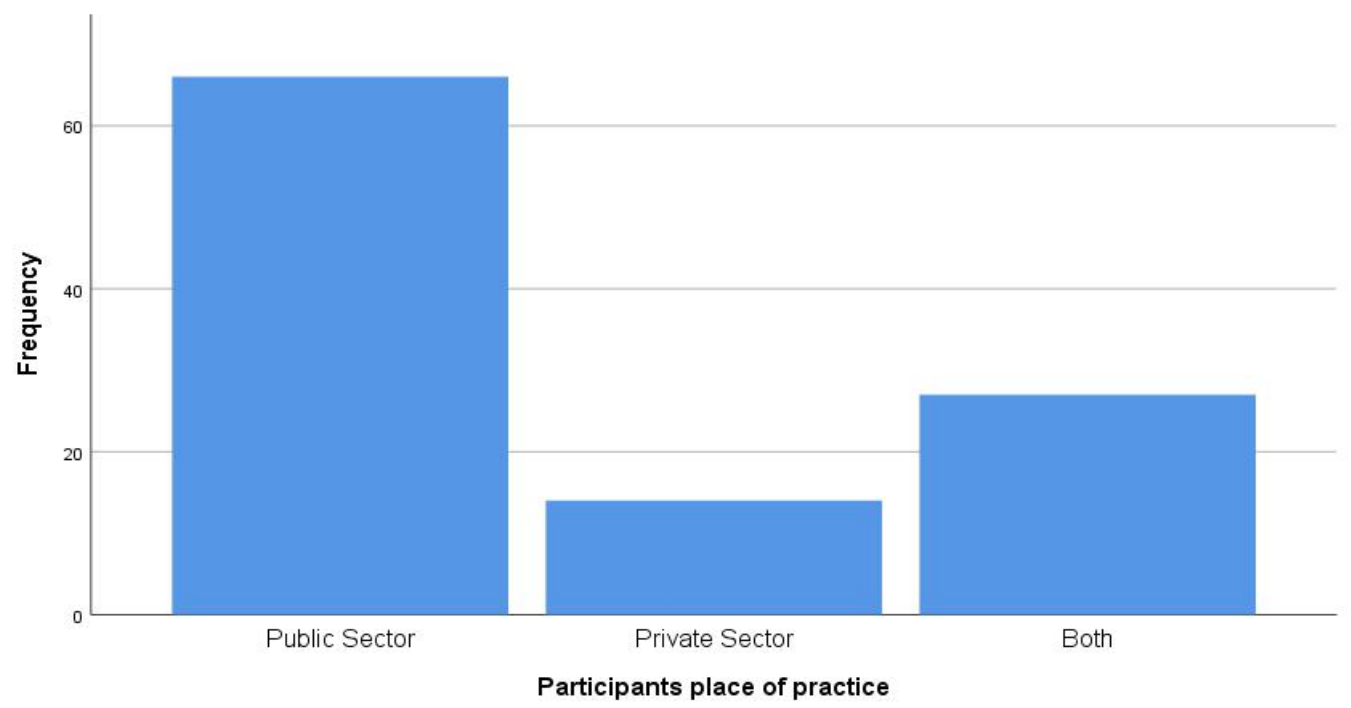

Figure 6.2: Bar graph showing participants' participants place of practice 


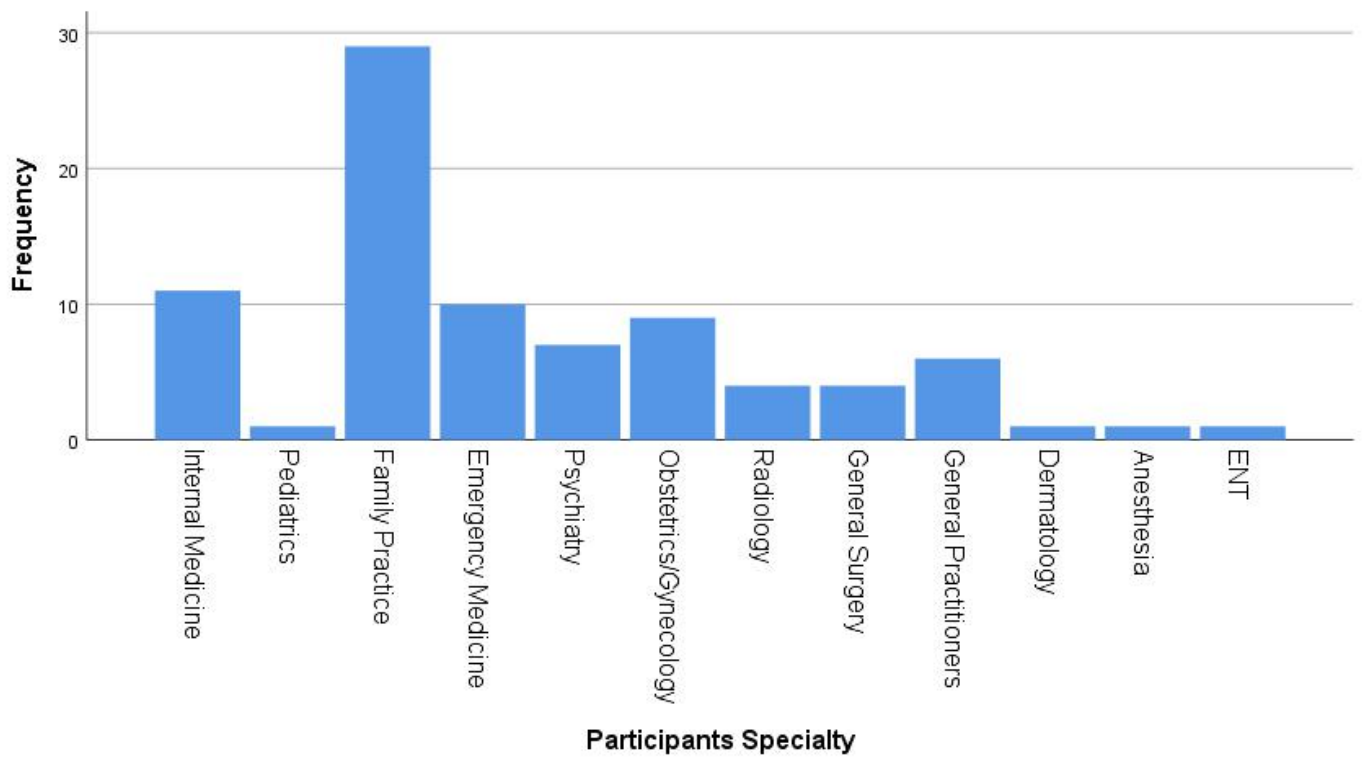

Figure 6.3: Bar Graph showing participants' specialty

\subsubsection{Participants' specialty}

Physician participants were grouped together according to specialty similarity for ease of statistical analysis. Of the 110 participants that indicated their specialty, groupings were as follows, General Practice/Public Health/A\&E with a total of 10 (9.9\%) participants, Family Medicine with a total of 54 (53.5\%) participants one of which was from Gerontology, Internal Medicine with a total of $22(21.8 \%)$ participants, and O\&G with a total of $15(14.9 \%)$ participants (See Fig. 6.4 below).

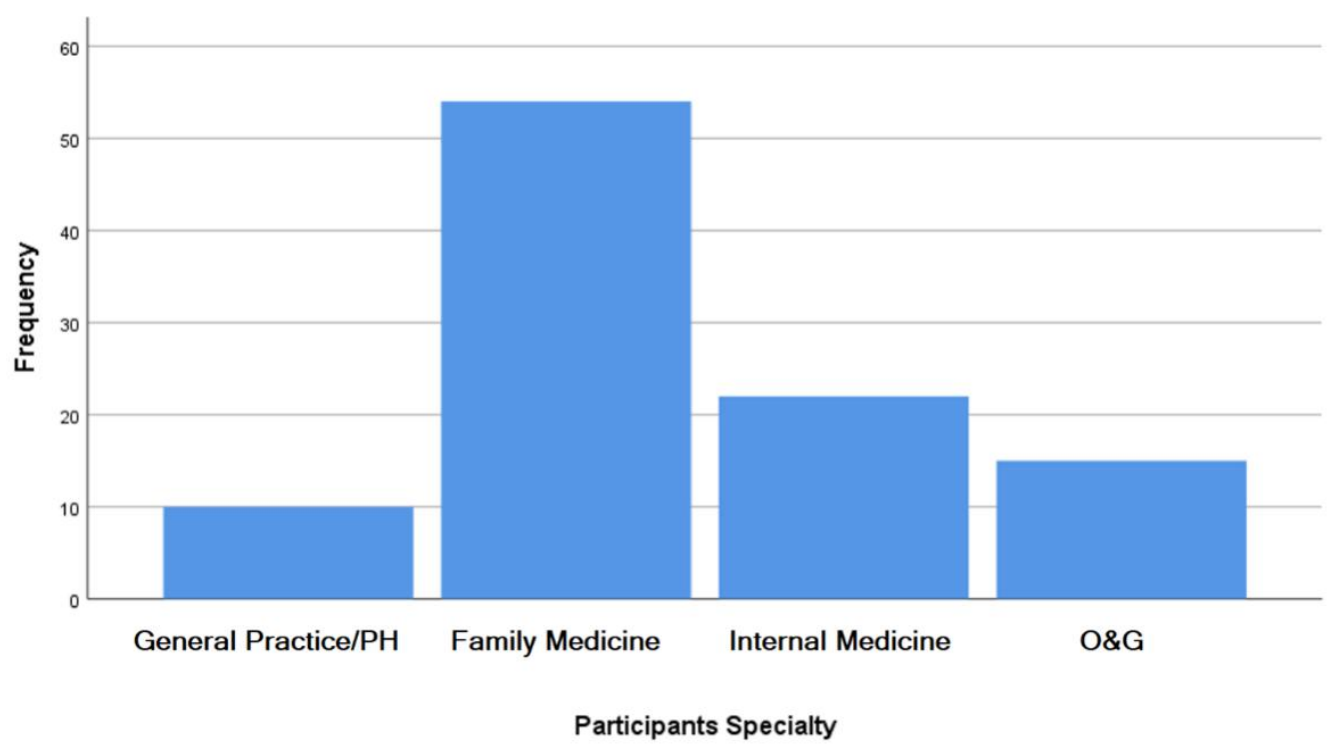

Figure 6.4: Bar graph showing number of physician participants by their specialty grouping 


\subsection{HEALTH LITERACY IN REGARDS TO METABOLIC SYNDROME}

\subsubsection{Familiarity with MetS}

Of the 110 participants, 109 (99.1\%) admitted to familiarity with Metabolic Syndrome.

\subsubsection{Treat patients with MetS}

Of those participants that responded to whether or not they treat patients with Metabolic syndrome, 96 (88.1\%) said "yes" and 13 (11.9\%) said "no".

There was a statistically significant very strong relationship between participants' level of training and whether or not they treat patients with MetS (Cramer's V $=0.385, \mathrm{p}=0.003$ ). Of the 38 Senior House Officers, 27 (71.1\%) said “yes", of the 22 Residents, 21 (95.5\%) said "yes", of 12 Registrars, all 12 (100\%) said "yes", of 7 Senior Registrars, all 7 (100\%) said "yes", and of the 29 Consultants, 28 (96.6\%) said "yes".

There was a statistically significant very strong relationship between participants' specialty grouping and whether or not they treat patients with MetS (Cramer's V $=0.600, \mathrm{p}=0.001$ ). Of 9 physician participants in the General Practice/Public Health grouping, 7 (77.8\%) indicated "yes" they do in fact treat patients with MetS. Of 54 physician participants in the Family Medicine grouping, 53 (98.1\%) indicated "yes" they do in fact treat patients with MetS. All 22 (100\%) physician participants in the Internal Medicine grouping indicated "yes" they do in fact treat patients with MetS. Of 15 physician participants in the O\&G grouping, 7 $(46.7 \%)$ indicated "yes" they do in fact treat patients with MetS.

\subsubsection{Which Physician should treat MetS}

Concerning physician participants' cumulative responses in regards to which physician they feel should treat patients with Metabolic Syndrome, 23 (20.9\%) cumulatively responded "Internist", 3 (2.7\%) cumulatively responded "Cardiologist", 16 (14.5\%) cumulatively responded "Endocrinologist", 38 (34.5\%) cumulatively responded "Family Physician", and 67 (60.9\%) cumulatively responded “Any Physician” (See Fig. 6.5 below). 


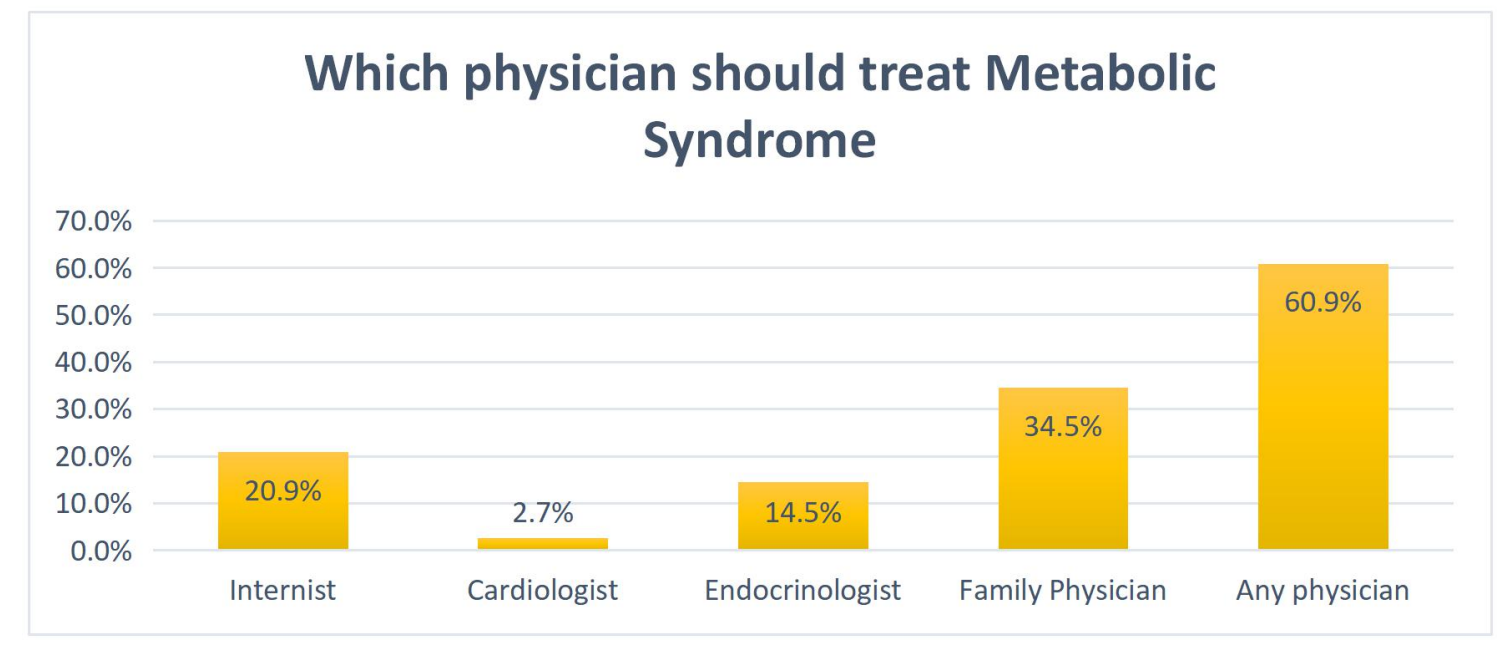

Figure 6.5: Bar Graph showing participants' cumulative response of which physician should treat patients with MetS

\subsubsection{Participants' beliefs on MetS population prevalence}

Of the 103 participants that answered, all (100\%) answered "yes" they believe metabolic syndrome to be prevalent in the population.

\subsubsection{Total number of criteria comprising MetS definition}

Pertaining to participants identifying the total number of criteria comprising the Metabolic syndrome, as according to the NCEP-ATP III, 74 (67.9\%) identified 5 (five) as the correct number of criteria (See Table 6.2/Fig. 6.6 below).

Table 6.2: Table showing total number of criteria included in Metabolic Syndrome

\begin{tabular}{|c|c|}
\hline Total Number of Criteria comprising MetS & Frequency (\%) \\
\hline 3 & $7(6.4)$ \\
\hline 4 & $25(22.9)$ \\
\hline 5 & $74(67.9)$ \\
\hline 6 & $2(1.8)$ \\
\hline 7 & $1(0.9)$ \\
\hline
\end{tabular}




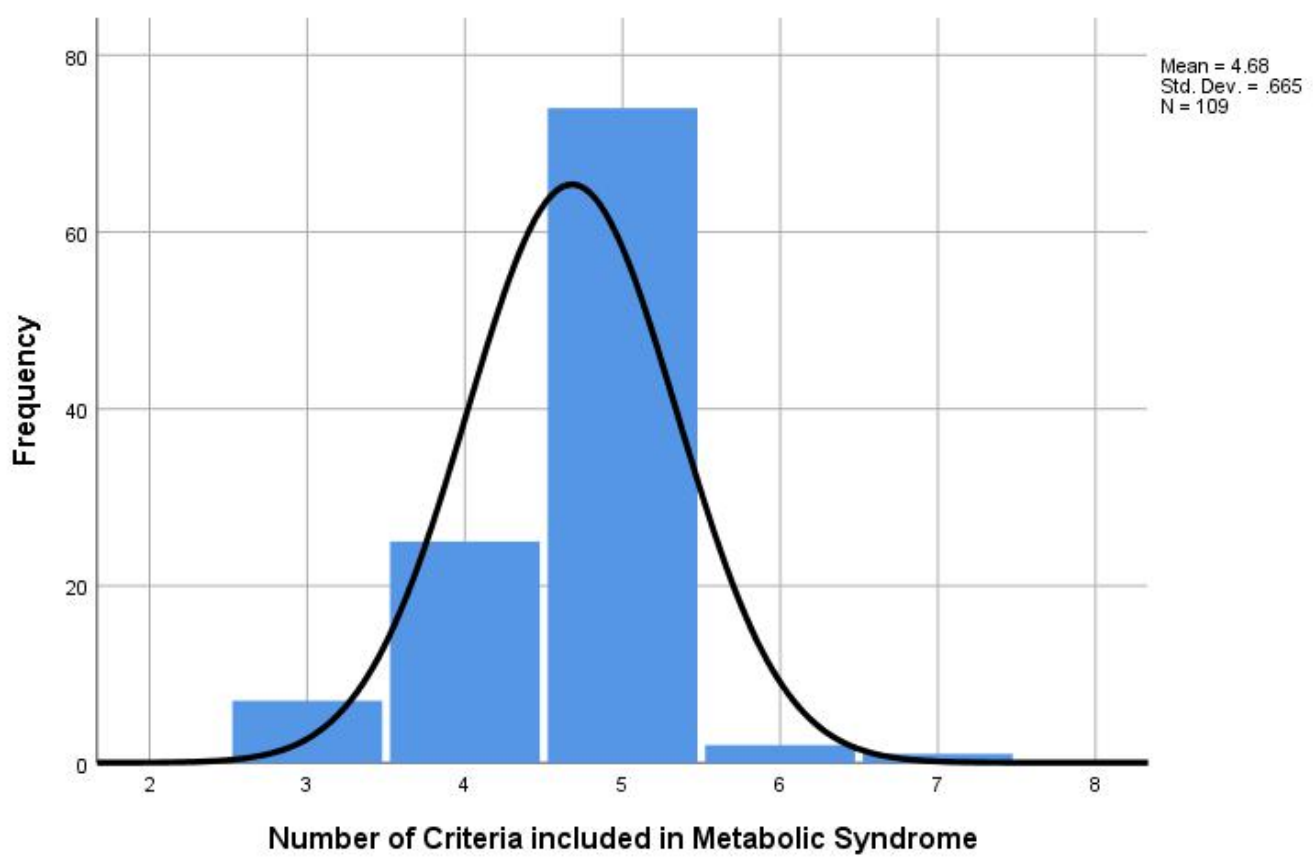

Figure 6.6: Histogram showing participants' answer frequency for total number of criteria comprising MetS

There was a statistically significant very strong relationship between participants' level of training and identifying the total number of criteria included in MetS (Cramer's V $=0.414, p$ $=0.001)$. Of the 39 Senior House Officers, $21(53.8 \%)$ correctly identified that five criteria are included in MetS, of the 22 Residents, 12 (54.5\%) correctly identified five criteria, of the 12 Registrars, 6 (50\%) correctly identified five criteria, of 7 Senior Registrars, 6 (85.7\%) correctly identified five criteria, of 29 Consultants, 28 (96.6\%) correctly identified that five criteria are included in MetS (See Fig. 6.7 below). 


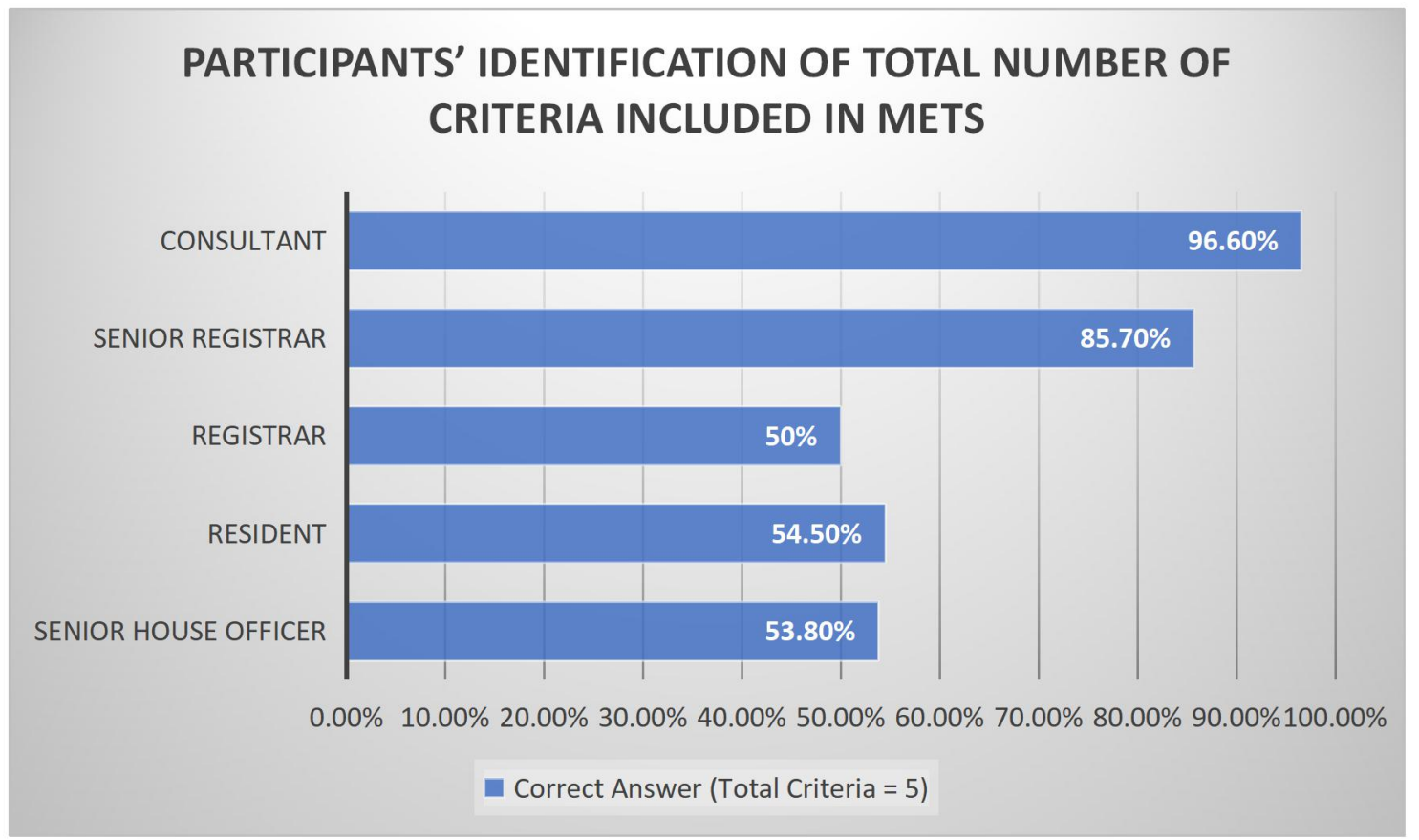

Figure 6.7: Bar Graph showing correct total number of criteria included in MetS by level of training

There was a statistically significant very strong relationship between participants' years in practice and identifying the total number of criteria included in MetS (Cramer's $\mathrm{V}=0.307, \mathrm{p}$ $=0.018)$. Those participants practicing $<5$ years, $9(45.0 \%)$ of 20 correctly identified that five criteria are included in MetS, of those participants practicing 5-10 years, 22 (62.9\%) of 35 correctly identified that five criteria are included in MetS, of those participants practicing 1120 years, $29(76.3 \%)$ of 38 correctly identified that five criteria are included in MetS, of those participants practicing $>20$ years, $12(92.3 \%)$ of 13 correctly identified that five criteria are included in MetS.

\subsubsection{Number of criteria needed for diagnosis of MetS}

Table 6.3: Table showing number of criteria included in diagnosis of Metabolic Syndrome

\begin{tabular}{|c|c|}
\hline Number of Criteria for diagnosis of MetS & Frequency (\%) \\
\hline 2 & $17(16.0)$ \\
\hline 3 & $71(67.0)$ \\
\hline 4 & $10(9.4)$ \\
\hline 5 & $8(7.5)$ \\
\hline
\end{tabular}


Pertaining to participants identifying the number of criteria needed for the diagnosis of Metabolic syndrome, $71(67.0 \%)$ identified three as the correct number of criteria for diagnosis (See Table 6.3 above/Fig. 6.8 below).

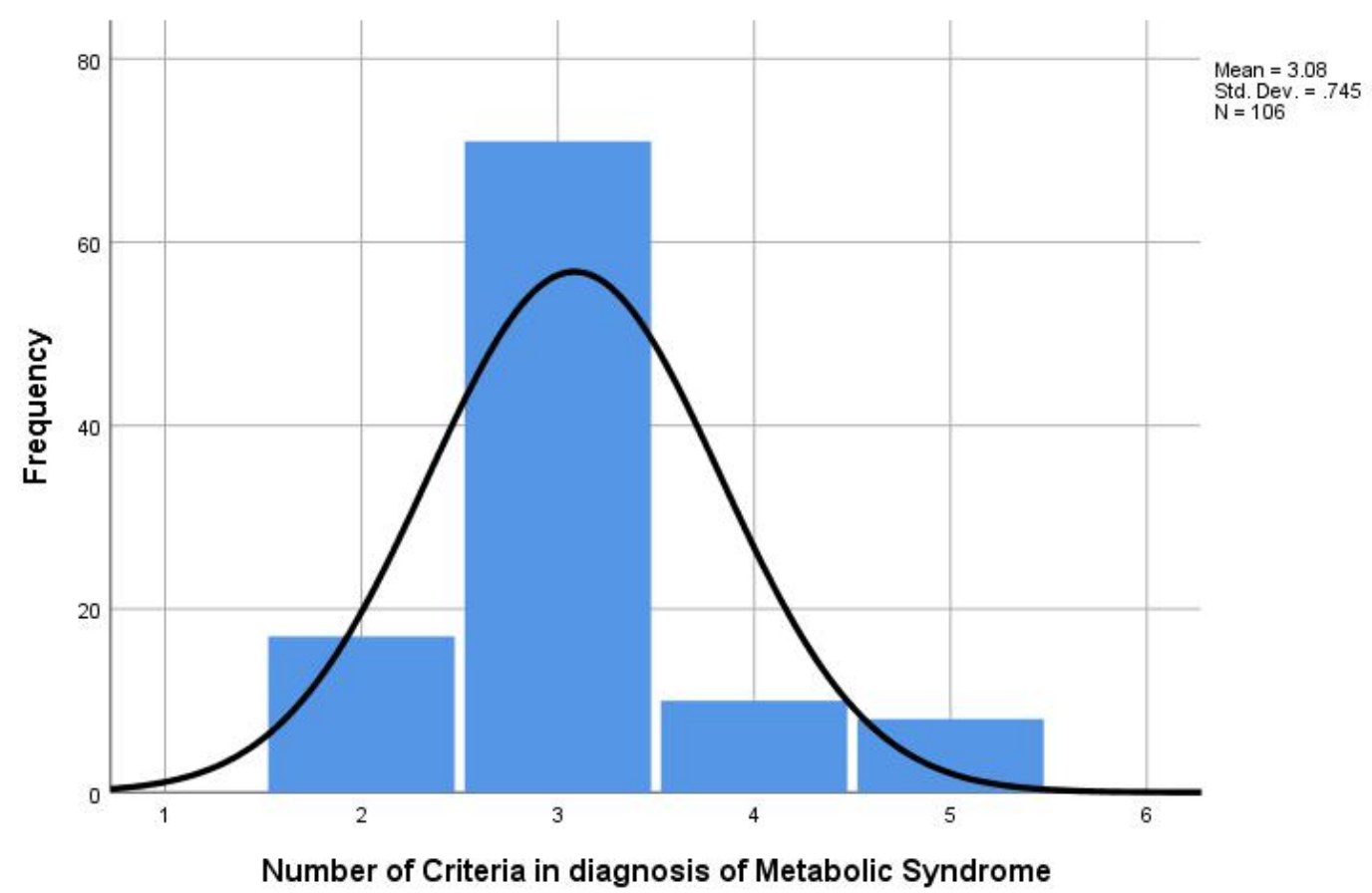

Figure 6.8: Histogram showing participants' answer frequency for number of criteria in diagnosis of MetS

There was a statistically significant very strong relationship between participants' level of training and identifying the number of criteria needed for the diagnosis of MetS (Cramer's V $=0.299, \mathrm{p}=0.046)$. Of the 39 Senior House Officers, $23(59.0 \%)$ correctly identified that three criteria are included in the diagnosis of MetS, of the 22 Residents, 11 (50.0\%) correctly identified three criteria, of the 11 Registrars, 6 (54.5\%) correctly identified three criteria, of 7 Senior Registrars, all (100\%) correctly identified three criteria, of 29 Consultants, 23 (79.3\%) correctly identified that three criteria are included in the diagnosis of MetS (See Fig. 6.9 below). 


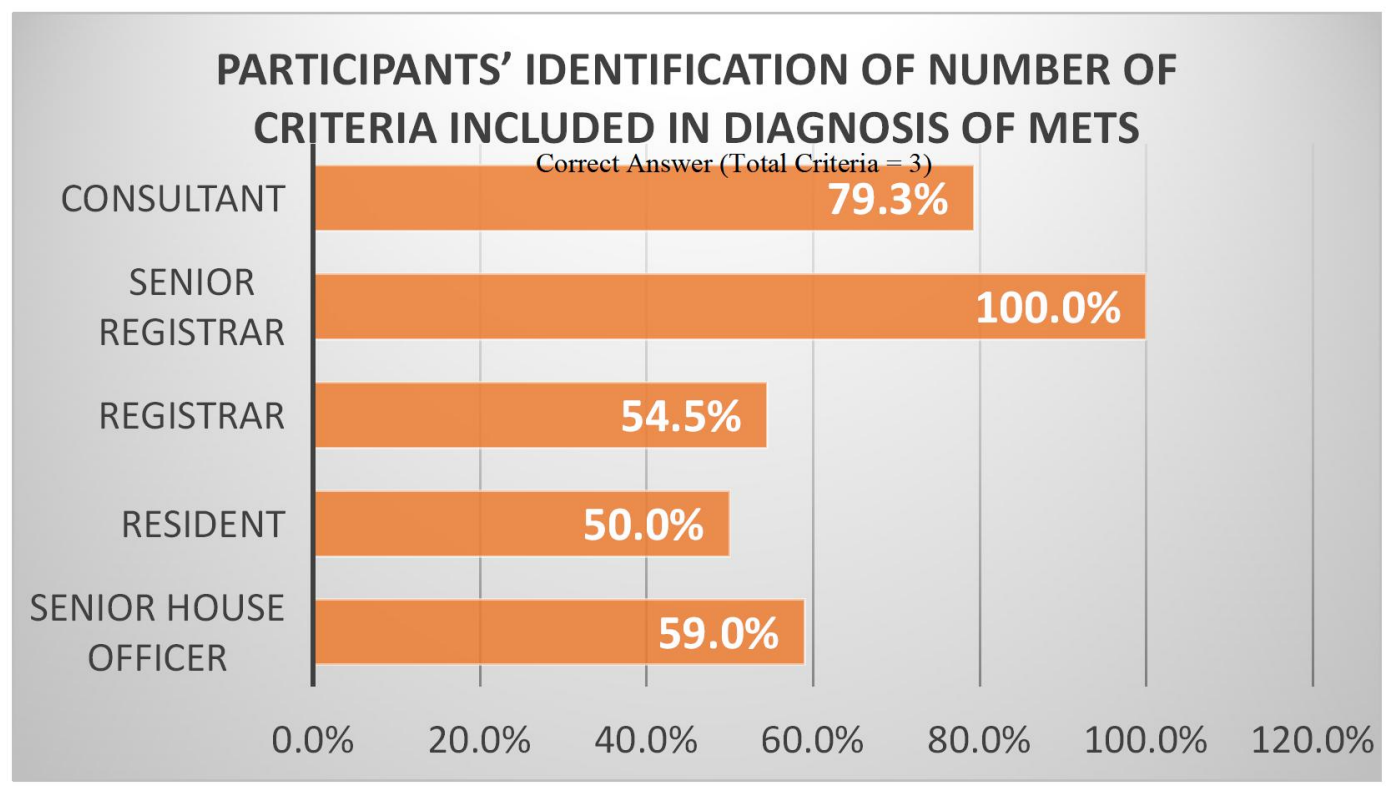

Figure 6.9: Bar graph showing correct number of criteria included in diagnosis of MetS by level of training

\subsubsection{Metabolic Syndrome Recognition of Clinical Cases}

When the 110 participants were all presented with five consecutive clinical scenarios regarding the definition of Metabolic Syndrome findings were as follows.

For first clinical case, $52(47.2 \%)$ correctly disagreed that a $60 \mathrm{y} / \mathrm{o}$ male, weighing $95 \mathrm{~kg}$, LDL $160 \mathrm{mg} / \mathrm{dL}, \mathrm{BP} 150 / 90 \mathrm{mmHg}$, and HDL $30 \mathrm{mg} / \mathrm{dL}$ TG $120 \mathrm{mg} / \mathrm{dL}$ is NOT consistent with the definition of Metabolic Syndrome.

For second clinical case, $39(35.5 \%)$ correctly agreed that a $50 \mathrm{y} / \mathrm{o}$ female, waist Circumference 90cm, BP 120/70mmHg, HDL 42mg/dL, TG $100 \mathrm{mg} / \mathrm{dL}$, and FPG $120 \mathrm{mg} / \mathrm{dL}$ is consistent with the definition of Metabolic Syndrome, while $71(64.5 \%)$ participants disagreed.

For third clinical case, $48(44.0 \%)$ correctly disagreed that a $45 \mathrm{y} / \mathrm{o}$ male, smoker, HbA1C 7\%, weighs $80 \mathrm{~kg}$, BP $145 / 95 \mathrm{mmHg}$, HDL $50 \mathrm{mg} / \mathrm{dL}$, and TG $147 \mathrm{mg} / \mathrm{dL}$ is NOT consistent with the definition of Metabolic Syndrome.

For fourth clinical case, $88(80.0 \%)$ correctly agreed that a $70 \mathrm{y} / \mathrm{o}$ female, LDL $180 \mathrm{mg} / \mathrm{dL}$, BP 150/90mmHg, HDL 30mg/dL, TG $147 \mathrm{mg} / \mathrm{dL}$, FPG $120 \mathrm{mg} / \mathrm{dL}$, and non-smoker is consistent with the definition of Metabolic Syndrome.

For fifth clinical case, $73(66.4 \%)$ correctly agreed that a $55 \mathrm{y} / \mathrm{o}$ male, waist Circumference $104 \mathrm{~cm}$, BP 125/80mmHg, HDL $35 \mathrm{mg} / \mathrm{dL}$, TG $152 \mathrm{mg} / \mathrm{dL}$, and FPG $-90 \mathrm{mg} / \mathrm{dL}$ is consistent with the definition of Metabolic Syndrome, while 37 (33.6\%) participants disagreed. 
There was a statistically significant very strong relationship between physician participants' specialty grouping and whether they correctly agreed that first clinical case was consistent with the definition for MetS (Cramer's $\mathrm{V}=0.293, \mathrm{p}=0.034$ ). Of 10 participants in the General Practice/Public Health grouping, 5 (50.0\%) correctly identified that first clinical case was consistent with the definition of MetS. Of 54 participants in the Family Medicine grouping, $22(40.7 \%)$ correctly identified that first clinical case was consistent with the definition of MetS. Of 22 participants in the Internal Medicine grouping, 14 (63.6\%) correctly identified that first clinical case was consistent with the definition of MetS. Of 15 participants in the O\&G grouping, $12(80.0 \%)$ correctly identified that first clinical case was consistent with the definition of MetS.

There was a statistically significant very strong relationship between physician participants' specialty grouping and whether they correctly disagreed that third clinical case was NOT consistent with the definition for MetS (Cramer's $V=0.298, p=0.031$ ). Of 9 participants in the General Practice/Public Health grouping, 5 (55.6\%) correctly disagreed that third clinical case was NOT consistent with the definition of MetS. Of 54 participants in the Family Medicine grouping, $33(61.1 \%)$ correctly disagreed that third clinical case was NOT consistent with the definition of MetS. Of 22 participants in the Internal Medicine grouping, $14(63.6 \%)$ correctly disagreed that third clinical case was NOT consistent with the definition of MetS. Of 15 participants in the O\&G grouping, only $3(20.0 \%)$ correctly disagreed that third clinical case was NOT consistent with the definition of MetS.

There was a statistically significant very strong relationship between participants level of training and whether or not they thought that the fifth clinical case involving a 55y/o male was consistent with the definition of Metabolic Syndrome (Cramer's V =0.305, p $=0.038$ ). Of the 39 Senior House Officers, 28 (71.8\%) said "yes" while 11 (28.2\%) said "no". Of the 22 Residents, 11 (50.0\%) said "yes". Of the 12 Registrars, 5 (41.7\%) said "yes" while 7 (58.3\%) said "no". Of the 7 Senior Registrars, 4 (57.1\%) said "yes" while 3 (42.9\%) said "no". Of the 29 Consultants, $24(82.8 \%)$ said "yes" while $5(17.2 \%)$ said "no".

\subsubsection{MetS influence on prognosis}

Regarding participants thoughts on whether Metabolic Syndrome influences prognosis 108 $(98.2 \%)$ said yes and only $2(1.8 \%)$ said no. 


\subsubsection{MetS as a risk factor for cancer}

In relation to cancer risk, $81(75.0 \%)$ of participants said "yes" they believe that Metabolic Syndrome is a risk factor and $27(25.0 \%)$ said no.

\subsubsection{Metabolic Syndrome Knowledge Level Scale (MetS-KS)}

Participants were also given a standardized 25 item modified Metabolic Syndrome Knowledge scale (MetS-KS) and responses were as follows.

Of the 110 participants, $90(81.8 \%)$ obtained a score of $75.0 \%(19 / 25)$ or higher on the MetSKS (See Fig. 6.10 below).

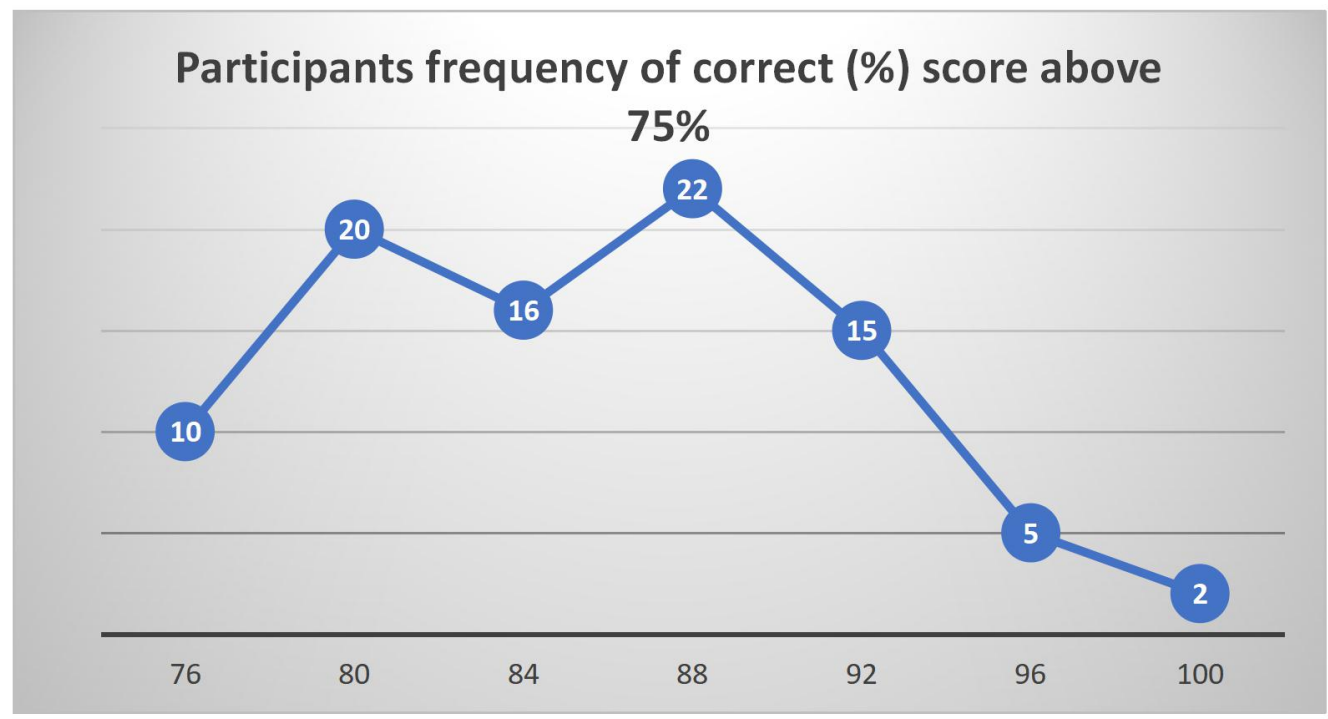

Figure 6.10: Line graph showing frequency of participants scoring higher than $\backslash 75 \%$ on MetS-KS

The participants' median percentage of the scores of those correctly answered in the MetS-KS was $84.0 \%$ (IQR: $76.0 \%, 88.0 \%$ ) equal to a score of $21 / 25$. The minimum was $0 \%$ seen in one participant, while the maximum was $100 \%$ obtained by two participants (See Fig. 6.10 above/Fig. 6.11 below). 


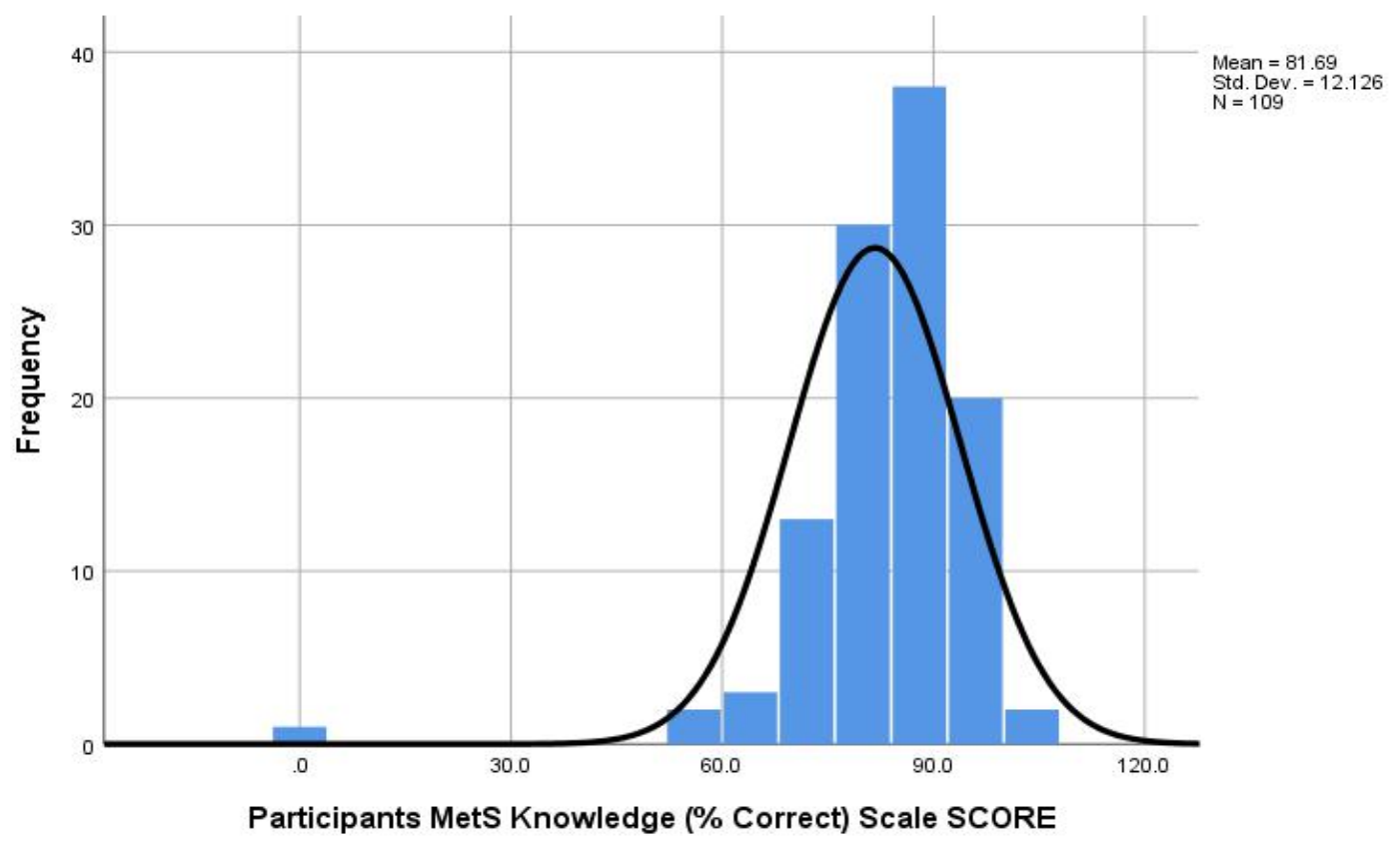

Figure 6.11: Histogram showing participants score performance on MetS-KS

When grouped by level of training, there were statistically significant differences among the medians $(\mathrm{p}=0.021)$. For Senior House Officers, the median score was 80.0\% (IQR: 76.0\%, $88.0 \%$ ), for Residents the median score was $82.0 \%$ (IQR: $76 \%, 88 \%$ ), for Registrars, the median score was $80.0 \%$ (IQR: 70.0\%, 86.0\%), for Senior Registrars, the median score was 84.0\% (IQR: 76\%, 90.0\%), for Consultants, the median score was 88.0\% (IQR: $84.0 \%, 92.0 \%$ ) (See Fig. 6.12 below).

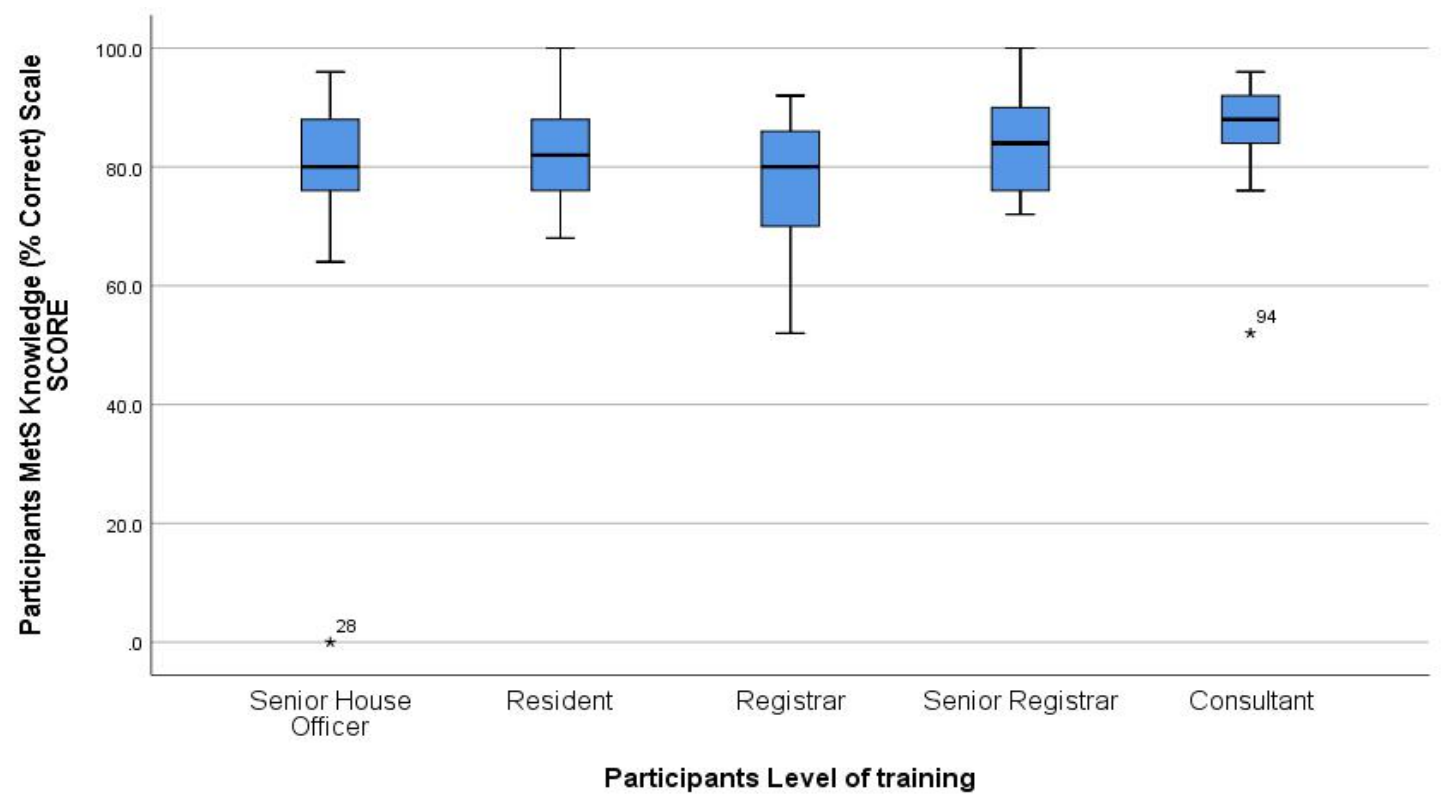

Figure 6.12: Box plot showing participants score performance on MetS-KS by level of training 
When grouped by specialty, there were statistically significant differences among the medians for the MetS Knowledge scale score concerning the percent correctly answered $(p=0.013)$. For General Practice/Public Health grouping, the median score was 80.0\% (IQR: 72.0\%, $88.0 \%$ ), with a minimum score of $68.0 \%$ and a maximum of $92.0 \%$, for Family Medicine grouping the median score was $84.0 \%$ (IQR: $80.0 \%$, 88.0\%), with a minimum score $68.0 \%$ and a maximum score of $96.0 \%$, for Internal Medicine grouping, the median score was $88.0 \%$ (IQR: $80.0 \%, 92.0 \%$ ), with a minimum score of $0 \%$ and a maximum of $100 \%$, for Obstetrics $\&$ Gynaecology grouping, the median score was $76.0 \%$ (IQR: $66 \%, 82.0 \%$ ), with a minimum score of $52.0 \%$ and a maximum of $100 \%$ ( See Fig. 6.13 below).

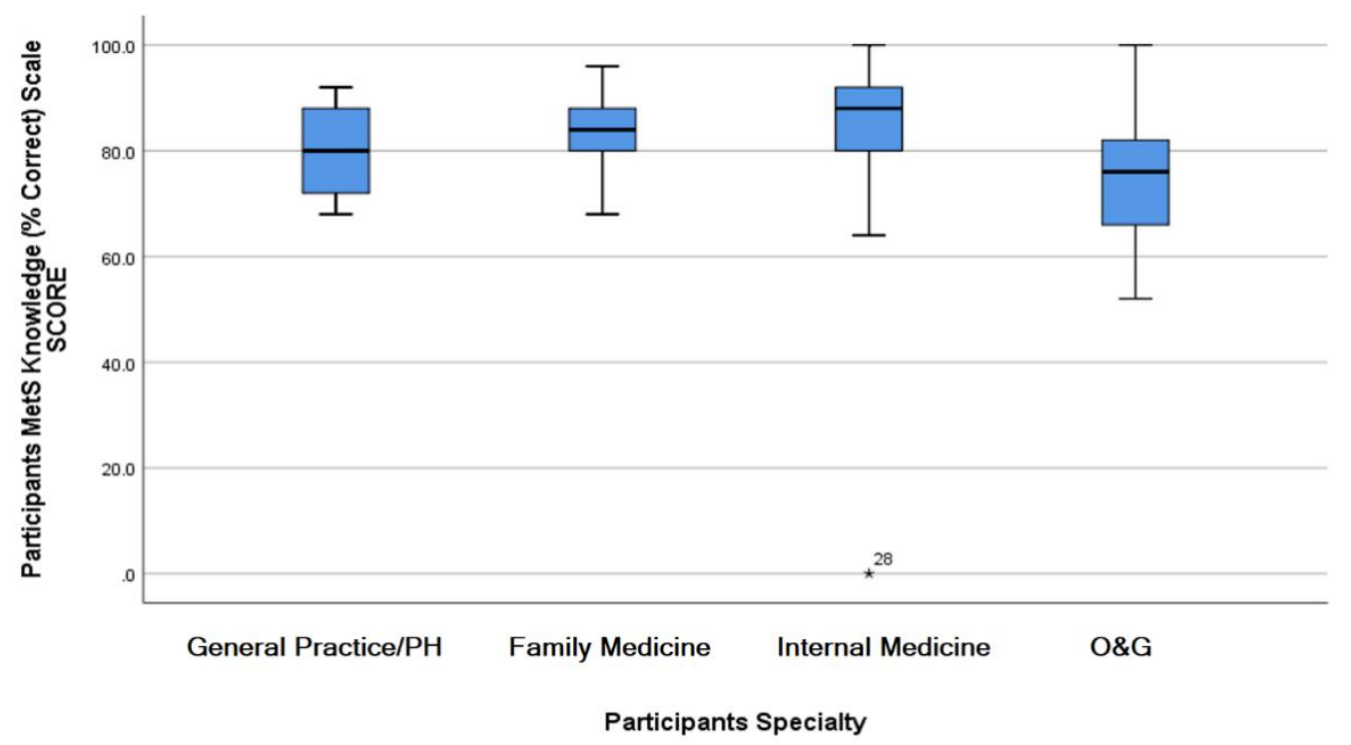

Figure 6.13: Box plot showing participants score performance on MetS-KS by specialty grouping 
Table 6.4: Table showing participants' frequency of correct answers (\%) in MetS-KS

\begin{tabular}{|c|c|c|}
\hline & MetS-KS Question & $\begin{array}{c}\text { Frequency Correct } \\
\text { Answers \% (n) }\end{array}$ \\
\hline Q1 & MetS is clinical condition comprised of five elements & $92.7(102)$ \\
\hline Q2 & MetS is a common condition & $91.8(101)$ \\
\hline Q3 & MetS prevalence increases with age & $84.5(93)$ \\
\hline Q4 & MetS can be seen in all age groups & $82.7(91)$ \\
\hline Q5 & MetS risk reduced with family member with heart disease & $70.9(78)$ \\
\hline Q6 & WC measurement is different in males and females & $94.5(104)$ \\
\hline Q7 & MetS is more common in females & $45.5(50)$ \\
\hline Q8 & Diet rich in fatty acids increases risk of MetS & $85.2(94)$ \\
\hline Q9 & Individuals with MetS have increased risk of AMI & $96.4(106)$ \\
\hline Q10 & Measurement of WC is an important component of MetS & $91.8(101)$ \\
\hline Q11 & High calorie nutrition is a risk factor for MetS & $68.2(75)$ \\
\hline Q12 & There is no need to measure lipids in MetS & $84.5(93)$ \\
\hline Q13 & MetS is more common in smokers & $45.5(50)$ \\
\hline Q14 & $\mathrm{BP}$ is higher than $130 / 85 \mathrm{mmHg}$ in MetS & $76.4(84)$ \\
\hline Q15 & $\begin{array}{l}\text { There is no relationship between ETOH consumption and } \\
\text { MetS formation }\end{array}$ & $23.6(26)$ \\
\hline Q16 & Individuals with MetS are at increased risk of DM & $95.5(105)$ \\
\hline Q17 & Physical inactivity facilitates formation of MetS & $95.5(105)$ \\
\hline Q18 & MetS is a treatable clinical condition & $97.3(107)$ \\
\hline Q19 & MetS is preventable & $96.4(106)$ \\
\hline Q20 & $\begin{array}{l}\text { Lifestyle change plays an important role in preventing } \\
\text { MetS }\end{array}$ & $97.3(107)$ \\
\hline Q21 & Individuals with MetS are less likely to have cancer & $74.5(82)$ \\
\hline Q22 & $\begin{array}{l}\text { If lifestyle changes are insufficient in MetS, drug } \\
\text { treatment can be applied }\end{array}$ & $91.9(101)$ \\
\hline Q23 & $\begin{array}{l}\text { MetS is less common in individuals who partake in a } \\
\text { balanced diet }\end{array}$ & $80.9(89)$ \\
\hline Q24 & Individuals with MetS have a high risk of stroke & $90.9(100)$ \\
\hline Q25 & MetS is less common in overweight individuals & $69.1(76)$ \\
\hline
\end{tabular}

There was statistically significant very strong relationship between physician participants' specialty grouping and whether or not they thought MetS is a clinical condition comprised of five elements (Cramer's $\mathrm{V}=0.298, \mathrm{p}=0.030$ ). Of the 10 participants in the General 
Practice/Public Health grouping, 7 (70.0\%) correctly agreed that MetS is a clinical condition comprised of five elements. Of the 54 participants in the Family Medicine grouping, 52 (96.3\%) correctly agreed that MetS is a clinical condition comprised of five elements. Of the 22 participants in the Internal Medicine grouping, 21 (95.5\%) correctly agreed that MetS is a clinical condition comprised of five elements. Of the 15 participants in the O\&G grouping, 13 $(86.7 \%)$ correctly agreed that MetS is a clinical condition comprised of five elements.

There was a statistically significant very strong relationship between participants level of training and whether they thought waist circumference measurement for MetS is different among sexes (Cramer's V $=0.278, \mathrm{p}=0.035)$. Of 38 Senior House Officers, $37(97.4 \%)$ said "yes"; of 21 Residents, all (100\%) said "yes"; of 12 Registrars, 11 (91.7\%) said "yes"; of 7 Senior Registrars, 6 (87.5\%) said “yes"; of 29 Consultants, 28 (96.6\%) said “yes".

There is a statistically significant strong relationship between participants sex and whether they thought MetS is more common in females (Cramer's V $=0.242, \mathrm{p}=0.044$ ). Of 28 males, 14 (50\%) said "yes", 8 (28.6\%) said "no", and 6 (21.4\%) said "not likely" or were "unsure". Of the 78 females, 36 (46.2\%) said "yes", 9 (11.5\%) said "no", and 33 (42.3\%) said "not likely/unsure".

There was statistically significant very strong relationship between physician participants' specialty grouping and whether or not they thought MetS is less common in overweight individuals (Cramer's $\mathrm{V}=0.323, \mathrm{p}=0.002$ ). Of the 8 participants in the General Practice/Public Health grouping, $6(75.0 \%)$ correctly disagreed that MetS is less common in overweight individuals. Of the 53 participants in the Family Medicine grouping, 44 (83.0\%) correctly disagreed that MetS is less common in overweight individuals. Of the 22 participants in the Internal Medicine grouping, 16 (72.7\%) correctly disagreed that MetS is less common in overweight individuals. Of the 15 participants in the $O \& G$ grouping, 4 $(26.7 \%)$ correctly disagreed that MetS is less common in overweight individuals. 


\subsection{PHYSICIANS' EXPERIENCES WITH SCREENING FOR METABOLIC SYNDROME}

\subsubsection{Evaluating for MetS}

Physician participants report how often they evaluate for MetS in their patients. The median frequency with which participants reported frequency of evaluating for Metabolic Syndrome was sometimes (IQR: occasional, often). Here, 45 (41.3\%) indicate that they "sometimes" evaluate, 25 (22.9\%) evaluate "occasionally", 18 (16.5\%) evaluate "often", 13 (11.9\%) evaluate "always" and 8 (7.3\%) "never" evaluate, 1 participant did not report how often they evaluate (See Table 5/Fig. 14 below).

Table 6.5: Table showing participants' frequency of evaluating for Metabolic Syndrome in their patients

\begin{tabular}{|c|c|}
\hline $\begin{array}{c}\text { Ranked Category: Participants Evaluating for } \\
\text { MetS in their patients }\end{array}$ & Frequency (\%) \\
\hline Never & $8(7.3)$ \\
\hline Occasionally & $25(22.9)$ \\
\hline Sometimes & $45(41.3)$ \\
\hline Often & $18(16.5)$ \\
\hline Always & $13(11.9)$ \\
\hline
\end{tabular}

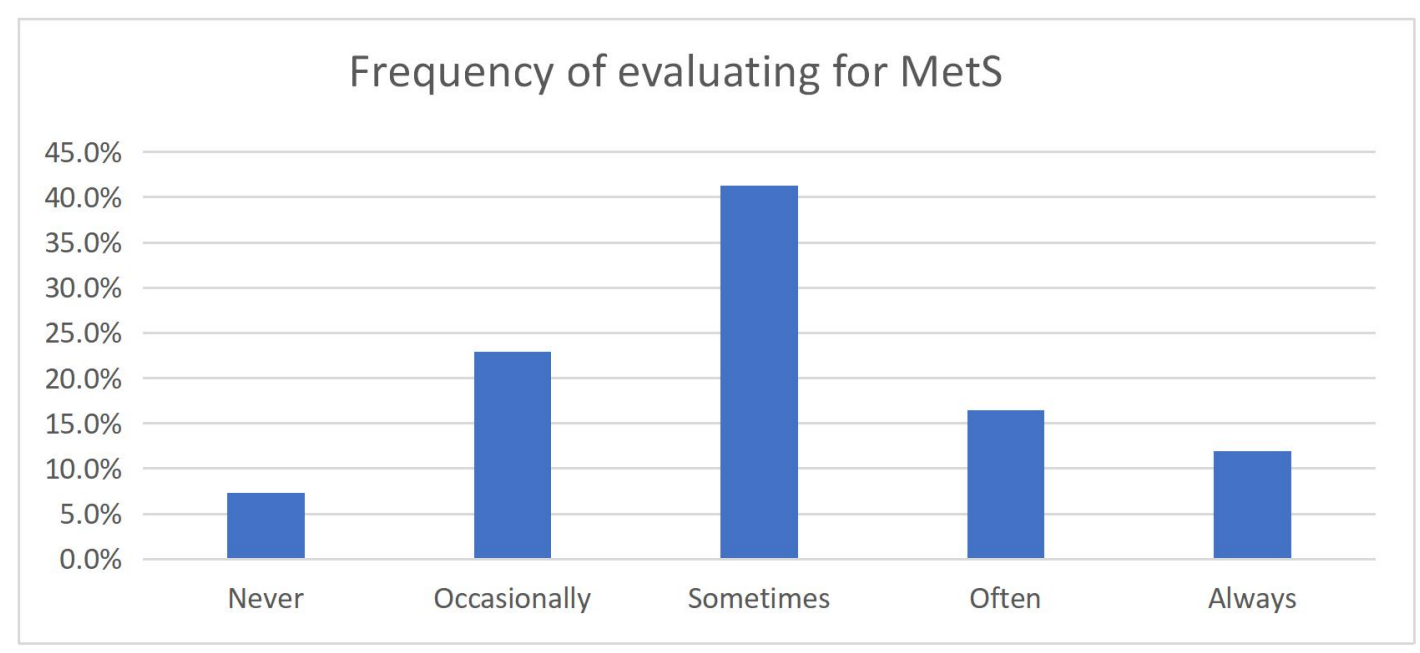

Figure 6.14: Bar Graph showing participants' frequency of evaluating MetS 
There was a statistically significant moderate positive relationship between participants' level of training and frequency of evaluating for MetS in their patients $(\mathrm{rSp}=0.333, \mathrm{p}=0.001)$. The median frequency with which Senior House Officers evaluate for MetS was Sometimes (IQR: occasional, sometimes). The median frequency with which Residents evaluate for MetS was Sometimes (IQR: occasional, often). The median frequency with which Registrars evaluate for MetS was Sometimes (IQR: sometimes, often). The median frequency with which Senior Registrars evaluate for MetS was Sometimes (IQR: sometimes, sometimes). The median frequency with which Consultants evaluate for MetS in their patients was Often (IQR: often, often).

\subsubsection{Measuring Waist Circumference}

The median frequency with which participants reported measuring waist circumference was Occasionally (IQR: never, occasionally). Here, 4 (3.6\%) measure waist circumference "everytime", 4 (3.6\%) measure "often", 19 (17.3\%) measure "sometimes", 31 (28.2\%) measure "occasionally", and 52 (47.3\%) "never" measure waist circumference.

There was a statistically significant moderate positive relationship between participants level of training and whether or not they measure waist circumference $(\mathrm{rSp}=0.356, \mathrm{p}<0.001)$. The median frequency with which Senior House Officers measure waist circumference was Never (IQR: never, occasionally). The median frequency with which Residents measure waist circumference was Occasionally (IQR: never, sometimes). The median frequency with which Registrars measure waist circumference was Occasionally (IQR: occasionally, sometimes). The median frequency with which Senior Registrars measure waist circumference was Occasionally (IQR: never, sometimes). The median frequency with which Consultants measure waist circumference was Occasionally (IQR: never, sometimes).

Participants' median frequency with which they measure waist circumference differed by their specialty grouping $(\mathrm{p}=0.020)$. The median frequency with which the General Practice/Public Health grouping measure waist circumference was Never (IQR: never, never). The median frequency with which the Family Medicine grouping measure waist circumference was Occasionally (IQR: never, sometimes). The median frequency with which the Internal Medicine grouping measure waist circumference was Never (IQR: never, sometimes). The median frequency with which the $O \& G$ grouping measure waist circumference was Never (IQR: never, never). 


\subsubsection{Calculating BMI}

The median frequency with which participants reported whether or not they calculate Body Mass Index (BMI) was Often (IQR: occasionally, often). Here, 7 (6.4\%) "never" calculate BMI, 22 (20.0\%) calculate BMI “occasionally", 25 (22.7\%) calculate "sometimes", 37 $(33.6 \%)$ calculate "often", and $19(17.3 \%)$ calculate "everytime".

There was a statistically significant moderate positive relationship between participants level of training and whether or not they calculate Body Mass Index $(\mathrm{rSp}=0.380, \mathrm{p}<0.001)$.

The median frequency with which Senior House Officers calculate BMI was Sometimes (IQR: occasionally, often). The median frequency with which Residents calculate BMI was Often (IQR: sometimes, everytime). The median frequency with which Registrars calculate BMI was Sometimes (IQR: occasionally, often). The median frequency with which Senior Registrars calculate BMI was Often (IQR: sometimes, everytime). The median frequency with which Consultants calculate BMI was Everytime (IQR: often, everytime).

Participants' median frequency with which they calculate BMI differed by their specialty grouping $(p=0.004)$. The median frequency with which the General Practice/Public Health grouping calculated BMI was Often (IQR: occasionally, often). The median frequency with which the Family Medicine grouping calculated BMI was Often (IQR: sometimes, often). The median frequency with which the Internal Medicine grouping calculated BMI was Sometimes (IQR: occasionally, sometimes). The median frequency with which the O\&G grouping calculated BMI was Sometimes (IQR: occasionally, often) (See Fig. 6.15). 


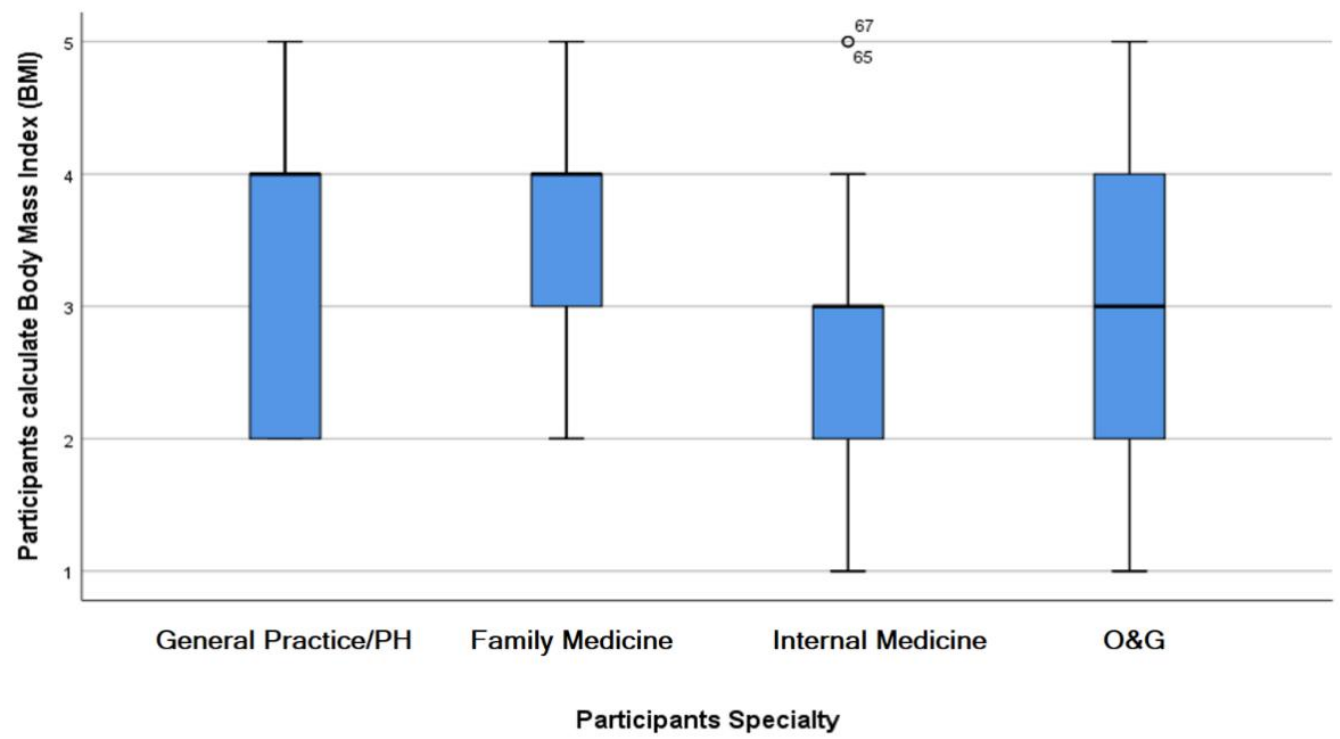

Figure 6.15: Box plot showing participants' median frequency with which they calculate BMI by specialty grouping

(Legend: $1=$ Never, $2=$ Occasionally, $3=$ Sometimes, $4=$ Often, $5=$ Everytime $)$

\subsubsection{Calculating ASCVD risk score}

The median frequency with which participants reported calculating ASCVD risk score was Sometimes (IQR: occasionally, often). Here, 19 (17.4\%) "never” calculate ASCVD risk score, 27 (24.8\%) calculate ASCVD “occasionally", 25 (22.9\%) calculate "sometimes", 27 (24.8\%) calculate "often", and $11(10.1 \%)$ calculate "everytime".

Participants' median frequency with which they calculate ASCVD risk score differed by their specialty grouping $(\mathrm{p}<0.001)$. The median frequency with which the General Practice/Public Health grouping calculated ASCVD risk score was Never (IQR: never, sometimes). The median frequency with which the Family Medicine grouping calculated ASCVD risk score was Sometimes (IQR: occasionally, often). The median frequency with which the Internal Medicine grouping calculated ASCVD risk score was Often (IQR: occasionally, often). The median frequency with which the O\&G grouping calculated ASCVD risk score was Never (IQR: never, sometimes). 


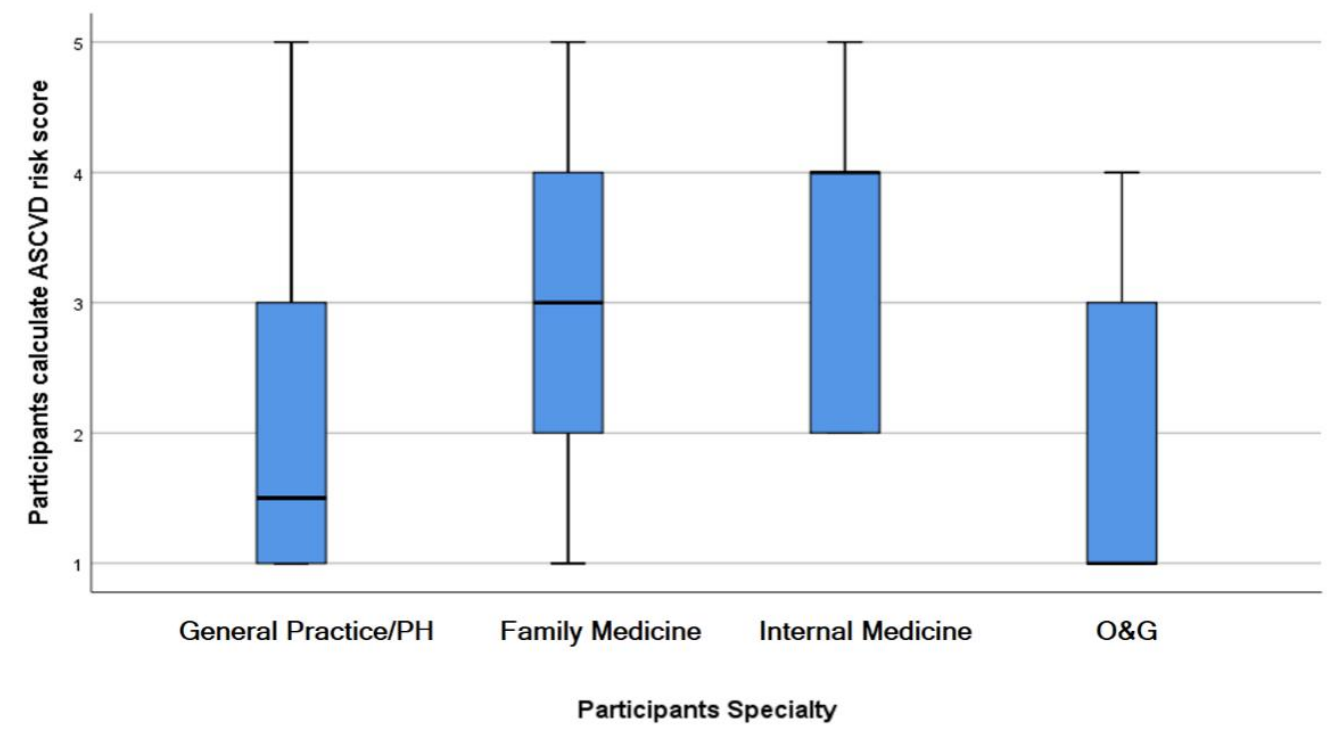

Figure 6.16: Box plot showing participants' median frequency with which they calculate ASCVD risk score by specialty grouping

(Legend: $1=$ Never, 2 = Occasionally, $3=$ Sometimes, 4 = Often, 5 = Everytime)

\subsection{PHYSICIANS' PERCEPTION TO WHICH THEY ENGAGE IN HEALTH EDUCATION ABOUT CARDIOVASCULAR RISK}

\subsubsection{Engaging patients in health education regarding cardiovascular risk}

The median frequency with which participants engage patients in health education regarding cardiovascular risk was Everytime (IQR: often, everytime). Here, 58 (52.7\%) engage in health education "everytime", 44 (40.0\%) engage "often", 5 (4.5\%) engage "sometimes", and 3 (2.7\%) engage "occasionally" (See Fig. 6.17 below). 


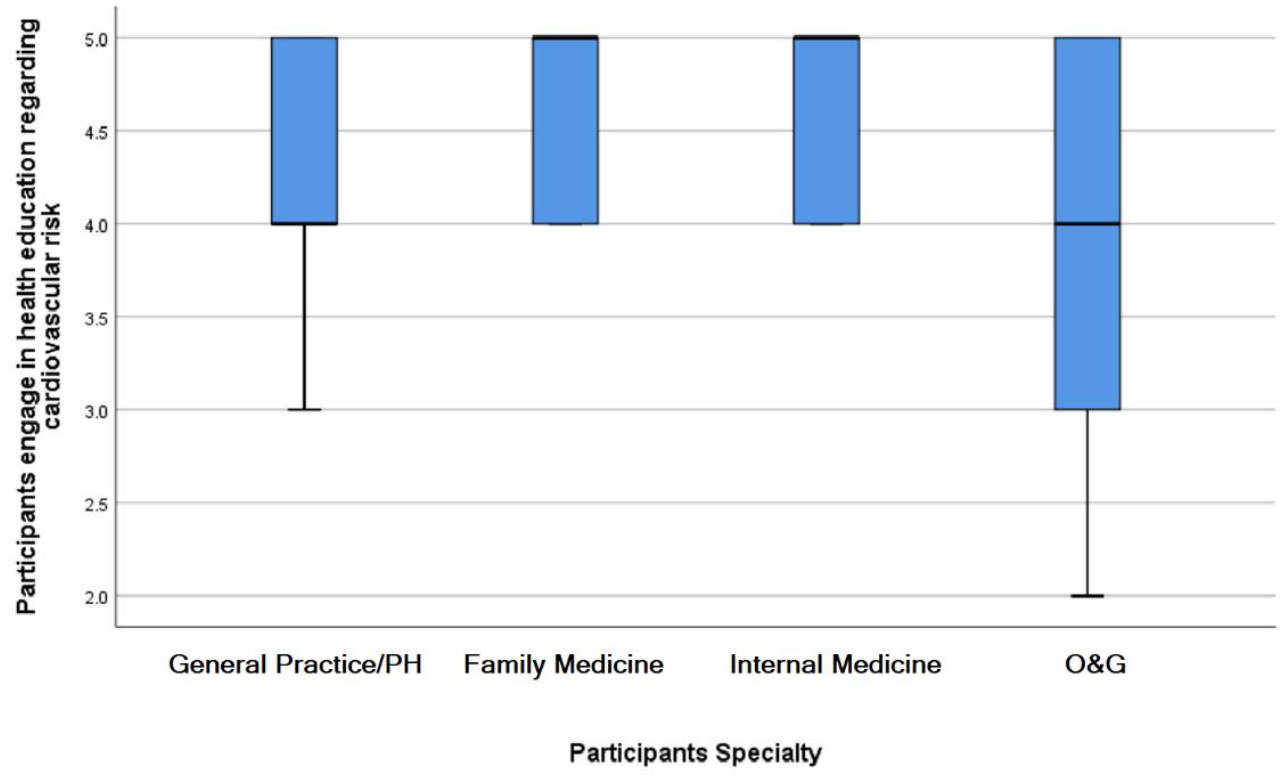

Figure 6.17: Box plot showing participants' median frequency with which they engage patients in health education regarding $\mathrm{CV}$ risk by specialty grouping

(Legend: 1 = Never, 2 = Occasionally, 3 = Sometimes, 4 = Often, 5 = Everytime)

Participants' median frequency with which they engage patients in health education regarding cardiovascular risk differed by their specialty grouping $(p=0.054)$. The median frequency with which the General Practice/Public Health grouping engaged patients in health education was Often (IQR: often, everytime). The median frequency with which the Family Medicine grouping engaged patients in health education was Everytime (IQR: often, everytime). The median frequency with which the Internal Medicine grouping engaged patients in health education was Everytime (IQR: often, everytime). The median frequency with which the O\&G grouping engaged patients in health education was Often (IQR: sometimes, everytime) (See Fig. 6.17 above).

\subsubsection{Patients feel well informed about $\mathrm{CV}$ risk post visit}

The median frequency with which participants reported whether or not they think their patients feel well informed about their $\mathrm{CV}$ risk post visit was Often (IQR: sometimes, often). Here, 56 (51.9\%) "often" feel patients are well informed, 25 (23.1\%) reported "sometimes", 24 (22.2\%) reported "everytime", 2 (1.9\%) reported "occasionally", and 1 $(0.9 \%)$ reported "never".

There was a statistically significant weak positive relationship between participants level of training and whether or not participants think patients feel well informed about cardiovascular risk post visit $(\mathrm{rSp}=0.213, \mathrm{p}=0.027)$. The median frequency with which Senior House 
Officers thought patients feel well informed about CV risk post visit was Often (IQR: sometimes, often). The median frequency with which Residents thought patients leave post visit well informed about CV risk was Often (IQR: sometimes, everytime). The median frequency with which Registrars thought patients leave post visit well informed about CV risk was Often (IQR: sometimes, often). The median frequency with which Senior Registrars thought patients leave post visit well informed about CV risk was Often (IQR: often, everytime). The median frequency with which Consultants thought patients leave post visit well informed about CV risk was Often (IQR: often, everytime).

Participants' median frequency with which they thought patients feel well informed about CV risk post visit differed by their specialty grouping $(p=0.005)$. The median frequency with which the General Practice/Public Health grouping thought patients feel well informed about CV risk post visit was Often (IQR: often, everytime). The median frequency with which the Family Medicine grouping thought patients feel well informed about CV risk post visit was Often (IQR: often, everytime). The median frequency with which the Internal Medicine grouping thought patients feel well informed about CV risk post visit was Often (IQR: sometimes, often). The median frequency with which the O\&G thought patients feel well informed about CV risk post visit was Often (IQR: sometimes, often) (See Fig. 6.18 below).

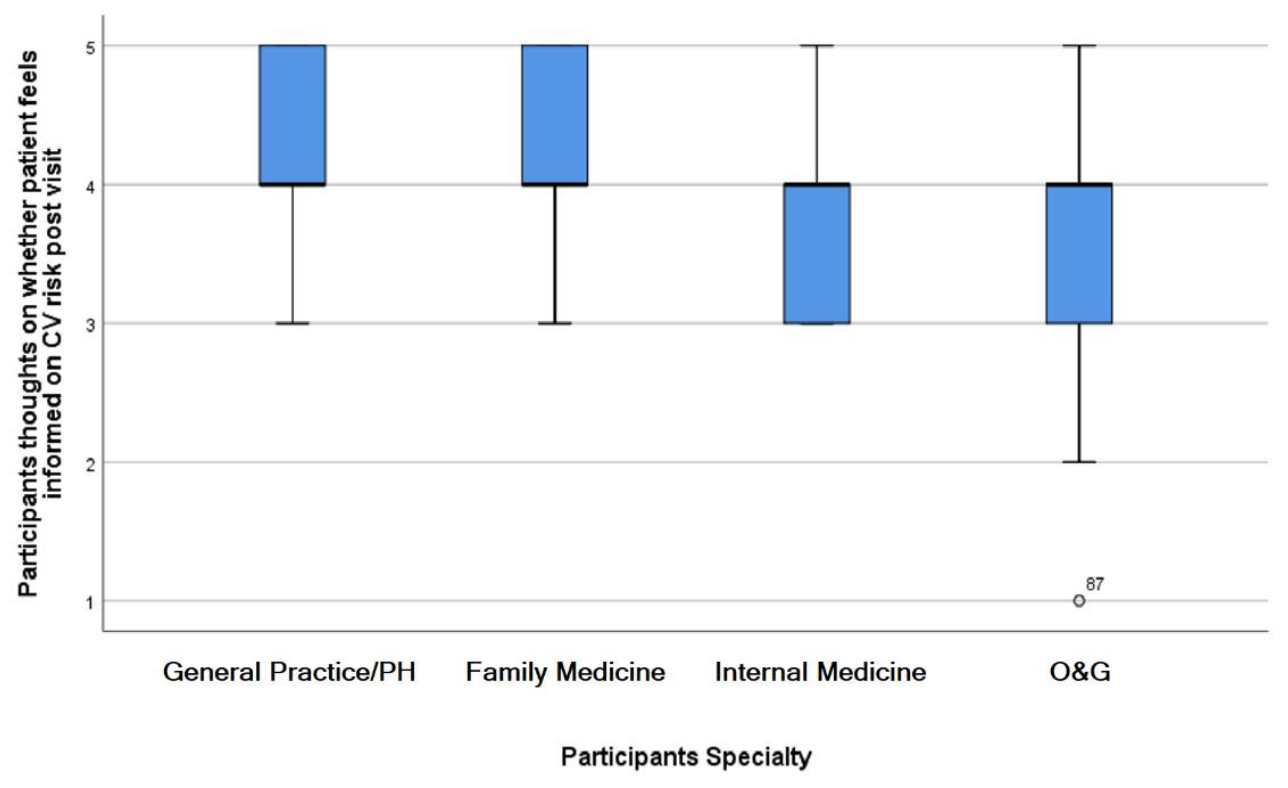

Figure 18: Box plot showing participants' median frequency with which they thought patients feel well informed about $\mathrm{CV}$ risk post visit by specialty grouping (Legend: 1 = Never, 2 = Occasionally, $3=$ Sometimes, $4=$ Often, $5=$ Everytime) 


\subsubsection{Recommending adjustment of risk factors}

Physician participants report whether they recommend adjustment of risk factors upon discharge of their patients. The median frequency with which participants recommend adjustment of risk factors upon discharge was Often (IQR: sometimes, always). Here, 49 (45.4\%) indicate that they "always" recommend adjustment of risk factors, $28(25.9 \%)$ recommend "often", 22 (20.4\%) recommend "sometimes", 5 (4.6\%) recommend "occasionally" and 4 (3.7\%) "never" recommend adjustment of risk factors upon discharge (See Table 6.6).

Table 6.6: Table showing participants recommending adjustment of risk factors upon discharge

\begin{tabular}{|c|c|}
\hline $\begin{array}{c}\text { Ranked Category: Participants recommending } \\
\text { adjustment of risk factors upon discharge to } \\
\text { their patients }\end{array}$ & Frequency (\%) \\
\hline Never & $4(3.7)$ \\
\hline Occasionally & $5(4.6)$ \\
\hline Sometimes & $22(20.4)$ \\
\hline Often & $28(25.9)$ \\
\hline Always & $49(45.4)$ \\
\hline
\end{tabular}

There was a statistically significant moderate positive relationship between participants' level of training and whether they recommend adjustment of risk factors upon discharge $(\mathrm{rSp}=$ $0.274, \mathrm{p}=0.004)$. The median frequency with which Senior House Officers recommend adjustment of risk factors upon discharge was Often (IQR: sometimes, always). The median frequency with which Residents recommend adjustment of risk factors upon discharge was Often (IQR: sometimes, always). The median frequency with which Registrars recommend adjustment of risk factors upon discharge was Often (IQR: often, always). The median frequency with which Senior Registrars recommend adjustment of risk factors upon discharge was Always (IQR: always, always). The median frequency with which Consultants recommend adjustment of risk factors upon discharge of their patients was Always (IQR: often, always) (See Fig. 6.19 below). 


\section{Frequency of recommending adjustment of risk factors upon patient discharge}

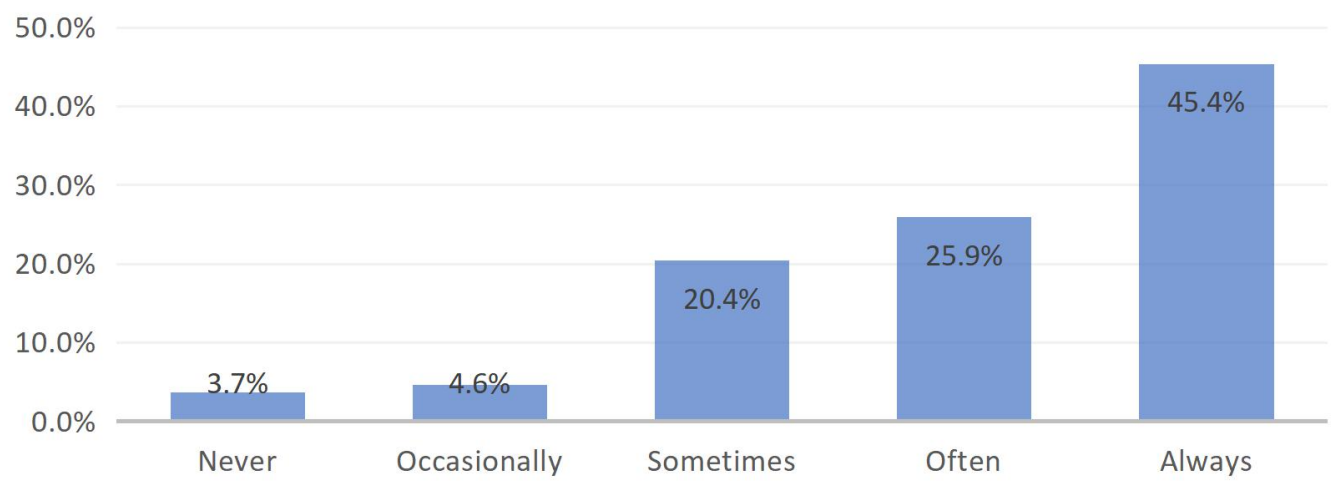

Figure 6.19: Bar graph showing participants' frequency of recommending risk factors upon patient discharge

Participants reported which risk factors they most commonly recommend to be adjusted (See Table 6.7 below)

Table 6.7: Table showing risk factors recommended by participants for adjustment

\begin{tabular}{|c|c|c|}
\hline Risk Factor & Frequency & Percent \\
\hline Blood Pressure/HTN & 25 & 22.7 \\
\hline Weight Loss & 62 & 56.4 \\
\hline Blood glucose/DM & 20 & 18.2 \\
\hline Lipid lowering & 19 & 17.3 \\
\hline Diet & 24 & 21.8 \\
\hline Exercise & 18 & 16.4 \\
\hline BMI & 5 & 4.5 \\
\hline Waist Circumference & 23 & 20.9 \\
\hline Medication compliance & 4 & 3.6 \\
\hline Decreased fat intake & 2 & 1.8 \\
\hline Smoking cessation & 13 & 11.8 \\
\hline Lifestyle change & 6 & 5.5 \\
\hline Total & $\mathbf{1 1 0}$ & $\mathbf{1 0 0 . 0}$ \\
\hline
\end{tabular}




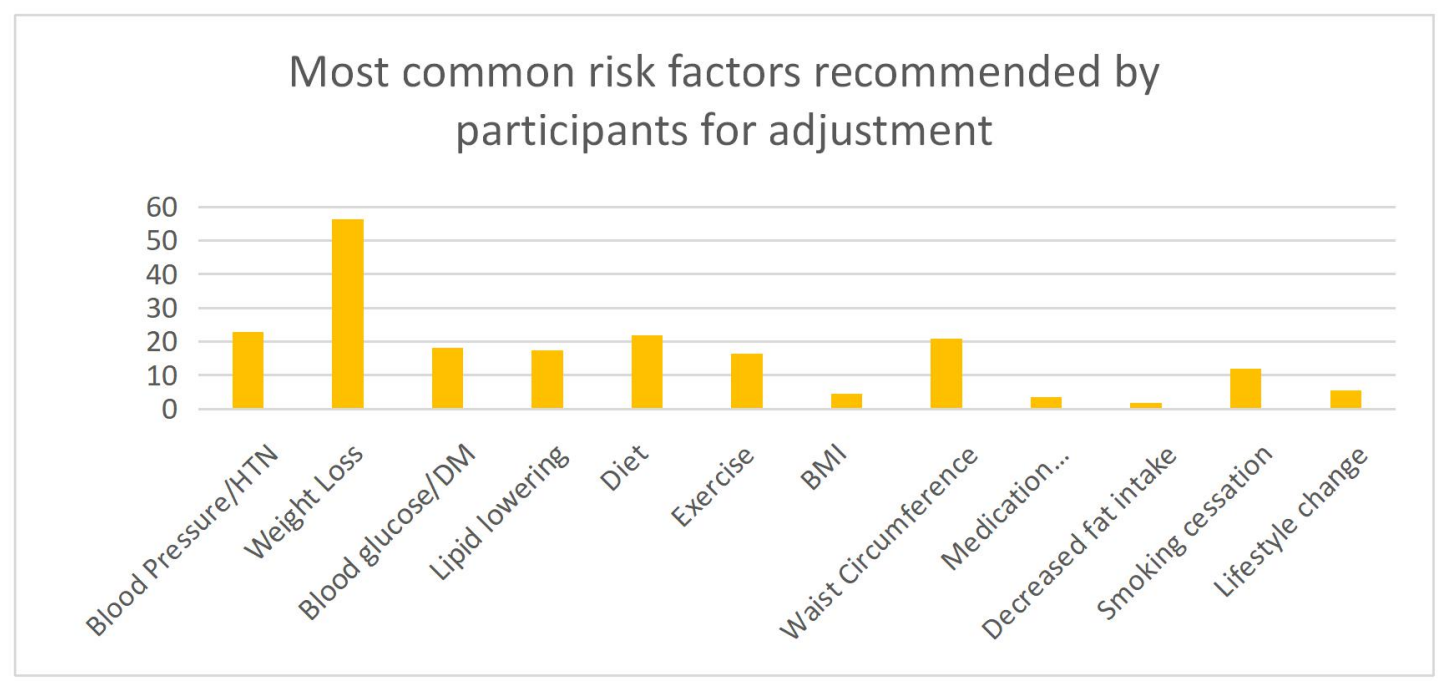

Figure 6.20: Bar graph showing most common risk factors recommended by participants for adjustment

\subsubsection{Risk Factor: Waist Circumference}

There was a statistically significant very strong relationship between level of training and participants reporting whether they thought waist circumference should be recommended as an adjusted risk factor in MetS (Cramer's $\mathrm{V}=0.360, \mathrm{p}=0.007$ ). Of the 39 Senior House Officers, 7 (17.9\%) reported that WC should be an adjusted risk factor, of the 22 Residents, 5 $(22.7 \%)$ reported that it should be, of the 12 Registrars, none reported that it should be, of the 7 Senior Registrars, 5 (71.4\%) reported that it should be, of the 29 Consultants, 6 (20.7\%) reported that WC should be an adjusted risk factor in MetS (See Fig. 20 above).

\subsubsection{Risk Factor: Blood Glucose}

There was a statistically significant very strong relationship between level of training and participants reporting whether they thought blood glucose should be recommended as an adjusted risk factor in MetS (Cramer's $\mathrm{V}=0.317, \mathrm{p}=0.027$ ). Of the 39 Senior House Officers, 5 (12.8\%) reported that blood glucose should an adjusted risk factor, of 22 Residents, $1(4.5 \%)$ reported that it should be an adjusted risk factor, of 12 Registrars, $3(25.0 \%)$ reported that it should be, of 7 Senior Registrars, none reported that it should be, and of 29 Consultants, 10 (34.5\%) reported that blood glucose should be an adjusted risk factor in MetS (See Fig. 20 above).

\subsubsection{Risk Factor: Lifestyle change}

There was a statistically significant very strong relationship between level of training and participants reporting whether they thought lifestyle change should be recommended as an 
adjusted risk factor in MetS (Cramer's $\mathrm{V}=0.314, \mathrm{p}=0.030$ ). Of the 39 Senior House Officers, $1(2.6 \%)$ reported that lifestyle change should be an adjusted risk factor, of the 22 Residents, none reported that lifestyle change should be an adjusted risk factor, of the 12 Registrars, none reported that it should be, of the 7 Senior Registrars, none reported that it should be, of the 29 Consultants, $5(17.2 \%)$ reported that lifestyle change should be an adjusted risk factor in MetS (See Fig. 6.21 below).

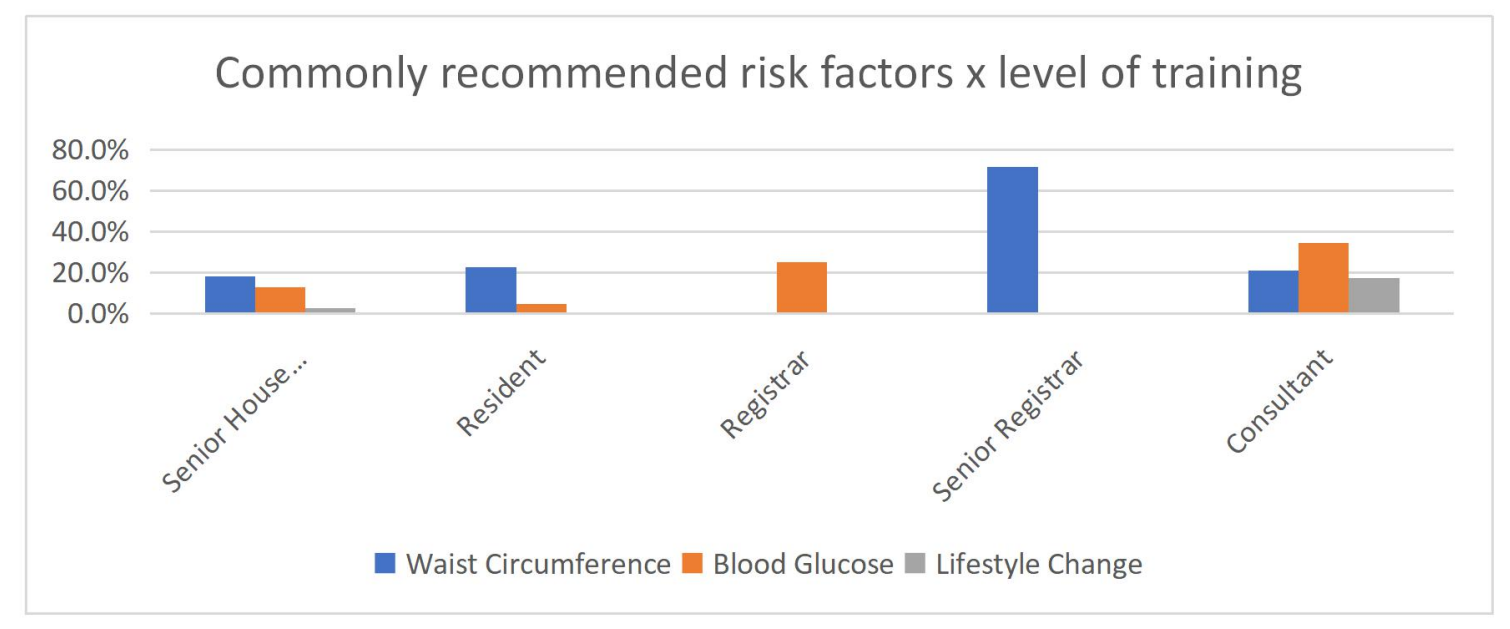

Figure 6.21: Bar graph showing most commonly recommended risk factors for adjustment by level of training

\subsubsection{Counselling on Lifestyle modification}

The median frequency with which participants counsel on lifestyle modification was Everytime (IQR: often, everytime). Here, 80 (73.4\%) counsel on lifestyle modification "everytime", 26 (23.9\%) counsel "often", 2 (1.8\%) counsel "sometimes", and 1 (0.9\%) "never" counsels on lifestyle modification.

\subsection{ADHERENCE TO NCEP-ATP III CLINICAL PRACTICE GUIDELINES}

\subsubsection{Criteria used for Diagnosis of MetS}

Participants indicated which of four standard criteria (or none of them) they used when diagnosing metabolic syndrome. Here, 58 (54.2\%) participants used the NCEP-ATP III criteria, those that used WHO totaled $25(23.4 \%)$, those that used AACE totaled $6(5.6 \%)$, those that used IDF totaled $3(2.8 \%)$ and those that used none or other totaled $15(14.0 \%)$ (See Table 6.8/Fig. 6.22 below). 
Table 6.8: Table showing which criteria participants use for diagnosis of Metabolic Syndrome

\begin{tabular}{|c|c|}
\hline Criteria used for Diagnosis of Metabolic Syndrome & Frequency (\%) \\
\hline NCEP-ATP III & $58(54.2)$ \\
\hline World Health Organization (WHO) & $25(23.4)$ \\
\hline American Academy of Clinical Endocrinologists (AACE) & $6(5.6)$ \\
\hline International Diabetes Foundation (IDF) & $3(2.8)$ \\
\hline None of the above & $13(12.1)$ \\
\hline Other & $2(1.9)$ \\
\hline
\end{tabular}

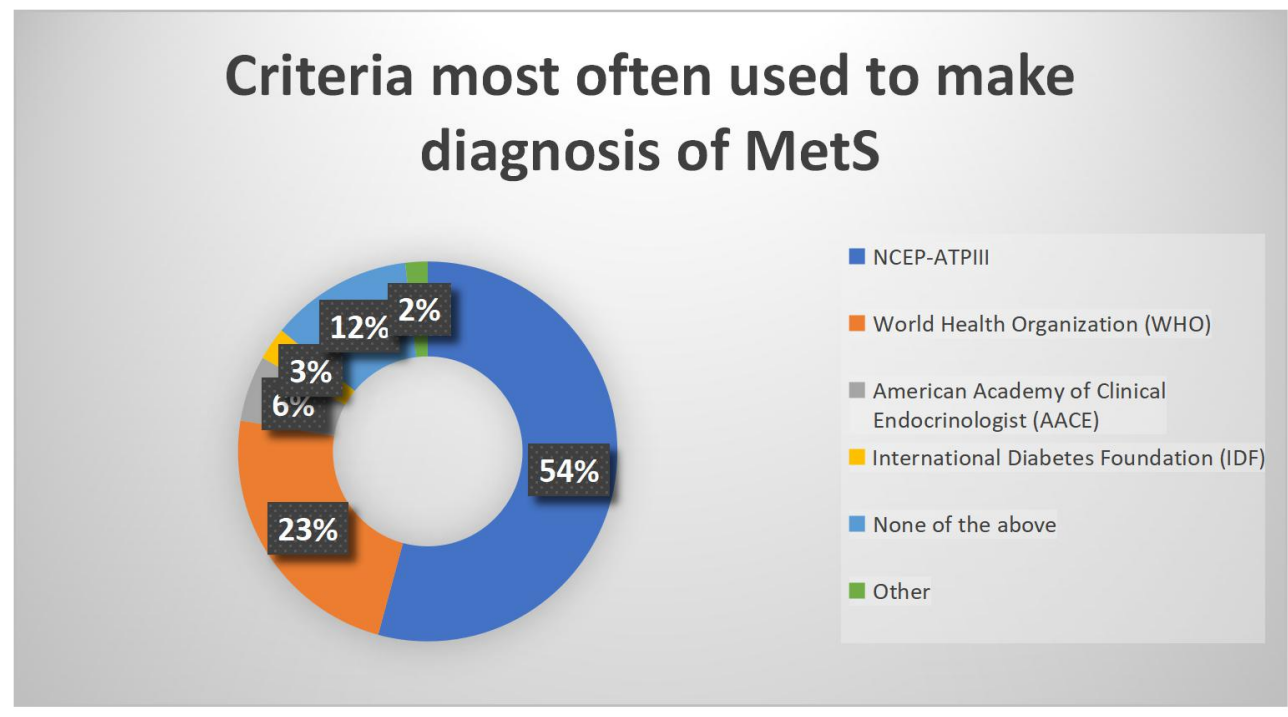

Figure 6.22: Figure showing Criteria most often used by participants to make diagnosis of MetS

There was statistically significant very strong relationship between physician participants' specialty grouping and which guideline criteria they used for diagnosing metabolic syndrome (Cramer's V $=0.364, \mathrm{p}=0.001$ ). Of the 10 participants in the General Practice/Public Health grouping, 6 (60.0\%) used NCEP-ATP III, none used WHO, 1 (10.0\%) used AACE, 1 (10.0\%) used IDF, and $2(20.0 \%)$ used none of the choices listed. Of the 52 participants in the Family Medicine grouping, 38 (73.1\%) used NCEP-ATP III, 4 (7.7\%) used WHO, 2 (3.8\%) used AACE, none used IDF, 8 (15.3\%) indicated using another criteria for diagnosing MetS rather than the choices listed. Of the 21 participants in the Internal Medicine grouping, $5(23.8 \%)$ used NCEP-ATP III, 11 (52.4\%) used WHO, 2 (9.5\%) used AACE, 1 (4.8\%) used IDF, and 2 $(9.5 \%)$ used none of the criteria choices listed. Of the 15 participants in the O\&G grouping, 5 
(33.3\%) used NCEP-ATP III, 8 (53.3\%) used WHO, none used AACE or IDF, and 2 (13.3\%) used none of the criteria choices listed (See Fig. 6.23 below).

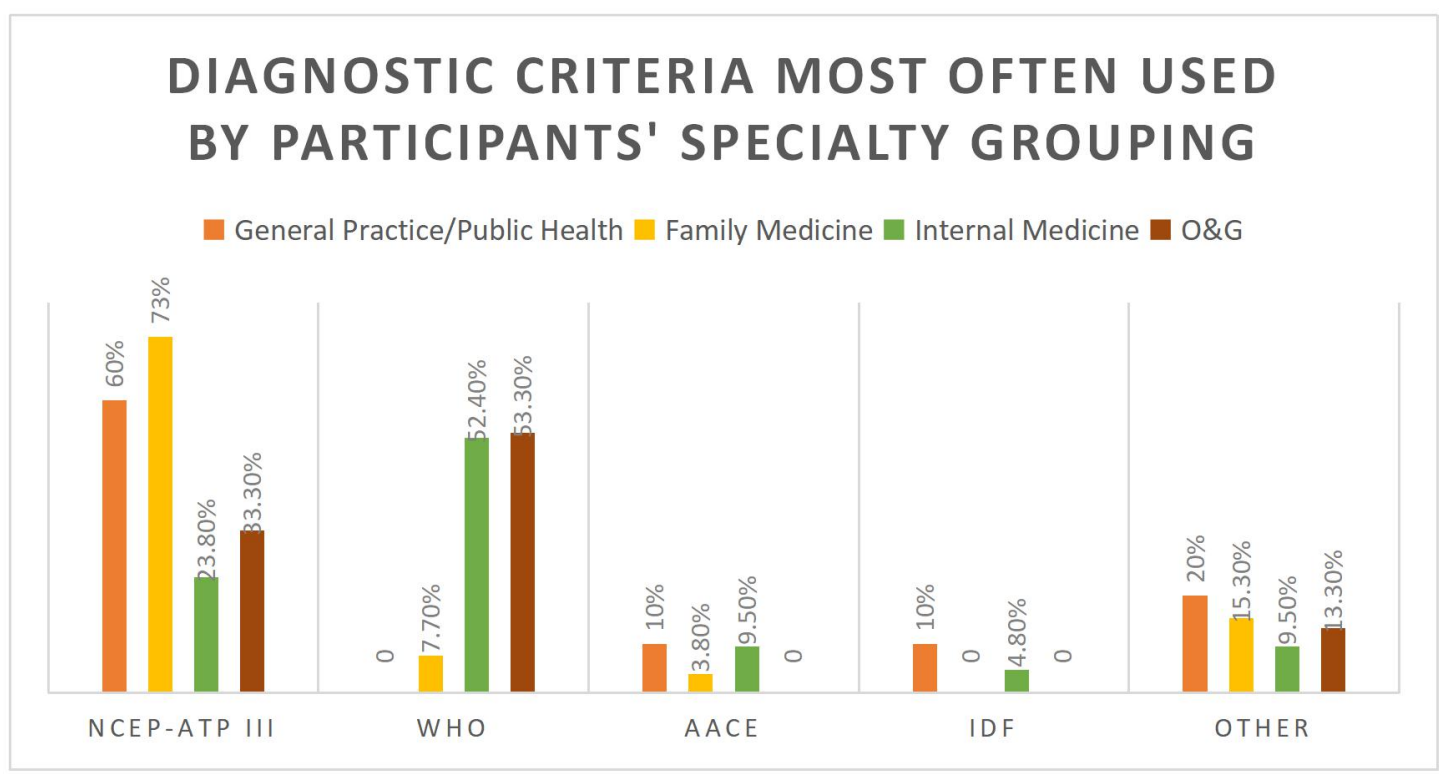

Figure 6.23: Bar graph showing diagnostic criteria most often used by participants' specialty grouping

\subsubsection{Knowledge of parameters consistent with NCEP-ATP III guidelines}

Regarding participants knowledge of parameters consistent with NCEP-ATPIII guidelines, 61 $(56.0 \%)$ of the participants correctly chose category " $\mathrm{C}$ " and of the $48(44.1 \%)$ who chose incorrectly (i.e., A or B), 26 (54.2\%) chose category A while the other 22 (45.8\%) chose category B (See Table 6.10/Fig. 6.24 below). 
Table 6.9: Table showing parameters for differing clinical practice guidelines by category ${ }^{23-26}$

\begin{tabular}{|c|c|c|c|}
\hline & & Category & \\
\hline & $\mathbf{A}$ & $\mathbf{B}$ & $\mathbf{C}$ \\
\hline $\begin{array}{l}\text { Raised } \\
\quad \text { triglycerides }\end{array}$ & $\begin{array}{l}\geq 150 \mathrm{mg} / \mathrm{dL}(1.7 \mathrm{mmol} / \mathrm{L}) \text { or } \\
\text { specific treatment for this lipid } \\
\text { abnormality }\end{array}$ & $\begin{aligned} \geq & 150 \mathrm{mg} / \mathrm{dL} \\
& (1.7 \mathrm{mmol} / \mathrm{L})\end{aligned}$ & $\geq 150 \mathrm{mg} / \mathrm{dL}(1.7 \mathrm{mmol} / \mathrm{L})$ \\
\hline $\begin{array}{l}\text { Reduced HDL } \\
\text { cholesterol }\end{array}$ & $\begin{array}{l}\text { Men: }<40 \mathrm{mg} / \mathrm{dL}(1.03 \mathrm{mmol} / \mathrm{L}) \\
\text { Women: }<50 \mathrm{mg} / \mathrm{dL}(1.29 \mathrm{mmol} / \mathrm{L}) \\
\text { Or specific treatment for this lipid } \\
\text { abnormality }\end{array}$ & $\begin{array}{l}\text { Men: }<35 \mathrm{mg} / \mathrm{dL} \\
(0.9 \mathrm{mmol} / \mathrm{L}) \\
\text { Women: }<39 \mathrm{mg} / \mathrm{dL} \\
\quad(1.0 \mathrm{mmol} / \mathrm{L})\end{array}$ & $\begin{array}{l}\text { Men: }<40 \mathrm{mg} / \mathrm{dL} \\
(1.03 \mathrm{mmol} / \mathrm{L}) \\
\text { Women: }<50 \mathrm{mg} / \mathrm{dL} \\
(1.29 \mathrm{mmol} / \mathrm{L})\end{array}$ \\
\hline $\begin{array}{l}\text { Raised blood } \\
\text { pressure }^{\mathrm{d}}\end{array}$ & $\begin{array}{l}\geq 130 / \geq 85 \mathrm{~mm} \mathrm{Hg} \text { or treatment } \\
\text { of previously diagnosed } \\
\text { hypertension }\end{array}$ & $\geq 140 / 90 \mathrm{~mm} \mathrm{Hg}$ & $\geq 130 / \geq 85 \mathrm{~mm} \mathrm{Hg}$ \\
\hline $\begin{array}{l}\text { Raised fasting } \\
\text { plasma glucose }\end{array}$ & $\begin{array}{l}\geq 100 \mathrm{mg} / \mathrm{dL}(5.6 \mathrm{mmol} / \mathrm{L}) \text { or } \\
\text { previously diagnosed type } 2 \\
\text { diabetes }\end{array}$ & - & $\geq 110 \mathrm{mg} / \mathrm{dL}(6.1 \mathrm{mmol} / \mathrm{L})$ \\
\hline Central obesity & (Main component) & $\begin{array}{l}\text { Men: waist-to-hip } \\
\text { ratio }>0.90 \\
\text { Women: waist-to-hip } \\
\text { ratio }>0.85 \\
\text { Or BMI }>30 \mathrm{~kg} / \mathrm{m}^{2}\end{array}$ & $\begin{array}{l}\text { Men: waist circumference } \\
\quad>102 \mathrm{~cm}(>40 \text { inches) } \\
\text { Women: waist circumference } \\
>88 \mathrm{~cm} \text { ( }>35 \text { inches) }\end{array}$ \\
\hline Microalbuminuria & - & $\begin{array}{l}\text { Urinary albumin } \\
\text { excretion rate } \\
\geq 20 \mu \mathrm{g} / \mathrm{min} \text { or } \\
\text { albumin:creatinine } \\
\text { ratio } \geq 30 \mathrm{mg} / \mathrm{g}\end{array}$ & - \\
\hline
\end{tabular}

Table 6.10: Table showing participants' frequency choosing parameters consistent with NCEPATPIII guidelines

\begin{tabular}{|c|c|}
\hline $\begin{array}{c}\text { Category: Parameters consistent with NCEP- } \\
\text { ATP III guidelines }\end{array}$ & Frequency (\%) \\
\hline A & $26(23.9)$ \\
\hline B & $22(20.2)$ \\
\hline C & $61(56.0)$ \\
\hline
\end{tabular}

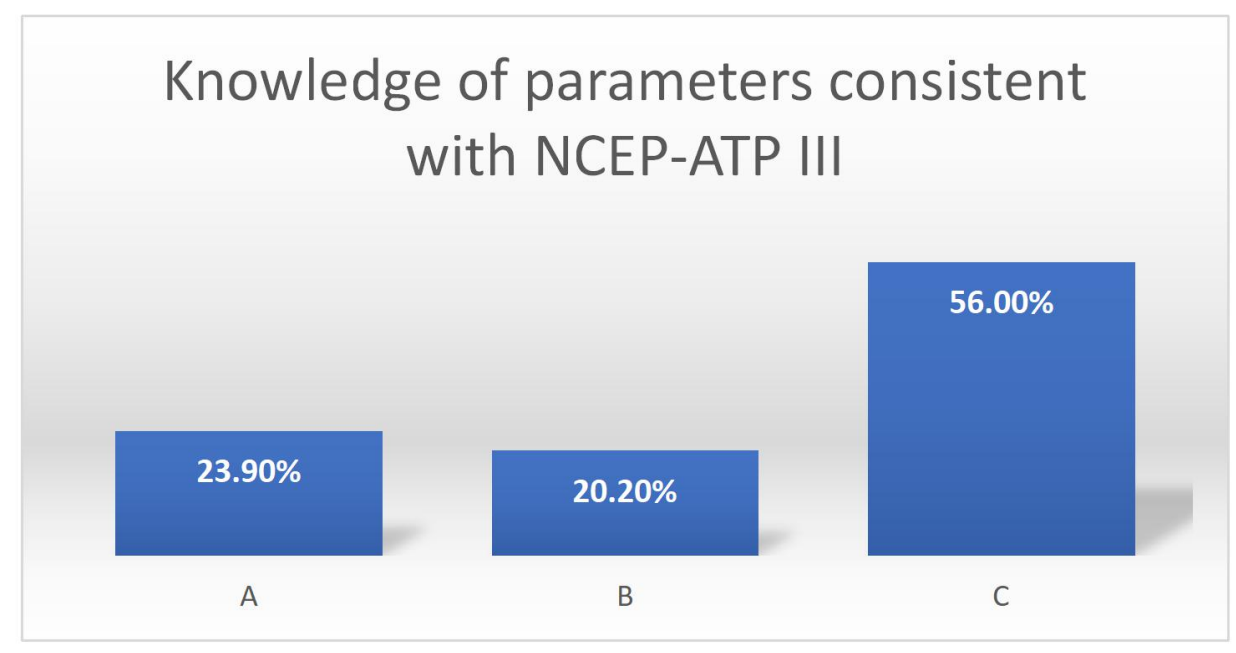

Figure 6.24: Bar Graph showing participants' frequency choosing parameters consistent with NCEPATPIII guidelines 
There was a statistically significant very strong relationship between physician participants' knowledge of parameters consistent with NCEP-ATP III guidelines and their specialty grouping (Cramer's V $=0.308, \mathrm{p}=0.004)$. Of 10 participants in the General Practice/Public Health grouping, 5 (50.0\%) correctly identified category "C" as being specific to NCEP-ATP III guidelines. Of 53 participants in the Family Medicine grouping, 35 (66.0\%) correctly identified category "C" as being specific to NCEP-ATP III guidelines. Of 22 participants in the Internal Medicine grouping, 14 (63.6\%) correctly identified category " $\mathrm{C}$ " as being specific to NCEP-ATP III guidelines. Of 15 participants in the O\&G grouping, only 4 (26.7\%) correctly identified category "C" as being specific to NCEP-ATP III guidelines (See Fig. 6.25 below).

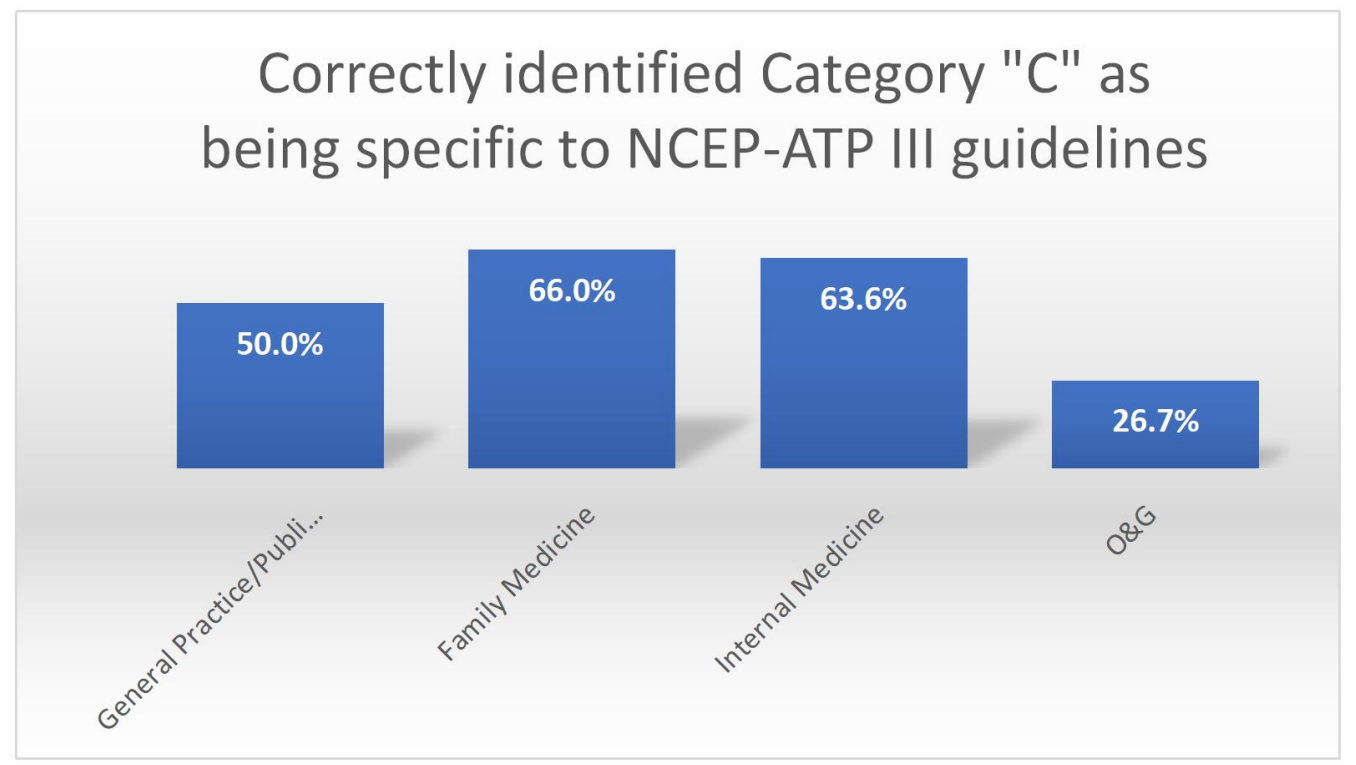

Figure 6.25: Bar graph showing participants' frequency of correctly identifying category " $C$ " as being specific to NCEP-ATP III guidelines according to specialty grouping

\subsubsection{Screening patients adhering to NCEP-ATP III guideline criteria}

Participants answered how often they screen patients adhering to guideline criteria for metabolic syndrome. The median frequency with which participants reported actually screening patients adhering to guideline criteria for metabolic syndrome was Sometimes (IQR: occasionally, often). Here, 38 (34.5\%) "often" screened, 30 (27.3\%) "sometimes" screened, 27 (24.5\%) "occasionally" screened, and 15 (13.6\%) "never" screened.

There was a statistically significant moderate positive relationship between participants level of training and how often they actually screen patients adhering to guideline criteria for MetS $(\mathrm{rSp}=0.362, \mathrm{p}<0.001)$. The median frequency with which Senior House Officers screen for MetS was Occasionally (IQR: never, sometimes). The median frequency with which 
Residents screen for MetS was Sometimes (IQR: occasionally, often). The median frequency with which Registrars screen for MetS was Sometimes (IQR: occasionally, often). The median frequency with which Senior Registrars screen for MetS was Sometimes (IQR: occasionally, often). The median frequency with which Consultants screen for MetS was Often (IQR: sometimes, often).

Physician participants' median frequency with which they screen patients adhering to guideline criteria for MetS was statistically significantly different by their specialty grouping $(\mathrm{p}<0.001)$. The median frequency with which the General Practice/Public Health grouping screen their patients for MetS was Occasionally (IQR: never, sometimes). The median frequency with which the Family Medicine grouping screen their patients for MetS was Sometimes (IQR: occasionally, often). The median frequency with which the Internal Medicine grouping screen their patients for MetS was Sometimes (IQR: sometimes, often). The median frequency with which the O\&G grouping screen their patients for MetS was Occasionally (IQR: never, occasionally).

\subsubsection{Screening for comorbidities in isolation}

Participants answered how often they screen for comorbidities in isolation. The median frequency with which participants reported screening for comorbidities in isolation was Often (IQR: sometimes, often). Here, 21 (19.3\%) screen in isolation "everytime", 48 (44.0\%) screen in isolation "often", $14(12.8 \%)$ screen in isolation "sometimes", 14 (12.8\%) screen in isolation "occasionally", and 12 (11.0\%) "never" screen.

There was a statistically significant weak positive relationship between participants level of training and how often they screen for comorbidities in isolation $(\mathrm{rSp}=0.240, \mathrm{p}=0.012)$.

The median frequency with which Senior House Officers screen for comorbidities in isolation was Sometimes (IQR: occasionally, often). The median frequency with which Residents screen in isolation was Often (IQR: often, everytime). The median frequency with which Registrars screen in isolation was Often (IQR: often, everytime). The median frequency with which Senior Registrars screen in isolation was Often (IQR: often, everytime). The median frequency with which Consultants screen in isolation was Often (IQR: occasionally, everytime). 


\section{CHAPTER 7}

\section{DISCUSSION}

This study provided insight into knowledge regarding Metabolic Syndrome (MetS), and adherence to the NCEP-ATP III clinical practice guidelines among physicians in New Providence, Bahamas. Contrary to a priori, expectations that $<40 \%$ of physicians would have low level of health literacy regarding knowledge of MetS, study findings consisted of several avenues to examine the depth of knowledge and awareness of MetS amongst physicians and showed that 99.1\% (109) participants were familiar with the term Metabolic Syndrome, $88.1 \%$ (96) treat patients with MetS, 67.9\% (74) of physicians identified the correct number of criteria comprising the NCEP-ATP III definition of metabolic syndrome, and $67 \%$ (71) of physicians correctly identified the number of criteria needed to make the diagnosis of metabolic syndrome. Most importantly, 81.8\% (90) of physician participants were found to obtain a score of $75.0 \%$ (19/25) or higher on the Metabolic Syndrome Knowledge Level scale $\left(\right.$ MetS-KS) ${ }^{56}$ and collectively, all participants surveyed averaged a score of $84.0 \%(21 / 25)$.

There was initial posit that there will be low intentionality regarding screening for the complex that makes up the syndrome, instead it was expected that $85 \%$ of physicians targeted would be found to do fragmented screening for the separate components in isolation, study findings revealed in a ranked scale that the median frequency with which participants reported evaluating for metabolic syndrome in their patients was "Sometimes" (IQR: occasionally, often), with only $16.5 \%$ (18) "often" evaluating, and 41.3\% (45) "sometimes" evaluating; and the median frequency with which participants reported screening for comorbidities in isolation was "Often" (IQR: sometimes, often), with only 19.3\% (20) screening in isolation "everytime", and 44.0\% (48) screening in isolation "often".

$50 \%$ of physician participants were expected to perceive that they engage in health education, this study favorably indicated that the median frequency with which participants engage in health education regarding cardiovascular risk was "Everytime" (IQR: often, everytime), with just above margin of $52.7 \%$ (58) engaging in health education "everytime" and $40.0 \%$ (44) engaging "often". Concerning adherence to the NCEP-ATP III guidelines, it was anticipated that at least $65 \%$ of participants would be found to adhere to those specific guidelines. This study confirmed that only 53.3\% (57) used the NCEP-ATP III diagnostic criteria and further to that, $56 \%$ (61) of participants were able to successfully identify the parameters consistent 
with NCEP-ATP III criteria (Category "C"), and only 35\% (38) participants actually screen patients adhering to the NCEP-ATP III guidelines "often" .

This study also confirmed that physicians' profile (demographics including gender, age, ethnicity, nationality, level of training, number of years since graduating medical school, sector of practice and practice specialty) was related to the level of knowledge regarding metabolic syndrome and educating patients about their subsequent cardiovascular risk.

\subsection{Physicians' Profile}

Similar to a study performed in Tel Aviv, Israel on metabolic syndrome awareness in hospital health providers ${ }^{53}$ that had a mean age of $37( \pm 6)$ years for physicians, the mean age $( \pm 1 \mathrm{SD})$ in this study was $38.6( \pm 7.6)$ years. Female participants comprised $72.5 \%(79)$ while the remaining 27.5\% (30) were male. The most common specialty was Family Medicine occupying 53.5\% (54) participants, followed closely by the Internal Medicine specialty with $21.8 \%$ (22) participants, the subspecialties made up the least representation, with each only contributing 1\% participants. Most participants' level of training were that of Senior House Officers (SHO's) with 35.8\% (39). The highest level of training, Consultants, represented $26.6 \%$ (29). This was an important aspect of this study as it was found to be statistically relevant and related to level of MetS knowledge. This was in contrast to the model study used to assess metabolic syndrome clinical knowledge where both nurses and physicians comprised the participant body, and among physicians, the most prevalent level of experience was Resident (68.5\%), and the most prevalent field of practice was Internal Medicine $(45.5 \%)^{53}$; their study revealed that field of practice did not have a significant influence on the results. Participants' median number of years since graduating medical school/practicing was 5-10yrs (33\%) at the Senior House Officer, Resident, Registrar levels, however, the majority of physician participants, that consisted of the senior levels of training, both Senior Registrar and Consultant, had a median number of years since graduating medical school/practicing of 11$20 y r s$ (35\%); this was vaguely similar to the Heart Study 2005 in Finland assessing general practitioners knowledge and level of detection of MetS, those GPs collecting the patient data were mainly senior doctors, and $67.5 \%$ of them had over 10 years of work experience ${ }^{50}$.

There was relevance in terms of participants' place of practice and their level of training. 86.5\% (32) Senior House Officers, 90.9\% (20) Residents, 83.3\% (10) Registrars, 42.9\% (3) Senior Registrars worked in the Public sector only, while 44.8\% (13) Consultants worked in the Private sector only, and 10.8\% (4) SHOs, 9.1\% (2) Residents, 16.7\% (2) Registrars, $57.1 \%$ (4) Senior Registrars, and 51.7\% (15) Consultants worked in both the Public and 
Private sector. The public sector being both outpatient/clinic and hospital/tertiary care and private sector being only outpatient private office setting. This showed the higher the level of training, the more access to both sectors, therefore more ability to capture and assess patients with MetS once sensitive to its knowledge. Surveys done in the Finnish public primary care system ${ }^{41}$, the Shapes of the Nation survey in the $\mathrm{UK}^{52}$ and in hospital health care providers in Israel ${ }^{44}$ collectively parallel the balance of participants' place of practice composition of this study.

\subsection{Physician's Health Literacy in regards to Metabolic Syndrome}

According to Joshi et al, health literacy is broadly defined as the "degree to which individuals have the capacity to understand basic health information and services needed to make appropriate health decisions" ${ }^{23-26}$. In this study, 99.1\% (109) participants were familiar with the term Metabolic Syndrome, this finding was in keeping with the Israel study on hospital health providers where $98 \%$ of participants stated that they were familiar with the term MetS $^{53} .88 .1 \%$ (96) of participants admit to treating patients with MetS.

Physician participants were asked to identify the total number of criteria comprising the Metabolic Syndrome (as according to NCEP-ATP III), 67.9\% correctly chose five (5) as the total number of criteria comprising the MetS. As physicians became more experienced, the knowledge level improved, $96 \%$ of Consultants correctly identified the total number of criteria included in the MetS. Same applied for identifying the correct number of criteria needed for the diagnosis of MetS, $67 \%$ of participants correctly identified three (3) as the number of criteria needed in order to diagnose MetS. Again, the higher levels of training performed best with this question, however, in this category, 100\% of Senior Registrars answered this question correctly. Globally, there was a favorable response rate among levels of training $(>50 \%)$, but it is evident that as level of training increased, correct knowledge of criteria improved, although still indicating there is room for knowledge improvement on criteria and diagnosis among lower levels of training. The findings from this study were parallel to the model study where most of the participants knew the correct number of criteria included in MetS definition and the number of criteria needed for MetS diagnosis $(84 \%$ and $90 \%$, respectively) ${ }^{53}$.

When participants were asked who, in their opinion, should treat MetS, the cumulative response $(60.9 \%)$ was "Any Physician". In theory, this holds true, as any physician involved in first contact, continual primary care should be able to manage patients fitting the criteria that meets the diagnosis of MetS. The Bahamas is an archipelago of islands that spreads 
across hundreds of miles in the Atlantic ocean and therefore some islands only have one physician responsible for seeing any and everything, and all patients, therefore, culturally this has been accepted as sufficient for all medical modalities regardless of specialty, to be able to see, treat and manage most diagnoses within their competency scope. This is more than likely why there was a large portion of this surveyed population that chose "Any Physician".

As mentioned previously, several parameters were surveyed to assess physician participants' knowledge in regards to MetS. Questionnaire adapted from Havakuk et al ${ }^{53}$ outlined five clinical cases to identify MetS cases from non-MetS cases; $52.7 \%$ (58) of participants correctly agreed that the first case should be classified as MetS, 35.5\% (39) of participants correctly agreed that the second case should be classified as MetS, 44.0\% (48) of participants correctly disagreed that the third case did not meet MetS criteria, 80.0\% (88) of participants correctly agreed that the fourth case should be classified as MetS, and 66.4\% (73) of participants correctly agreed that the fifth case should be classified as MetS. These results exhibited that this physician population is more knowledgeable as compared to the model study that showed "participants performed poorly with identifying MetS cases; only 12\% were able to discriminate correctly all MetS cases from non-MetS ones" ${ }^{\text {53 }}$. It is evident that there seems to be a good foundation of knowledge base about the clinical syndrome MetS, in that all levels of training are able to identify the syndrome and therefore leaves room for subsequent management and patient education. Almost $50 \%$ of physician participants correctly discerned the only non-MetS $\left(3^{\text {rd }}\right)$ case, this was considerably higher than those participants in the Israel model case. This may imply that physicians in this region are more sensitized to the syndrome because of its prevalence. This can be seen in our Bahamian population as according to the preliminary results of the Bahamas STEPS Survey 2019, $36.7 \%$ of respondents have an elevated blood pressure, 4 of 10 (38\%) have elevated blood pressures and do not know, there was a $11.6 \%$ diabetes prevalence, the average BMI was found to be 29.8 with $27.9 \%$ of Bahamians BMI falling between 25-29 and average waist-tohip ratio of 0.9 in both sexes, and lastly there was found to be a $25.3 \%$ prevalence of raised cholesterol or on medication for such, with an average blood cholesterol of $153.1 \mathrm{mg} / \mathrm{dL}^{57}$. Regional statistics also to serve in support, Ferguson et al found MetS prevalence to be $21.1 \%$ in Jamaican adults using the IDF criteria ${ }^{44}$. In Trinidad, C.E. Ezenwaka et al had prevalence rate of approximately $22.3 \%$ (using IDF-based metabolic syndrome definition, inclusive of abdominal obesity +2 or more components $)^{45}$; and in St. Lucia, study conducted to assess prevalence of MetS risk factors found thirty-six percent (36.4\%) of females and thirty-three 
percent (33.0\%) of males lead sedentary lifestyles and 31\% had BMI of 25 or over indicating overweight or obese ${ }^{46}$.

The second clinical case for MetS identification, seemed to have posed the most difficulty for participants, as only $35.5 \%$ (39) of physician participants correctly agreed that this case was consistent with the definition of MetS, this could be in part because although all other parameters were in keeping with MetS, the normal BP measurement of 120/70 most likely obscured participants judgement as to whether to classify case as MetS or not. "Since high BP is a key component of MetS, it is not surprising that in MetS patients' arterial hypertension is highly prevalent"; The Pressioni Arteriose Monitorate E Loro Associazioni (PAMELA) population study revealed that high normal BP values and hypertension were present in $80 \%$ of individuals with MetS 58,59. In the Progetto Ipertensione Umbria Monitoraggio Ambulatoriale (PIUMA) study, a prospective observational investigation of 1742 Italian adult subjects with essential hypertension, MetS, defined according to ATP III criteria, was diagnosed in $34 \%$ of the population ${ }^{58,60}$. Although, higher MetS prevalence is most times found in conjunction with higher BP levels, it remains imperative for physicians to keep at the forefront that any three of the five criteria, not specifically inclusive of blood pressure, for NCEP-ATP III can be used to diagnose a patient with MetS.

\subsection{MetS-KS}

The Metabolic Syndrome Knowledge Level scale (MetS-KS) was developed with its validity and reliability tested in a Turkish population ${ }^{56}$. Prior to its development, there was no formal measurement tool to assess level of metabolic syndrome knowledge. The minimally modified (with permission) 25-item questionnaire, was administered in the Bahamian physician population and garnered interesting results. Each correct question is worth one point, the more points achieved, the higher the score out of 25, subsequently detailing the higher the level of MetS knowledge. Ninety (81.8\%) physician participants scored $75.0 \%$ or higher on the MetSKS, quite similar to the median score $(19 / 25)$ achieved by those participants $<40$ years of age in Atalay et $\mathrm{al}^{56}$, and in turn represents the large majority of the physician population surveyed. It also gives insight into the high level of health literacy among participants concerning MetS contrary to the percentage initially hypothesized $(<40 \%)$. It can be postulated that this population of Bahamian physicians, although surveyed from both the public and private sectors, because majority of physicians work within and around the teaching hospital setting this may have had influence on the high scores obtained in this study. 
As expected, MetS knowledge level increased as level of training increased. Senior House Officers had a median score of $80.0 \%$, Residents median score was $82.0 \%$, Registrars median score was $80.0 \%$, Senior Registrars median score was $84.0 \%$, and Consultants demonstrating the highest median score with $88.0 \%$. Comparatively, Atalay et al, whose scale was not tested in physicians, measured educational level in three categories, middle-school, college and university, and of course median scores trended favorably as education level increased indicating that median score for participants at university level was 20/25 $5^{56}$. Again demonstrating, the higher the level of training, the higher the level of MetS knowledge. In terms of physician participants' performance by specialty grouping, Internal Medicine specialty grouping scored highest with a median score of $88.0 \%$, followed closely by Family Medicine specialty grouping with a median score of $84.0 \%$. Although all specialties identified in this survey are at some level involved in first contact primary care, historically, both Internal medicine and Family medicine more frequently encounter these patients and therefore have the ability to identify and risk stratify them appropriately and this is reflected in their MetS-KS scores. Notably, some other studies have reported dissimilar results. Havakuk et al found that field of practice did not have a significant influence on the results in their study testing health provider MetS knowledge; staff from internal medicine wards performed similarly as staff from surgical departments ${ }^{53}$. In the Mexican study on the development and validation of an instrument to measure family physicians' clinical aptitude in MetS, global aptitude results were very low for family physicians $(45.6 \%)^{61}$. Internal Medicine and Family Medicine departments here in our healthcare system are almost overwhelmed with the amount of chronic non-communicable diseases we manage and treat every-day, mostly due in part to our high Afro-Caribbean ethnic population, and therefore this is more than likely the reason why our physicians performed so much better compared to the model studies referenced.

There were several questions in the MetS-KS that demonstrated statistical clinical significance and warrant further mention. In relation to participants' response to whether or not they thought MetS was less common in individuals who partake in a balanced diet, there was a statistically significant very strong relationship with participants' level of training. All $29(100 \%)$ of Consultants, over $70 \%$ of Senior House Officers, Residents and Senior Registrars, and over $50 \%$ of Registrars all correctly agreed that MetS is indeed less common in individuals who partake in a balanced diet. Diet is primarily one of the main risk factors for developing MetS, as diets rich in polyunsaturated fats and refined sugars ultimately lead to insulin resistance which is the mainstay to the pathophysiology of MetS. Low glycemic-index 
diets are recommended for patients with $\mathrm{MetS}^{62-64}$, contributing to decreased CVD risk, and reduced levels of glycosylated hemoglobin in type I and II DM patients ${ }^{62,65,66}$. The overwhelming correct response among all levels of training signifies that physician participants recognize the importance of dietary habits in the prevention and treatment of MetS. When Hoyas et al explored Nutritional challenges in Metabolic Syndrome, it was noted that the most effective intervention for metabolic intervention is caloric restriction; the quality and quantity of individual macronutrients have an influence on the development and resolution of this syndrome ${ }^{62}$. It goes on further to denote, that nutrition change to support a $7-10 \%$ weight loss is an appropriate goal for people with pre-diabetes. The contributions of different nutrient to success in the reduction have to be seen in the context of the general eating plan of the patient. There is no perfect combination of macronutrients useful for all individuals. Compliance with a healthier lifestyle and dietary intake are more important than a particular dietary pattern. This represents an advantage for patients confronting MetS. Irrespective of the macronutrient balance in the diet, total energy intake should be appropriate to accomplish the weight management goals ${ }^{62}$.

In relation to participants' response to whether or not they thought MetS is less common in overweight individuals, there was a statistically significant very strong relationship with their specialty grouping. The Family Medicine specialty grouping had the highest frequency of participants $(83 \%)$ correctly disagreeing that MetS is less common in overweight persons. Most specialty groupings correctly answered this question $(>70 \%)$ and this further reflects on Bahamian physician knowledge about the linear relationship between BMI and MetS, particularly for those practicing in Family Medicine. As previously mentioned, the average BMI in the Bahamas is 29.8 according to the 2019 STEP SURVEY ${ }^{57}$, all levels of healthcare are exposed to our overweight culture, Family Medicine in particular, whose practice mainly consists of managing patients with CNCDs, is sensitive to the potential of those patients who are overweight and present with comorbidities to likely fit the MetS profile.

\subsection{Physician's experiences with screening for Metabolic Syndrome}

Over $40 \%$ of participants report evaluating for the presence of MetS in their patients "sometimes". All levels of training, except the level of Consultant, had a statistically significant median frequency of evaluating "sometimes". Consultant level's median frequency was a category higher at "often". Screening for comorbidities in isolation was "often" done by $44 \%$ of participants, so this gives an inclination as to why our physicians felt they only "sometimes" evaluated for the syndrome in its entirety. Anecdotally, in practice, it can 
become easy to see a patient and compartmentalize every separate component of their visit i.e. an elevated blood pressure, elevated glucose reading and complaint history of nocturia, and leave the patient's assessment with multiple diagnoses as supposed to linking all pieces of the clinical puzzle; because of this, it was hypothesized that $\sim 85 \%$ of physicians would do fragmented screening, but from the high level of MetS Knowledge demonstrated in Bahamian physicians in this study, this reflects positively on the lower percentage of fragmented screening. However, the discrepancy between the lower levels of training and Consultants speaks to the notion previously mentioned, therefore it would be beneficial to encourage those lower levels to amalgamate the entire clinical picture so there is sufficient patient counselling about respective CV risk.

According to the NCEP-ATP III guidelines, waist circumference measurement differs in males ( $>40 \mathrm{in})$ and females ( $>35 \mathrm{in})$, and there was a very strong statistical significance between participants' level of training and whether they thought this was actually true. On an average, over $90 \%$ of participants reported that they did indeed think that waist circumference differed in males and females, the highest percentage from the SHO level with $97.4 \%$, followed closely by the Consultant level with $96.6 \%$. This aspect varied in clinical practice, the median frequency with which participants measured waist circumference was only "occasionally", with an outstanding figure of $47.3 \%$ (52) participants "never" measuring waist circumference, $54.9 \%$ (28) being SHOs, during routine patient encounters. The median frequency for all specialty groupings was "never" except for the Family Medicine specialty. Similarly, Smith et al, in the Shape of the Nations Survey, found that almost half $(45 \%)$ of PCPs reported never measuring waist circumference, and primary care physicians (PCPs) measured $\mathrm{WC}$ in only $17 \%$ of patients ${ }^{52}$. Theoretically, this study shows that physicians are aware that waist circumference measurement is not only a vital component of the syndrome, but also recognizes that there is a gender disparity that contributes to cardiovascular risk, however, it is evident that this simple anthropometric measurement is not being practiced in all primary care outlets and more so amongst the lower levels of training. This might be in part due to the fact that, in both the private and public sector, the Senior House Officer's primary responsibility is placed on ensuring patient quantity is seen and accounted for. So with this, it is apparent that although the knowledge is there, there needs to be continual reinforcement, amongst house staff in particular, to use all the anthropometric sources available to them, in order to foster quality patient care. Ultimately, Smith et al demonstrated similar findings in that PCPs' awareness of waist circumference as a measure of abdominal 
obesity and cardio-metabolic risk was poor ${ }^{52}$. Worldwide, only a minority of PCPs knew the threshold WC that is considered to confer significantly increased risk in men or women, and $52 \%$ overestimated this threshold; this is consistent with the observation that only $13 \%$ of atrisk patients reported having had their waist circumference measured by a doctor or a nurse ${ }^{52}$.

Two other important screening factors surveyed in this study was calculating BMI and ASCVD risk score. Grundy et al highlighted, that to reduce lifetime risk for ASCVD, all individuals found to have the metabolic syndrome deserve long-term management and followup in the clinical setting ${ }^{11}$ and the primary aim is to reduce the underlying risk factors ${ }^{11}$. $33.6 \%$ of participants calculate BMI "often" and 17.3\% calculate BMI "every-time". When analyzed against level of training, the median frequency range of which all lower levels of training calculate BMI ranged from "sometimes" to "often" however, the Consultant level calculate BMI "every-time". This shows that as compiled experience increased with level of training so did the action of calculating and documenting BMI. This is also seen for calculating ASCVD risk score, over $45 \%$ of participants report calculating ASCVD risk score "sometimes" to "often", with only $10 \%$ calculating "everytime". This screening tool statistically significantly differed by specialty grouping, revealing that the median frequency with which Internal Medicine calculate ASCVD risk score was "often", the highest frequency response of all the specialty groupings. The physician participants from Internal Medicine were mostly from the public sector, meaning that most of them practice in hospital, therefore it has become almost mandatory in practice to calculate this score on patient admission, especially with diagnoses of AMI and CVA, so this is more than likely the reason why this specialty grouping does it more so than the other specialties surveyed.

\subsection{Physician's perception to which they engage in health education about} Cardiovascular risk

The median frequency with which participants perceived they engage their patients in health education about cardiovascular risk was "every-time". NHANES III survey confirmed MetS was significantly associated with $\mathrm{MI} /$ stroke in both women and men $^{70}$. Over $52 \%$ of physician participants reported to do so "every-time", of that 52\%, Family Medicine and Internal Medicine were the two specialty groupings that reported engaging in health education "everytime". Another interesting observation was that $0 \%$ "never" engaged in health education with their patients. This is quite significant and encouraging. A large population of the physicians surveyed always engage their patients in health education about CV risk and even for those that don't do so every-time, $40 \%$ do so "often". This speaks well to the Bahamian physician 
population, as it relays they are following through with their duty to ensure patients are educated, empowered and held accountable about their own health. It would be interesting to see, in another arm of this study from the patient's perspective, if they actually felt educated upon leaving their doctor's visit as well as remain compliant with recommended management. In tandem with this study, participants were asked if they think their patients feel well informed about $\mathrm{CV}$ risk post visit, $52 \%$ of participants' median frequency response was "often". This response was seen across the board for all levels of training however, it is evident that as level of training increases, participants are more confident in their thinking that patients feel more informed about their CV risk upon leaving a visit.

When participants were asked to list which risk factors they most commonly recommend to adjust in their patients with MetS, weight loss was the most frequently listed risk factor with $56.4 \%$ (62) of participants stating so. Although there were no statistically significant relationships with this risk factor, the participants' frequency "weight loss" response eludes to the fact that this physician population is aware that weight loss is imperative in order to decrease morbidity associated with the syndrome. Weight reduction was the main goal of most intervention studies; it is associated with significant improvements in all parameters of $\mathrm{MetS}^{62}$. Even moderate weight loss (around 7\%) resulted in substantial reductions in blood pressure, blood glucose, triglyceride and total cholesterol concentrations ${ }^{62,67,68}$. Obesity in Bahamian culture has been normalized to a degree, and culturally accepted as "sexy" and even "healthy" to some. Bahamian physicians recognize that the majority of the population is overweight to obese. This realization is a hurdle that must be overcome in everyday clinical practice. In an effort to re-teach what a "healthy" weight actually is, this gives insight into the overwhelming response to adjust weight when combating MetS. It has been shown, that a reasonable first goal for obese patients is to aim for weight loss of approximately $10 \%$ of baseline weight in six months; if they achieve this objective, insulin resistance will improve along with risk reduction of MetS and $\mathrm{CVD}^{62,69}$. Even a lower weight loss, between $5-10 \%$, improves the sensitivity to insulin between 30 and $60 \%$, an effect greater than that seen with insulin-sensitizing drugs ${ }^{62,70}$.

Two other important risk factors participants listed to be adjusted were blood glucose and lifestyle change. When asked whether or not participants counsel their patients on lifestyle modification, $73.4 \%$ admit to counselling their patients "every-time". Only 1 (0.9\%) participant reported "never" counselling their patients on lifestyle modification. This large result reflects that most Bahamian physicians recognize the importance of lifestyle 
modification in reducing comorbidities and cardiovascular risk, it closely coincides with their overwhelming response of recommending weight loss as an adjusted risk factor, but of course taking into account exercise, diet, and healthy lifestyle habits that exclude alcohol consumption and smoking. The Family Practitioner needs to regularly counsel and motivate their patients about diet, exercise, stress management and other lifestyle measures just like they would about medicines ${ }^{71}$. The social fabric of Bahamian society, especially here in the capital of Nassau, entails working hard and playing harder, leaving little room for healthy lifestyle, so it is safe to project that because our physician population is aware that most of their patients probably do not exercise regularly, primarily eat fast food, and partake in libations more frequent than not, they take lifestyle modification seriously and ensure to counsel patients on it with every visit. The combination of diet, exercise and behavioral modification is the most effective approach to weight control; behavioral approaches that teach patients to rearrange their daily schedules and thus support healthy eating habits and exercise routines are important for long-term maintenance of behavioral changes ${ }^{71}$.

\subsection{Adherence to NCEP-ATP III Clinical Practice Guidelines}

NCEP-ATP III originally introduced a simple system of risk assessment that employed counting of categorical risk factors; this system represented a blending of the concepts of relative and absolute risk in an effort to effectively institute both long-term and short-term prevention $^{25}$. Physicians were assessed on recognition, frequency of use and whether or not they adhere to these specific clinical practice guidelines.

A large percentage of the physician participants (54.2\%) report using NCEP-ATP III clinical practice guidelines as their choice of criteria to diagnose and manage metabolic syndrome. Of that $54 \%$, when grouped by specialty, Family Medicine had a frequency of $73 \%$ most commonly using NCEP-ATP III guidelines, followed closely by the General Practice/Public Health grouping with $60 \%$. A section of the questionnaire, extracted from Joshi et $\mathrm{al}^{23-26}$, depicts a table with the specific parameters for three different organizations, IDF (depicted as Category A), WHO (depicted as Category B) and NCEP-ATP III (depicted as Category C). Participants were asked to identify which category was consistent with the parameters for NCEP-ATP III to assess their knowledge of said clinical practice guideline, $56 \%$ correctly chose Category "C". There was a statistical significant relationship between participants' knowledge of parameters and their specialty grouping. Family Medicine and Internal Medicine specialty groupings both had frequencies of over $60 \%$ of those physicians correctly identifying the NCEP-ATP III parameters, demonstrating distinctly for the Family Medicine 
grouping their knowledge of the NCEP-ATP III guidelines was consistent with their use of the criteria in the diagnosis of MetS. Although most participants from the Internal Medicine grouping knew the parameters, this specialty was found to use the WHO criteria more frequently when diagnosing patients with MetS. Both these specialties, as previously stated, most likely see and treat MetS more-so than the other specialty groupings, therefore having more knowledge of the parameters. Comparatively, the O\&G specialty grouping was found to have only $26.7 \%$ participants that had knowledge of the NCEP-ATP III, however over $50 \%$ of them reported using WHO guidelines to diagnose MetS. The affinity for using the WHO guidelines for O\&G participants might likely be due to the fact that only two or more parameters are needed to diagnose MetS, making it easier for them to recall in practice. Some of the barriers postulated, for the Internal Medicine grouping in particular as this group demonstrated adequate knowledge of the NCEP parameters but did not use, would most likely be time constraints in hospital setting with inability to perform anthroprometrics i.e. waist circumference due to patient load, time constraints also cuts down the time one is able to counsel patient on proper lifestyle modification, and also lack of quick recall of all parameters because treating patients with tunnel vision or individual components, i.e. the patient with elevated blood pressure who presents with CVA.

Even though a sizeable portion of the participants report using the NCEP-ATP III guidelines, when asked about screening patients adhering to the NCEP-ATP III guidelines, physician participants' median frequency response was "sometimes" (IQR: occasional, often), with only $35 \%$ screening adhering to guideline criteria "often", $27.3 \%$ screening adhering to criteria "sometimes" and $25 \%$ screening adhering to criteria "occasionally". This would suggest only adequate, not satisfactory adherence to NCEP-ATP III guidelines. Comparatively, Bain et al performed a clinical audit of pharmacological adherence to the JNC VII amongst Bahamian Family physicians at the public Family Medicine clinic in New Providence and demonstrated that physicians generally adhered to pharmacological recommendations for patients with comorbidities and had an adequate level of adherence to the JNC $7^{72}$. Levels of training differed in their median responses. Residents, Registrars, and Senior Registrars all had a median frequency of "sometimes", SHO's median response was "occasional” (IQR: never, sometimes) and Consultants median response was "often" (IQR: sometimes, often). It is important to pay close attention to the inter-quartile ranges given. The lowest level of training, SHO's, range begins at "never" and only ascends to "sometimes" adhering while screening, whereas the highest level of training, Consultants, range is in closer proximity to its median 
frequency response. This indicates that there is evident room for education at the lowest level of training for adherence to clinical practice guidelines. Senior house officers are the workforce of the healthcare system, working long hours with high volumes of patients, and although that is not an excuse for their lack of guideline adherence, it does give insight into why they may not be accessing the knowledge available to them to ensure they keep current with guidelines and practice evidence based medicine. From Residents to Consultants, all these levels of training are representative of either active training, recently acquired DM, or practicing trained specialist physicians all associated with the teaching facility, $\mathrm{PMH}$, so therefore are seemingly more compelled to adhere to clinical practice guidelines as often as possible when managing patients.

\subsection{Limitations}

There were a few limitations to this study. Firstly, the study sample is mainly physicians located in New Providence, the capital of The Bahamas and due to time and financial constraints there was inability to sample physicians from other outlying family islands, however due to the fact that the vast majority of primary care is situated here in the capital, the study still provides a reasonable representation of the physician body.

Of note, secondly, another limitation is that most of physician participants surveyed mainly from the Public Hospitals Authority teaching institution of Princess Margaret Hospital and therefore this may have impacted the high level of scoring in terms of knowledge level. Other physicians outside of PHA were invited to participate, but it was found that this group comprised the majority of the non-responders. Those physicians either lost the questionnaires or refused to do it due to their busy schedules. These non-responders tended to be about ten years older than the responders and more-so males than females, and more than $60 \%$ were from the General Practice/Public Health practice grouping.

Thirdly, some participants did not answer every question in questionnaire, as well as there may have been the possibility of response bias. The aim is to ideally obtain answers to all questions even if the answer is "unsure/not likely" but there were instances where some questions were left blank. When select demographics were compared between the nonresponders and responders it was found that responses came from participants ten years younger and predominantly female. This in part did not have a negative effect on the data analysis, however it may have affected results by not being entirely representative of what may actually be happening in practice. This response bias also may have impacted overall median knowledge level assessed as those non-responders' ten year age difference may have 
also reflected knowledge and experience level. Further to that, as with self-reported surveys, participants may have over reported in instances regarding evaluating for MetS and counseling on health education and cardiovascular risk, therefore possibly skewing results to favor this practice.

Fourthly, another limitation was not being able to capture more physicians in specialties providing primary care, specifically cardiology, to get their input and perspective on the subject matter as it pertains to cardiovascular risk.

Lastly, the COVID-19 WORLDWIDE PANDEMIC, a major limitation that halted data analysis due to social distancing and tragically our statistician being diagnosed. This in turn pushed back all due dates in an effort to facilitate any major psychosocial adverse effects and this delayed timely completion.

\section{CHAPTER 8}

\section{CONCLUSION}

There is a high level of Metabolic Syndrome Knowledge among physicians in New Providence, Bahamas. Physician participants admit to 'sometimes' adhering to NCEP-ATP III guidelines when screening patients for MetS. Family Medicine specialty was found to have the most knowledge of and most often uses NCEP-ATP III clinical practice guidelines for MetS. As years in practice and level of training increases, knowledge level, frequency of screening, and health education increases to 'everytime'.

\subsection{RECOMMENDATIONS}

Although, this study proves that there is a high level of knowledge of MetS among levels of training and specialty groupings, there still leaves room for improvement, with that said, there needs to be continued medical education on prevalence of MetS and its role in cardiovascular health. This can be done by encouraging clinical practice guideline adherence. Physician knowledge of the syndrome is paramount because prevention is key and early treatment for reversible clinical outcomes is the mainstay of MetS management. Educational intervention for physicians geared towards patient risk assessment is needed to improve quality of cardiovascular preventative care and in turn lower cardiovascular morbidity and mortality.

Ensuring health education and lifestyle counselling is done at every visit with patients, providing credible sources of information for them to read in their own time to help them become more accountable for their own cardiovascular health. 
Lastly, advocating for health education as social policy. Public service announcements on television, radio and social media informing the public about Metabolic Syndrome and its close tie to abdominal obesity and poor eating habits to increase population awareness.

\section{REFERENCES}

[1] Ramic, E., Prasko, S., Mujanovic, O., \& Gavran, L. (2016). Metabolic Syndrome Theory and Practice. Materia Socio Medica, 28(1), 71. doi:10.5455/msm.2016.28.71-73

[2] Ford, E. S. (2005). Risks for All-Cause Mortality, Cardiovascular Disease, and Diabetes Associated With the Metabolic Syndrome: A summary of the evidence. Diabetes Care, 28(7), 1769-1778. doi:10.2337/diacare.28.7.1769

[3] Galassi, A., Reynolds, K., \& He, J. (2006). Metabolic Syndrome and Risk of Cardiovascular Disease: A Meta-Analysis. The American Journal of Medicine, 119(10), 812-819. doi:10.1016/j.amjmed.2006.02.031

[4] Sattar, N., Gaw, A., Scherbakova, O., Ford, I., O’Reilly, D. S., Haffner, S. M., Shepherd, J. (2003). Metabolic Syndrome With and Without C-Reactive Protein as a Predictor of Coronary Heart Disease and Diabetes in the West of Scotland Coronary Prevention Study. Circulation, 108(4), 414-419. doi:10.1161/01.cir.0000080897.52664.94

[5] Isomaa, B., Almgren, P., Tuomi, T., Forsen, B., Lahti, K., Nissen, M., Groop, L. (2001). Cardiovascular Morbidity and Mortality Associated With the Metabolic Syndrome. Diabetes Care, 24(4), 683-689. doi:10.2337/diacare.24.4.683

[6] Wille, E., Scholze, J., Alegria, E., Ferri, C., Langham, S., Stevens, W., Uhl-Hochgraeber, K. (2010). Modelling the costs of care of hypertension in patients with metabolic syndrome and its consequences, in Germany, Spain and Italy. The European Journal of Health Economics, 12(3), 205-218. doi:10.1007/s10198-010-0223-9

[7] Schwarz, P., Reimann, M., Li, J., Bergmann, A., Licinio, J., Wong, M., \& Bornstein, S. (2007). The Metabolic Syndrome - A Global Challenge for Prevention. Hormone and Metabolic Research, 39(11), 777-780. doi:10.1055/s-2007-990312

[8] Vashitz, G., Meyer, J., Parmet, Y., Henkin, Y., Peleg, R., \& Gilutz, H. (2011). Physician adherence to the dyslipidemia guidelines is as challenging an issue as patient adherence. Family Practice, 28(5), 524-531. doi:10.1093/fampra/cmr025

[9] Gade, W., Schmit, J., Collins, M., \& Gade, J. (2010). Beyond Obesity: The Diagnosis and Pathophysiology of Metabolic Syndrome. American Society for Clinical Laboratory Science, 23(1), 51-61. doi:10.29074/ascls.23.1.51 
[10] Mccracken, E., Monaghan, M., \& Sreenivasan, S. (2018). Pathophysiology of the metabolic syndrome. Clinics in Dermatology, 36(1), 14-20. doi:10.1016/j.clindermatol.2017.09.004

[11] Grundy, S., Cleeman, J., Donato, K., Eckel, R., Franklin, B. (2005). Diagnosis and management of the metabolic syndrome: an American Heart Association/National Heart, Lung, and Blood Institute Scientific Statement. Circulation 112, 2735-52.

[12] Harikrishnan, S., Sarma, S., Sanjay, G., Jeemon, P., Krishnan, M. N., Venugopal, K., Zachariah, G. (2018). Prevalence of metabolic syndrome and its risk factors in Kerala, South India: Analysis of a community based cross-sectional study. Plos One, 13(3). doi:10.1371/journal.pone.0192372

[13] Wang, M. (2005). Nutrition \& Metabolism, 2(1), 3. doi:10.1186/1743-7075-2-3

[14] Alberti, K., \& Zimmet, P. (1998). Definition, diagnosis and classification of diabetes mellitus and its complications. Part 1: Diagnosis and classification of diabetes mellitus. Provisional report of a WHO Consultation. Diabetic Medicine, 15(7), 539-553. doi:10.1002/(sici)1096

$$
\text { i. } \quad-9136(199807) 15: 73.0 . c 0 ; 2-s
$$

[15] Alexander, C. M., Landsman, P. B., Teutsch, S. M., \& Haffner, S. M. (2003). NCEPDefined Metabolic Syndrome, Diabetes, and Prevalence of Coronary Heart Disease Among NHANES III Participants Age 50 Years and Older. Diabetes, 52(5), 1210-1214. doi:10.2337/diabetes.52.5.1210

[16] Ninomiya, J. K., L'Italien, G., Criqui, M. H., Whyte, J. L., Gamst, A., \& Chen, R. S. (2004). Association of the Metabolic Syndrome With History of Myocardial Infarction and Stroke in the Third National Health and Nutrition Examination Survey. Circulation, 109(1), 42-46. doi:10.1161/01.cir.0000108926.04022.0c

[17] Comment on the provisional report from the WHO consultation. (1999). Diabetic Medicine, 16(5), 442-443. doi:10.1046/j.1464-5491.1999.00059.x

[18] Third Report of the National Cholesterol Education Program (NCEP) Expert Panel on Detection, Evaluation, and Treatment of High Blood Cholesterol in Adults (Adult Treatment Panel III) Final Report. (2002). Circulation, 106(25), 3143-3143. doi:10.1161/circ.106.25.3143

[19] Clinical Guidelines on the Identification, Evaluation, and Treatment of Overweight and Obesity in Adults - the Evidence Report. National Institutes of Health. (1998) Obes Res, $6(2), 51 \mathrm{~S}-209 \mathrm{~S}$ 
[20] Face, D. E. (2003). American College of Endocrinology Position Statement on the Insulin Resistance Syndrome*. Endocrine Practice, 9(Supplement 2), 5-21. doi:10.4158/ep.9.s2.5

[21] International Diabetic Federation (2006). The Metabolic Syndrome -The IDF consensus worldwide definition of the metabolic syndrome. Retrieved from https://www.idf.org/elibrary/consensus-statements/60-idfconsensus-worldwide-definitionof-the-metabolicsyndrome

[22] You, T., Yang, R., Lyles, M. F., Gong, D., \& Nicklas, B. J. (2005). Abdominal adipose tissue cytokine gene expression: Relationship to obesity and metabolic risk factors. American Journal of Physiology-Endocrinology and Metabolism, 288(4). doi:10.1152/ajpendo.00419.2004

[23] Joshi, A., Mehta, S., Grover, A., Talati, K., Malhotra, B., \& Perin, D. M. (2013). Knowledge, Attitude, and Practices of Individuals to Prevent and Manage Metabolic Syndrome in an Indian Setting. Diabetes Technology \& Therapeutics, 15(8), 644-653. doi:10.1089/dia.2012.0309

[24] Alberti, G., Zimmet, P., Shaw, J., Grundy, S. (2006) The IDF Consensus Worldwide Definition of the Metabolic Syndrome. Brussels: International Diabetes Foundation.

[25] Expert Panel On Detection, Evaluation, And Treatment Of High Blood Cholesterol In Adults. (2001). Executive Summary of the Third Report of the National Cholesterol Education Program (NCEP) Expert Panel on Detection, Evaluation, and Treatment of High Blood Cholesterol in Adults (Adult Treatment Panel III). JAMA: The Journal of the American Medical Association, 285(19), 2486-2497. doi:10.1001/jama.285.19.2486

[26] World Health Organization. († 1999)» . Definition, diagnosis and classification of diabetes mellitus and its complication: report of a WHO consultation. Part 1, Diagnosis and classification of diabetes mellitus. Geneva: World Health Organization, 31-33. Retrieved from http://www.who.int/iris/handle/10665/66040

[27] Zimmerman M., Mehr S. (2013) The Controversial Question of Metabolic Syndrome Can Targeting This Symptom Complex Reduce the Burden of Diabetes and Cardiovascular Disease? AJMC 19, SP2

[28] van Herpt, T. T., Dehghan, A., van Hoek, M., Ikram, M. A., Hofman, A., Sijbrands, E. J., \& Franco, O. H. (2016). The clinical value of metabolic syndrome and risks of cardiometabolic events and mortality in the elderly: the Rotterdam study. Cardiovascular diabetology, 15, 69. https://doi.org/10.1186/s12933-016-0387-4 
[29] Unwin N. (2006) The metabolic syndrome. $J \quad R$ Soc Med. 99(9):457-462. doi:10.1258/jrsm.99.9.457

[30] Scuteri A., Najjar S., Morrell C.H., Lakatta E.G. (2005) The metabolic syndrome in older individuals: prevalence and prediction of cardiovascular events: the cardiovascular health study. Diabetes Care 28, 882 -7

[31] Kahn R., Buse J., Ferrannini E., Stern M. (2005) The metabolic syndrome: time for a critical appraisal. Joint statement from the American Diabetes Association and the European Association for the Study of Diabetes. Diabetes Care 28, 2289-304.

[32] Stern M.P., Williams K., Gonzalez-Villalpando C., Hunt K.J., Haffner S.M. (2004) Does the metabolic syndrome improve identification of individuals at risk of type 2 diabetes and/or cardiovascular disease? Diabetes Care 27, 2676-81.

[33] De Backer G., Ambrosioni E., Borch-Johnsen K. (2003) European guidelines on cardiovascular disease prevention in clinical practice. Third Joint Task Force of European and Other Societies on Cardiovascular Disease Prevention in Clinical Practice. Eur Heart $J 24,1601-10$

[34] Wassink A. M. J., Olijhoeck J. K., Visseren F. L. J. (2007) The metabolic syndrome: metabolic changes with vascular consequences. European Journal of Clinical Investigation, 37, 8-17.

[35] Vinicor, F., \& Bowman, B. (2004). The Metabolic Syndrome: The Emperor Needs Some Consistent Clothes: Response to Davidson and Alexander. Diabetes Care, 27(5), 1243 1243. doi:10.2337/diacare.27.5.1243

[36] Mph, E. S. (2003). Insulin Resistance Syndrome: The Public Health Challenge. Endocrine Practice, 9 (Supplement 2), 23-25. doi:10.4158/ep.9.s2.23

[37] Lakka, H. (2002). The Metabolic Syndrome and Total and Cardiovascular Disease Mortality in Middle-aged Men. Jama, 288(21), 2709. doi:10.1001/jama.288.21.2709

[38] Hunt, K. J., Resendez, R. G., Williams, K., Haffner, S. M., \& Stern, M. P. (2004). National Cholesterol Education Program Versus World Health Organization Metabolic Syndrome in Relation to All-Cause and Cardiovascular Mortality in the San Antonio Heart Study. Circulation, 110(10), 1251-1257. doi:10.1161/01.cir.0000140762.04598.f9

[39] Assmann, G., Guerra, R., Fox, G., Cullen, P., Schulte, H., Willett, D., \& Grundy, S. M. (2007). Harmonizing the Definition of the Metabolic Syndrome: Comparison of the Criteria of the Adult Treatment Panel III and the International Diabetes Federation in United States American and European Populations. The American Journal of Cardiology, 99(4), 541-548. doi:10.1016/j.amjcard.2006.08.045 
[40] Grundy S., Cleeman J., Bairey Merz C.N., Brewer H.B., Clark L. T., Hunninghake D., Pasternak R., Smith S., Stone N. J. (2004) Implications of Recent Clinical Trials for the National Cholesterol Education Program Adult Treatment Panel III Guidelines. J Am Coll Cardiol. 44, 720-32.

[41] Health Information \& Research Unit. (2005). Healthy lifestyle in The Bahamas: Findings from the Bahamas CNCD Prevalence study and risk factor survey (February - March, 2005). Retrieved from https:/www.bahamas.gov.bs/wps/wcm/connect/ddbe77af-63494f4988d1-a3ca4897c2ad/Healthy+Lifestyles+Summary.pdf?MOD=AJPERES

[42] Bahamas Government. (June 2011 to March 2012). Bahamas (Site) STEPS Survey 2012 [Fact Sheet]. Retrieved from https://www.bahamas.gov.bs/wps/wcm/connect/e60916998e84-4304-a1b5-813fde735f6e/FactSheet -2013+BAH+$+060314+$ Update+Final.pdf?MOD=AJPERES

[43] Brennen, D., Brathwaite, N.,\& Deleveaux,C.(2014). The Prevalence of raised blood pressure and self-reported hypertension in The Bahamas: Findings from the STEPS Survey, 2012. Presented at UWI Research day 2014. Nassau, Bahamas. Retrieved from https:/www.bahamas.gov.bs/wps/wcm/connect/40048036-76ef-4e42-

921865670b9e7eb7/UWI+Hypertension+Presentation+\%282014\%29.pdf?MOD=AJPER ES

[44] Ferguson, T., Younger, N., Tulloch-Reid, M., Forrester, T., Cooper, R., VandenBroeck, J., Wilks, R. (2010). Prevalence of the Metabolic Syndrome in Jamaican Adults and its Relationship to Income and Education Levels. West Indian Med J 59(3), 265

[45] Ezenwaka, C., Nwagbara, E., Seales, D., Okali, F., Hussaini, S., Raja, B., Wheeler, V., Sell, H., Avci, H., \& Eckel, J. (2007). A comparative study of the prevalence of the metabolic syndrome and its components in type 2 diabetic patients in two Caribbean islands using the new International Diabetes Federation definition. Archives of Physiology and Biochemistry 113(4/5), 202-210

[46] Cherry, C. O., Serieux, E., Didier, M., Nuttal, M. E., \& Schuster, R. J. (2014). Prevalence of Risk Factors for the Metabolic Syndrome in the Middle Income Caribbean Nation of St. Lucia. Advances in Preventive Medicine, 2014, 1-5. doi:10.1155/2014/501972

[47] Saklayen, M. G. (2018). The Global Epidemic of the Metabolic Syndrome. Current Hypertension Reports, 20(2). doi:10.1007/s11906-018-0812-z

[48] Falkner, B., \& Cossrow, N. D. (2014). Prevalence of Metabolic Syndrome and ObesityAssociated Hypertension in the Racial Ethnic Minorities of the United States. Current Hypertension Reports, 16(7). doi:10.1007/s1 1906-014-0449-5 
[49] Shin, D., Kongpakpaisarn, K., \& Bohra, C. (2018). Trends in the prevalence of metabolic syndrome and its components in the United States 2007-2014. International Journal of Cardiology, 259, 216-219. doi:10.1016/j.ijcard.2018.01.139

[50] Helminen, E., Mäntyselkä, P., Nykänen, I., \& Kumpusalo, E. (2009). Far from easy and accurate - detection of metabolic syndrome by general practitioners. BMC Family Practice, 10(1). doi:10.1186/1471-2296-10-76

[51] Ullah. (2011). The Awareness and Prevalence of Metabolic Syndrome in Medical Community of Bahawalpur. Oman Medical Journal, 26(1), 26-28. doi:10.5001/omj.2011.07

[52] Smith, S. C., \& Haslam, D. (2006). Abdominal obesity, waist circumference and cardiometabolic risk: Awareness among primary care physicians, the general population and patients at risk - the Shape of the Nations survey. Current Medical Research and Opinion, 23(1), 29-47. doi:10.1185/030079906x159489

[53] Havakuk, O., Perl, M. L., Praisler, O., Barkagan, M., Sadeh, B., Margolis, G., Arbel, Y. (2017). The awareness to metabolic syndrome among hospital health providers. Diabetes \& Metabolic Syndrome: Clinical Research \& Reviews, 11(3), 193-197. doi:10.1016/j.dsx.2016.09.005

[54] Echlin, P. S., Upshur, R. E., \& Markova, T. P. (2004). Lack of chart reminder effectiveness on family medicine resident JNC-VI and NCEP III guideline knowledge and attitudes. BMC Family Practice, 5(1). doi:10.1186/1471-2296-5-14

[55] Al-Gelban, S. K., Yunus Khan, M., Al-Khaldi, Y. M. (2011). Adherence of Primary Health Care Physicians to Hypertension Management Guidelines in the Aseer Region of Saudi Arabia, Saudi J Kidney Dis Transpl 22(5), 941-948. pmid: 21912023

[56] Atalay, B. (2018). Development of Metabolic Syndrome Knowledge Level Scale (MetSKS) and its validity and reliability study for Turkey. Indian Journal of Research, 7(1). ISSN 2250-1991

[57] Bahamas Government. (January 2019 to April 2019). Bahamas (Site) STEPS Survey 2019 [Fact Sheet]. Retrieved from

http://www.bahamas.gov.bs/wps/wcm/connect/891fac39ad7d4aa8ac5439912a1afcea/Preliminary+Factsheet $+\mathrm{v} 7+\% 28 \mathrm{med}+\mathrm{res} 1 \% 27 \mathrm{n} \% 29 . \mathrm{pdf} ? \mathrm{M}$ $\underline{\mathrm{OD}=\mathrm{AJPERES}}$

[58] Giuseppe M., Ilenia C., Emilio N., Giovanni C., Santina C. (2014). Metabolic syndrome in hypertensive patients: An unholy alliance. World J Cardiology, 6(9), 890-907. 
[59] Mancia G., Bombelli M., Corrao G., Facchetti R., Madotto F., Giannattasio C., Trevano F.Q., Grassi G., Zanchetti A., Sega R. (2007). Metabolic syndrome in the Pressioni Arteriose Monitorate E Loro Associazioni (PAMELA) study: daily life blood pressure, cardiac damage, and prognosis. Hypertension 49, 40-47.

[60] Schillaci G., Pirro M., Vaudo G., Gemelli F., Marchesi S., Porcellati C., Mannarino E. (2004). Prognostic value of the metabolic syndrome in essential hypertension. J Am Coll Cardiol. 43, 1817-1822.

[61] Cabrera-Pivaral C. E., Gutiérrez-Ruvalcaba C. L., Peralta-Heredia I. C. (2008). Development and validation of an instrument to measure family physicians' clinical aptitude in metabolic syndrome in Mexico. Salud Publica Mex. 50(6), 457-462.

[62] Hoyas, I., Leon-Sanz, M. (2019). Nutritional Challenges in Metabolic Syndrome. J Clin Med. 8(9), 1301. doi:10.3390/jcm8091301

[63] McMillan-Price J., Petocz P., Atkinson F., O’Neill K., Samman S., Caterson I., BrandMiller J. (2006). Comparison of 4 diets of varying glycemic load on weight loss and cardiovascular risk reduction in overweight and obese young adults: A randomized controlled trial. Arch. Intern. Med. 166:1466-1475. doi:10.1001/archinte.166.14.1466.

[64] Horton E.S. (2009) Effects of lifestyle changes to reduce risks of diabetes and associated cardiovascular risks: Results from large-scale efficacy trials. Obesity.17:S43-S48. doi:10.1038/oby.2009.388

[65] Buyken A.E., Toeller M., Heitkamp G., Karamanos B., Rottiers R., Muggeo M. (2001). The Eurodiab Iddm Complications Study Group Glycemic index in the diet of European outpatients with type 1 diabetes: Relations to glycated hemoglobin and serum lipids. Am. J. Clin. Nutr. 73, 574-581. doi:10.1093/ajen/73.3.574

[66] Brand-Miller J., Hayne S., Petocz P., Colagiuri S. (2003). Low-glycemic index diets in the management of diabetes. A meta-analysis of randomized controlled trials. Diabetes Care. 26, 2261-2267. doi:10.2337/diacare.26.8.2261

[67] Case C.C., Jones P.H., Nelson K., Smith E.O., Ballantyne C.M. (2002). Impact of weight loss on the metabolic syndrome. Diabetes Obes. Metab. 4, 407-414. doi:10.1046/j.14631326.2002.00236.x

[68] Phelan S., A Wadden T., I Berkowitz R., Sarwer D.B., Womble L.G., Cato R.K., Rothman R. (2007). Impact of weight loss on the metabolic syndrome. Int. J. Obes. 31, 1442-1448. doi:10.1038/sj.ijo.0803606

[69] Nestel P. (2004). Nutritional aspects in the causation and management of the metabolic syndrome. Endocrinol. Metab. Clin. N. Am. 33, 483-492. doi:10.1016/j.ec1.2004.03.010 
[70] Ninomiya J.K., L'Italien G., Criqui M., Whyte J.L., Gamst A., Chen R. S. (2004). Association of the Metabolic Syndrome With History of Myocardial Infarction and Stroke in the Third National Health and Nutrition Examination Survey. Circulation. 109, 42-46. doi.org/10.1161/01.CIR.0000108926.04022.0C

[71] Ranjani H., Mohan V. (2009) Prevention and Control of Noncommunicable Diseases Role of Family Physicians in Improving Compliance to Lifestyle Modification. The Asian Journal of Diabetology. Vol. 11, no. 2

[72] Bain D., Patterson K., Deveaux G., Bevans S., Albury J., Frankson M., Pinder-Butler S., Hanna-Mahase C. (2015) Pharmacologic Adherence to the Joint National Committee VII Guidelines amongst Family Physicians at the Family Medicine Clinic Nassau, Bahamas. Public Hospital Authority Family Medicine Clinic, Department of Family Medicine, University of the West Indies, Nassau Campus, Bahamas.

\section{APPENDIX A}

\section{FURTHER DATA ANALYSIS}

There was a statistically significant very strong relationship between participants' nationality and level of training (Cramer's $\mathrm{V}=0.279, \mathrm{p}=0.013$ ). Participants were predominantly of Bahamian nationality. Of the 39 Senior House Officers, 38 (97.4\%) were Bahamian and 1 $(2.6 \%)$ was of another undisclosed nationality. Of 22 Residents, 18 (81.8\%) were Bahamian, 1 (4.5\%) was Jamaican, and 3 (13.6\%) were of undisclosed nationality. Of 12 Registrars, 11 (91.7\%) were Bahamian and 1 (8.3\%) was of undisclosed nationality. Of 7 Senior Registrars, $6(85.7 \%)$ were Bahamian and $1(14.3 \%)$ was of undisclosed nationality. Of 29 Consultants, all (100\%) were Bahamian.

The median (IQR: Q1, Q3) years since graduating medical school was in the range of 5-10 (IQR: $5-10,11-20)$ years. Twenty $(18.9 \%)$ of participants were practicing medicine for $<5$ years, 35 (33\%) were practicing for 5-10 years, 38 (35.8\%) were practicing 11-20 years, and $13(12.3 \%)$ were practicing $>20$ years (See Fig. A1 below). 


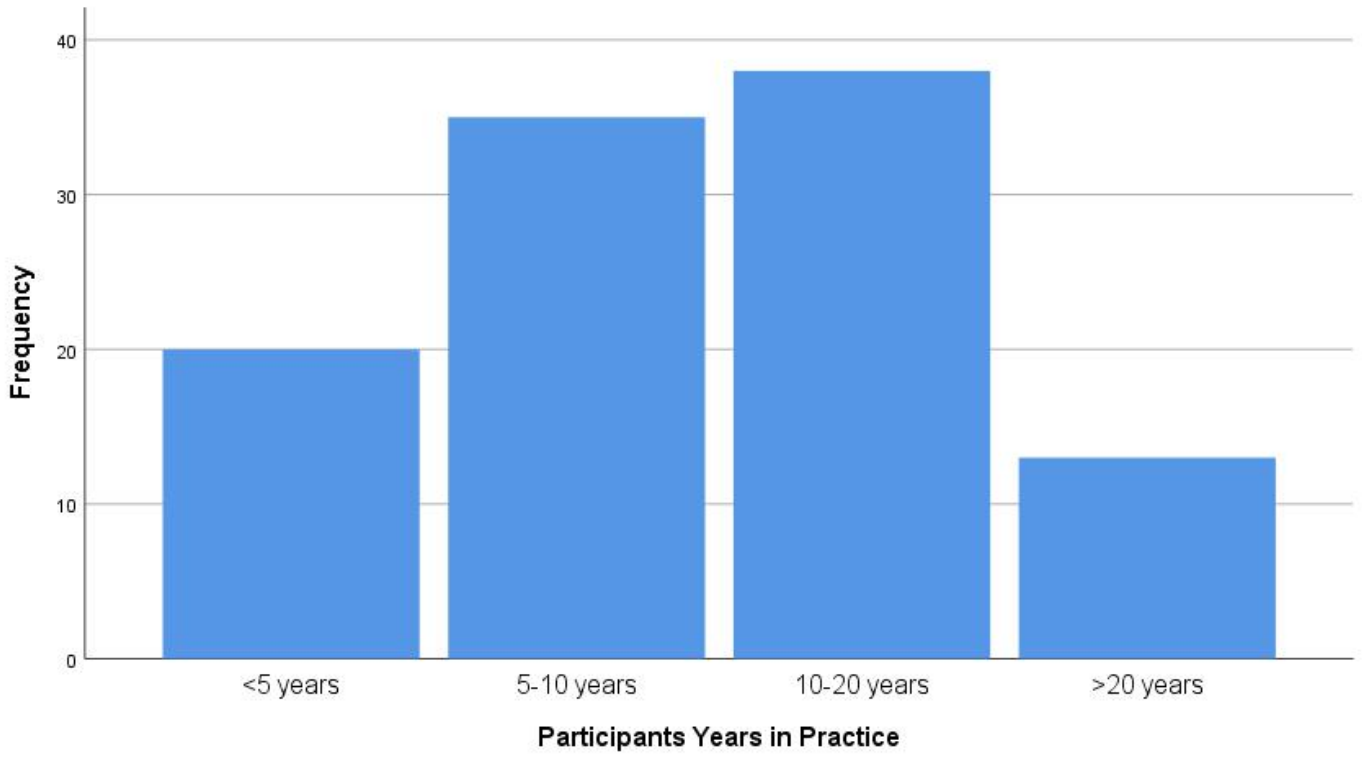

Figure A.1: Bar Graph showing participants' years in practice

There were statistically significant differences and strong positive relationship in participants' median (and accompanying IQR) number of years since graduating from medical school when grouped by their level of training $(\mathrm{rSp}=0.548, \mathrm{p}<0.001)$. The median years since graduating medical school for Residents was 5-10 (IQR: 5-10, 11-20) years, for Senior House Officers was 5-10 (IQR: <5, 11-20) years, for Registrars was 5-10 (IQR: 5-10, 11-20) years, for Senior Registrars was 11-20 (IQR: 5-10, 11-20) years, for Consultants was 11-20 (IQR: 11-20, > 20) years (See Fig. A2 below).

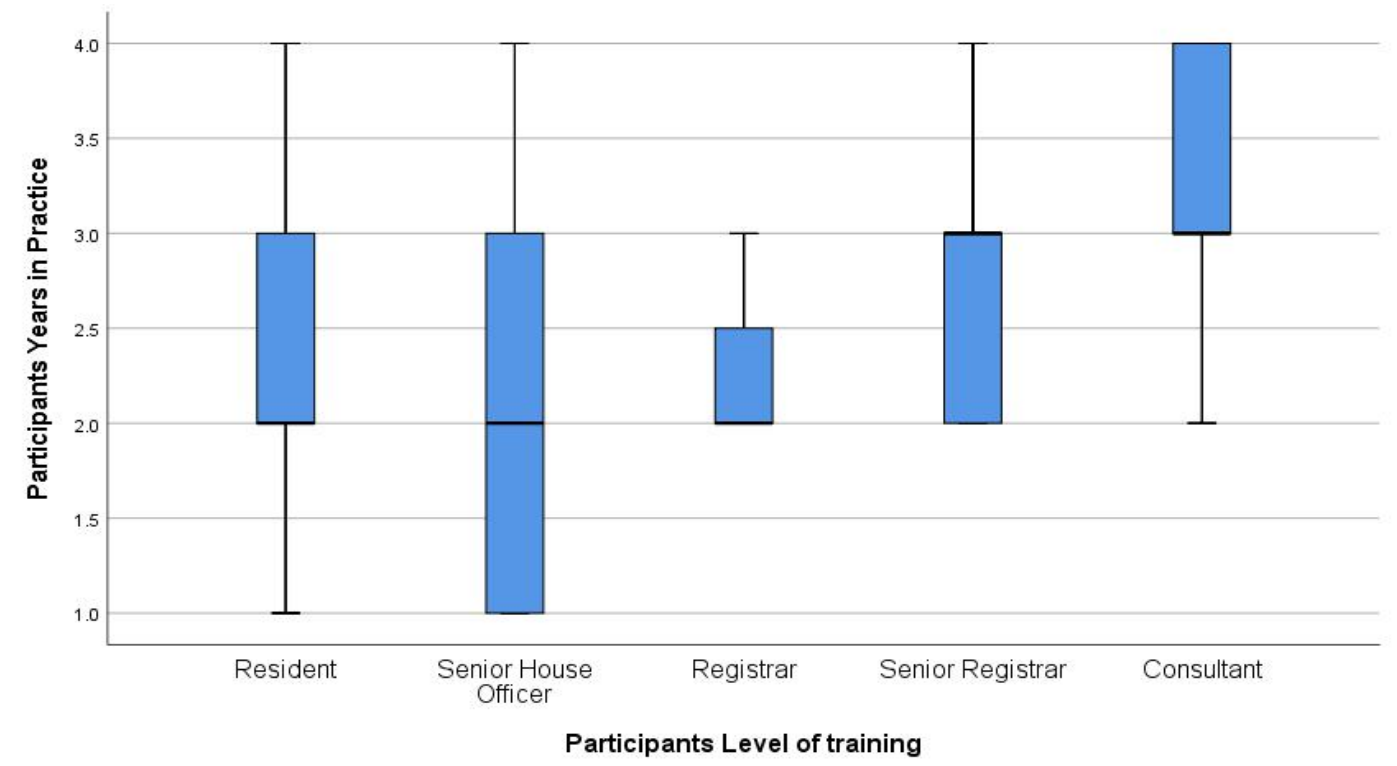

Figure A.2: Box plot showing participants' median years in practice by level of training

(Legend: $1=<$ years, $2=5-10$ years, $3=11-20$ years, $4=>20$ years) 
Table A.1: Table showing median number of years since graduating medical school by level of training

\begin{tabular}{|c|c|c|}
\hline Level of Training & $\begin{array}{c}\text { Median number of } \\
\text { years since } \\
\text { graduating med } \\
\text { school }\end{array}$ & IQR \\
\hline Resident & $5-10$ & $(5-10,11-20)$ \\
\hline $\begin{array}{c}\text { Senior House } \\
\text { Officer }\end{array}$ & $5-10$ & $(<5,11-20)$ \\
\hline Registrar & $5-10$ & $(5-10,11-20)$ \\
\hline Senior Registrar & $11-20$ & $(5-10,11-20)$ \\
\hline Consultant & $11-20$ & $(11-20,>20)$ \\
\hline
\end{tabular}

Participants' median number years in practice statistically significantly differed by specialty grouping $(\mathrm{p}=0.001)$. The median number of years in practice for the General Practice/Public Health specialty grouping was 5-10 (IQR: $<5,5-10)$ years. The median number of years in practice for the Family Medicine specialty grouping was 11-20 (IQR: 5-10, 11-20) years. The median number of years in practice for the Internal Medicine specialty grouping was 5-10 (IQR: $<5,5-10)$ years. The median number of years in practice for the O\&G specialty grouping was 5-10 (IQR: <5, 11-20) years (See Fig. A3 below).

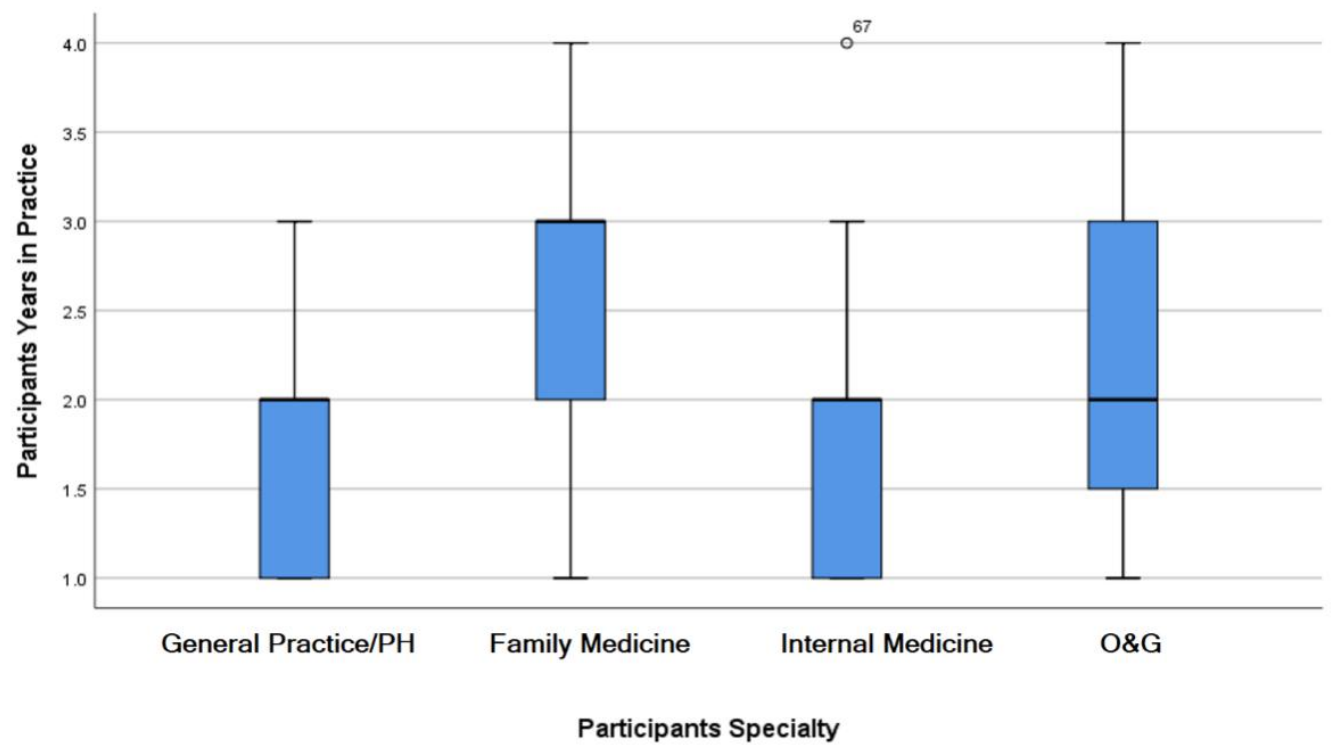

Figure A.3: Box plot showing participants' median number of years in practice by specialty grouping 


\section{(Legend: $1=<5 \mathrm{yrs}, 2=5-10 \mathrm{yrs}, 3=11-20 \mathrm{yrs}, 4=>20 \mathrm{years}$ )}

There was a statistically significant strong positive relationship between participants' place of practice and their level of training $(\mathrm{rSp}=0.607, \mathrm{p}<0.001)$. When compared by place of practice for the public sector, the participants' median level of training was Resident (IQR: SHO, Registrar), for the private sector, the participants' median level of training was Consultant (IQR: Consultant, Consultant) and for practicing in both public and private sectors, the participants' median level of training was Consultant (IQR: Senior Registrar, Consultant).

There was a statistically significant very strong relationship between participants place of practice and level of training (Cramer's $\mathrm{V}=0.577, \mathrm{p}<0.001$ ). Of the 37 Senior House Officers, 32 (86.5\%) worked in the Public Sector only, 1 (2.7\%) worked in the Private Sector only, while 4 (10.8\%) worked in both. Of the 22 Residents, 20 (90.9\%) worked in the Public Sector only, none worked in the Private Sector, 2 (9.1\%) worked in both the Public and Private Sectors. Of the 12 Registrars, 10 (83.3\%) worked in the Public Sector only, none worked in the Private Sector only, while $2(16.7 \%)$ worked in both. Of the 7 Senior Registrars, 3 (42.9\%) worked in the Public Sector only, none worked in the Private Sector only, 4 (57.1\%) worked in both. Of the 29 consultants, 1 (3.4\%) worked in the Public Sector only, 13 (44.8\%) worked in the Private Sector only, 15 (51.7\%) worked in both the Public and Private Sectors (See Fig. A4 below).

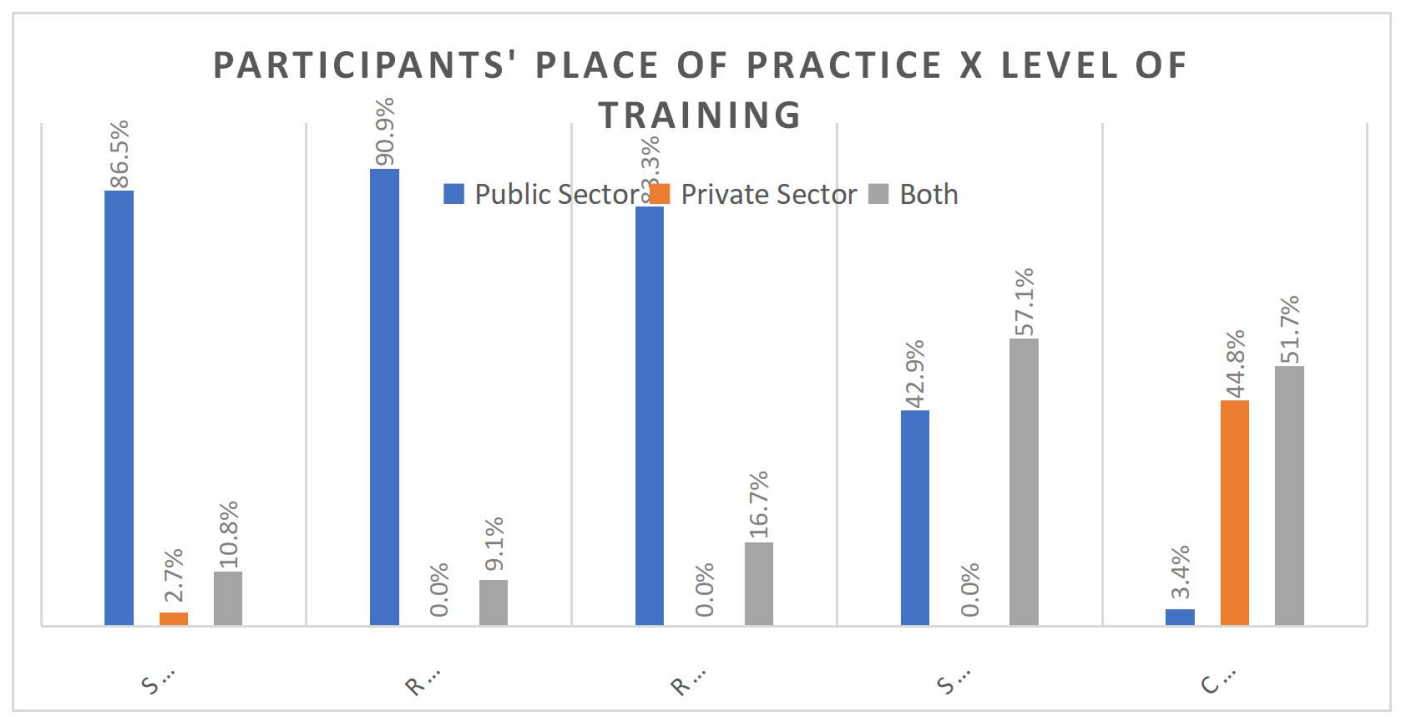

Figure A.4: Bar Chart showing participants' place of practice by level of training

There was a statistically significant very strong relationship between participants' median place of practice and their specialty grouping (Cramer's V =0.316, $p=0.003)$. All $10(100 \%)$ 
of physician participants in the General Practice/Public Health grouping practice in the Public sector only. Of 53 physician participants in the Family Medicine grouping, 23 (43.4\%) practice in the Public sector only, 9 (17\%) practice in the Private sector only, 21 (39.6\%) practice in both the Public and Private sectors. Of 22 physician participants in the Internal Medicine grouping, $16(72.7 \%)$ practice in the Public sector only, $3(13.6 \%)$ practice in the Private sector only, $3(13.6 \%)$ practice in both the Public and Private sectors. Of 15 physician participants in the O\&G grouping, 13 (86.7\%) practice in the Public sector only, none practice in the Private sector only, 2 (13.3\%) practice in both the Public and Private sectors.

There was a statistically significant very strong relationship between participants' specialty and their level of training (Cramer's $\mathrm{V}=0.387, \mathrm{p}=0.020)$. There were $8(7.3 \%)$ that did not specify their specialty, of that 8, $6(75 \%)$ were Senior House Officers, 1 (12.5\%) was a Resident, and 1 (12.5\%) was a Consultant.

Of the 39 Senior House Officers that did specify, 1 (2.6\%) was in Accident \& Emergency, 7 $(17.9 \%)$ were in Family Medicine, 9 (23.1\%) was in General Practice/Public Health, 8 (20.5\%) were in Internal Medicine, and 8 (20.5\%) were in Obstetrics \& Gynaecology. Of the 22 Residents that did specify their specialty, 17 (77.3\%) were in Family Medicine, 2 (9.1\%) were in Internal Medicine, while 2 (9.1\%) were in Obstetrics \& Gynaecology. Of the 12 Registrars, 4 (33.3\%) were in Family Medicine, 6 (50\%) were in Internal Medicine, 2 (16.7\%) were in Obstetrics and Gynaecology. Of the 7 Senior Registrars, 5 (71.4\%) were in Family Medicine, and $2(28.6 \%)$ were in Obstetrics \& Gynaecology. Of the 29 Consultants, 20 (69.0\%) were in Family Medicine, 1 (3.4\%) was in Geriatrics, 6 (20.5\%) were in Internal Medicine, 1 (3.4\%) was in Obstetrics \& Gynaecology.

Participants' median level of training statistically significantly differed by specialty grouping $(\mathrm{p}<0.001)$. The median level of training for the General Practice/Public Health specialty grouping was SHO (IQR: SHO, SHO). The median level of training for the Family Medicine specialty grouping was Registrar (IQR: Resident, Consultant). The median level of training for the Internal Medicine specialty grouping was Registrar (IQR: SHO, Consultant). The median level of training for the O\&G specialty grouping was SHO (IQR: SHO, Registrar) (See Fig. A5 below). 


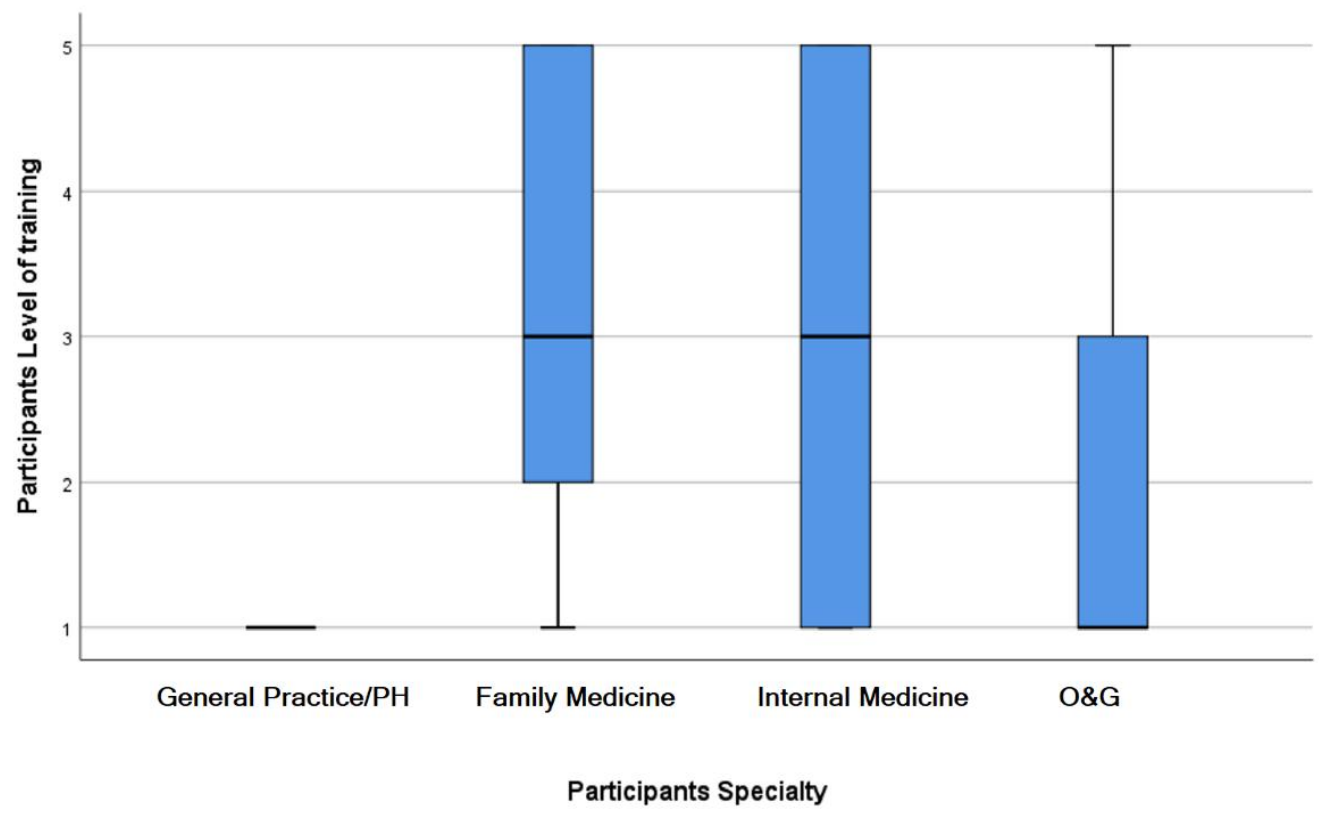

Figure A.5: Box plot showing participants' median level of training by specialty grouping

(Legend: $1=$ SHO, $2=$ Resident, $3=$ Registrar, $4=$ Senior Registrar, $5=$ Consultant $)$

When 110 physician participants were asked which physician they feel should treat patients with MetS, several participants chose more than one response. 2 (1.8\%) participants responded "Internist, Cardiologist, Endocrinologist, Family Physician", 1 (0.9\%) participant responded "Internist, Cardiologist, Family Physician, Any Physician”, 10 (9.1\%) participants responded "Internist, Endocrinologist, Family Physician", 3 (2.7\%) participants responded "Internist, Family Physician", 2 (1.8\%) participants responded "Internist, Family Physician, Any Physician", and 2 (1.8\%) participants responded "Family Physician, Any Physician". 5 (4.5\%) chose "Internist" only, 4 (3.6\%) chose "Endocrinologist" only, 18 (16.4\%) chose "Family Physician" only, and 62 (56.4\%) chose "Any Physician". 1 (0.9\%) participant did not respond.

In relation to participants correctly identifying the total number of criteria comprised in the MetS, of interest, of 38 Senior House Officers, 16 (42.1\%) said $<5$ criteria, of 22 Residents 9 $(40.9 \%)$ said $<5$ Criteria, of 12 Registrars, $6(50 \%)$ said $<5$ criteria, of the 7 Senior Registrars, only $1(14.3 \%)$ said $<5$ criteria, of the 29 Consultants, none said $<5$ criteria.

There were statistically significant differences in participants' mean ages among the five (5) groupings of frequency of evaluating for Metabolic Syndrome $(p<0.001)$. Specifically for the seven (7) participants who "never" evaluate for MetS, their mean age was $31.4( \pm 2.0)$ years old; for the 24 that did so "occasionally", mean age was $36.3( \pm 1.1)$ years old; for the 44 
doing so "sometimes" mean age was $37.8( \pm 0.9)$ years old; for the 17 that evaluated "often", mean age was $43.4( \pm 2.5)$ years old; and for the 11 participants that "always" evaluated for Metabolic Syndrome, mean age was $43.1( \pm 2.3)$ years old.

\section{METS-KS}

There is a statistically significant strong relationship between participants sex and whether or not MetS is a common clinical condition (Cramer's $V=0.240, p=0.044$ ). Specifically, for the 29 males, $24(82.8 \%)$ said "yes". $3(10.3 \%)$ and $2(6.9 \%)$ were "unsure". Of the 79 females, $76(96.2 \%)$ said “yes". 1 (1.3\%) said “no", 2 (2.5\%) were unsure.

There was statistically significant very strong relationship between physician participants' specialty grouping and whether or not they thought MetS can be seen in all age groups (Cramer's V $=0.341, \mathrm{p}=0.001$ ). Of the 9 participants in the General Practice/Public Health grouping, 7 (77.8\%) correctly agreed that MetS can be seen in all age groups. Of the 54 participants in the Family Medicine grouping, 50 (92.6\%) correctly agreed that MetS can be seen in all age groups. Of the 22 participants in the Internal Medicine grouping, 20 (90.9\%) correctly agreed that MetS can be seen in all age groups. Of the 12 participants in the O\&G grouping, $6(50.0 \%)$ correctly agreed that MetS can be seen in all age groups.

There is a very strong statistically significant relationship between participants sex and their thoughts on whether high calorie nutrition is a risk factor for Metabolic Syndrome (Cramer's $\mathrm{V}=0.275, \mathrm{p}=0.017)$. Of the 29 males, $16(55.2 \%)$ said "yes" and 4 (13.8\%) said "no". 9 (31\%) were unsure. Of the 78 females, 58 (74.4\%) said "yes", 13 (16.7\%) said "no", 7 (9.0\%) were "unsure".

There is a very strong statistically significant relationship between participants sex and their thoughts on whether there is need to measure lipids in Metabolic Syndrome (Cramer's V = $0.265, \mathrm{p}=0.022)$. Of the 29 males, $3(10.3 \%)$ said "yes", $22(75.9 \%)$ said "no", and $4(13.8 \%)$ were "unsure". Of the 79 females, $8(10.1 \%)$ said "yes", 70 (88.6\%) said "no", and $1(1.3 \%)$ was "unsure".

There was a statistically significant very strong relationship between participants' ethnicity and thinking that if lifestyle changes are insufficient in MetS, drug treatment can be applied (Cramer's $\mathrm{V}=0.345, \mathrm{p}=0.002)$. Of the 92 Afro-Caribbean study participants, $88(95.7 \%)$ agreed that if lifestyle changes are insufficient, drug treatment can be applied, $1(1.1 \%)$ did 
not think so, $3(3.3 \%)$ were unsure or thought it to be unlikely. Four (4) Afro-Americans were in this study and $3(75 \%)$ agreed with the above statement, while $1(25 \%)$ did not. 1 of $2(50 \%)$ Caucasian participants also agreed with that statement as did the $3(100 \%)$ Asians and 5 $(100 \%)$ regarding their ethnicity as other. Only $3(2.8 \%)$ of participants were unsure.

There was a statistically significant very strong relationship between participants level of training and whether they thought MetS is less common in individuals who partake in a balanced diet (Cramer's V =0.328, p = 0.020). Of 39 Senior House Officers, 30 (76.9\%) correctly answered "yes"; of 22 Residents, 17 (77.3\%) correctly answered "yes"; of 12 Registrars, 7 (58.3\%) correctly answered "yes"; of 7 Senior Registrars, 5 (71.4\%) correctly answered "yes"; All 29 Consultants (100\%) correctly answered "yes".

There were statistically significant differences among the five (5) groupings in participants' level of training and whether or not participants measure waist circumference $(p=0.066)$. Specifically for the 51 participants who "never" measure waist circumference, 28 (54.9\%) were Senior House Officers, 8 (15.7\%) were Residents, 5 (9.8\%) were Registrars, 2 (3.9\%) were Senior Registrars, while 8 (15.7\%) were Consultants; Of the 22 Residents, 6 (27.3\%) did so "occasionally", $6(27.3 \%)$ did so "sometimes", while $2(9.1 \%)$ did so "everytime". Of the 39 Senior House Officers, 8 (20.5\%) did so "occasionally", 2 (5.1\%) did so "sometimes", while 1 (2.6\%) did so "often". Of the 12 Registrars, 3 (25\%) did so "occasionally", 3 (25\%) did so "sometimes", while $1(8.3 \%)$ did so "often". Of the 7 Senior Registrars, 3 (42.9\%) did so "occasionally", 1 (14.3\%) did so "sometimes" while 1 (14.3\%) did so "everytime". Of the 29 Consultants, 11 (37.9\%) did so "occasionally", 7 (24.1\%) did so "sometimes", 2 (6.9\%) did so "often", while 1 (3.4\%) did so "everytime".

There were statistically significant differences in participants' level of training among the five (5) groupings of whether or not participants calculate Body Mass Index ( $p=0.042)$. Specifically for the 7 participants who "never" calculate BMI, 1 (14.3\%) was a Resident, 3 (42.9\%) were Senior House Officers, 1 (14.3\%) was a Registrar, and 2 (28.6\%) were Consultants; Of the 22 Residents, 3 (13.6\%) did so "occasionally", 8 (36.4\%) did so "sometimes", 7 (31.8\%) did so "often", while 3 (13.6\%) did so "everytime". Of the 39 Senior House Officers, 14 (35.9\%) did so "occasionally", 9 (23.1\%) did so "sometimes", 11 (28.2\%) did so "often" while $2(5.1 \%)$ did so "everytime". Of the 12 Registrars, 2 (16.7\%) did so "occasionally", 4 (33.3\%) did so "sometimes", 4 (33.3\%) did so "often" while 1 (8.3\%) did so "everytime". Of the 7 Senior Registrars, 1 (14.3\%) did so "occasionally", 2 (28.6\%) did so "sometimes", $2(28.6 \%)$ did so "often" while $2(28.6 \%)$ did so "everytime". Of the 29 
Consultants, 2 (6.9\%) did so "occasionally", 2 (6.9\%) did so "sometimes", 12 (41.4\%) did so “often", while 11 (37.9\%) did so "everytime".

Although not statistically significant, participants' median extent to which they recommend adjustment of risk factors upon discharge may differ by their specialty grouping $(p=0.067)$. The median frequency with which the General Practice/Public Health grouping recommend adjustment of risk factors upon discharge was Always (IQR: often, always). The median frequency with which the Family Medicine grouping recommend adjustment of risk factors upon discharge was Always (IQR: often, always). The median frequency with which the Internal Medicine grouping recommend adjustment of risk factors upon discharge was Often (IQR: often, often). The median frequency with which the O\&G grouping recommend adjustment of risk factors upon discharge was Sometimes (IQR: occasionally, always).

There was a statistically significant very strong relationship between participants' nationality and whether or not they think waist circumference should be recommended as an adjusted risk factor in MetS (Cramer's $\mathrm{V}=0.286, \mathrm{p}=0.030$ ). Of 102 Bahamian participants, 19 (18.6\%) agreed with this, the $1(100 \%)$ American respondent to both variables agreed as did the $1(100 \%)$ Jamaican respondent, $2(40 \%)$ of 5 who classified themselves as Other also agreed with the thought that waist circumference should be an adjusted risk factor in MetS.

When grouped by specialty, there were statistically significant differences among the medians for the MetS Knowledge scale score concerning the percent correctly answered $(p=0.013)$.

The one way ANOVA was also used to assess possible differences in the mean scores among the four specialty groupings and the Levine test of homogeneity of variances indicated that based on medians, the equality of variance assumption was met for doing so. It was not met however, when the Levine test was based on the mean $(p=0.035)$. Bearing this in mind, the omnibus ANOVA test indicated that at least one pair of the means was statistically significantly different and using both the least significant difference (LSD) t-test ( $p=0.005)$ as well as the Bonferroni adjusted t-test $(\mathrm{p}=0.031)$, it was solely the mean difference of $10.1 \%( \pm 3.5 \%)$ between the Family Medicine vs. O\&G specialty groupings that was statistically significant.

Although not statistically significant (Cramer's V $=0.056$ ), there may be a strong relationship between participants sex and whether or not they think individuals with Metabolic Syndrome are less likely to have cancer. 


\section{APPENDIX B}

\section{SURVEY PARTICIPANT CONSENT FORM}

Dear Physician Participant,

My name is Dr. Danielle Strachan-Bowleg, Doctorate of Medicine (DM) Family Medicine resident at the University of the West Indies. I am currently in the process of undertaking a research project entitled "Knowledge regarding Metabolic Syndrome and adherence to NCEPATP III clinical practice guidelines among physicians in New Providence, Bahamas" under the supervision of Drs. S. Pinder-Butler and C. Conliffe.

You are cordially invited to participate in the above research study. The purpose of this study is to assess the level of knowledge of physicians regarding metabolic syndrome in everyday clinical practice, as well as adherence to clinical practice guidelines, specifically the National Cholesterol Education Program Adult Treatment Panel III, in diagnosing metabolic syndrome. Your participation in this study is entirely voluntary and you may withdraw at any time. Your identity will remain anonymous and all information gathered from this study will be confidential.

Please see details below and sign in agreement with participation in this study.

I agree to participate in the above aforementioned study. I understand my participation is voluntary and that my identity will not be associated with any of my responses and kept confidential. By signing below, I agree to the above and grant permission for the results to be used for clinical research purposes.

Participant's signature:

Date:

Thanking you in advance for your time.

\section{APPENDIX C}

\section{QUESTIONNAIRE}

$\underline{\text { PART I - DEMOGRAPHICS }}$

Please circle the one best answer that is applicable: 
1. Gender:

a. Male

b. Female

2. Age:

3. Ethnicity:
a. Afro-Caribbean
b. African-American
c. Caucasian
d. Asian
e. Other

4. Nationality:
a. Bahamian
b. American
c. Jamaican
d. Cuban
e. Philipino
f. Other: (please specify)

5. Level of training:
a. Resident
b. Senior House Officer
c. Registrar
d. Senior Registrar
e. Consultant

6. Number of years practicing:
a. $<5$ years
b. 5-10 years
C. 11-20 years
d. $>20$ years

7. Where do you practice? 

a. Public sector
b. Private sector
c. Both

8. Specify area of practice/specialty:

\section{PART II [A]}

Please circle the one best answer that is applicable:

\begin{tabular}{|l|c|c|c|c|c|c|c|}
\hline $\begin{array}{l}\text { Are you familiar with the } \\
\text { term Metabolic } \\
\text { Syndrome? }\end{array}$ & \multicolumn{3}{|c|}{ YES } & & \multicolumn{3}{c|}{ NO } \\
\hline $\begin{array}{l}\text { Do you treat patients with } \\
\text { Metabolic Syndrome? }\end{array}$ & \multicolumn{3}{|c|}{ YES } & & & & \\
\hline $\begin{array}{l}\text { How many criteria are } \\
\text { included in Metabolic } \\
\text { Syndrome? }\end{array}$ & 1 & 2 & 3 & 4 & 5 & 6 & 7 \\
\hline $\begin{array}{l}\text { What is the number of } \\
\text { criteria required for the } \\
\text { diagnosis of Metabolic } \\
\text { Syndrome? }\end{array}$ & 1 & 2 & 3 & 4 & 5 & 6 & 7 \\
\hline
\end{tabular}

\begin{tabular}{|c|c|c|}
\hline $\begin{array}{l}\text { For cases considered to be suitable for the definition of Metabolic } \\
\text { Syndrome, please choose - Yes }\end{array}$ & & \\
\hline $\begin{array}{l}60 \text { y/o male, weighs } 95 \mathrm{~kg} \text {, LDL } 160 \mathrm{mg} / \mathrm{dl}, \mathrm{BP} 150 / 90 \mathrm{~mm} / \mathrm{Hg}, \mathrm{HDL} \\
30 \mathrm{mg} / \mathrm{dl}, \mathrm{TG} 120 \mathrm{mg} / \mathrm{dl}\end{array}$ & YES & NO \\
\hline $\begin{array}{l}50 \mathrm{y} / \text { o female, waist circumference } 90 \mathrm{~cm}, \mathrm{BP} 120 / 70 \mathrm{~mm} / \mathrm{Hg}, \mathrm{HDL} \\
42 \mathrm{mg} / \mathrm{dl}, \mathrm{TG} 100 \mathrm{mg} / \mathrm{dl}, \mathrm{FPG}-120 \mathrm{mg} / \mathrm{dl}\end{array}$ & YES & NO \\
\hline $\begin{array}{l}45 \text { y/o male, smoker, HbA1c 7\%, weighs } 80 \mathrm{~kg} \text {, BP } 145 / 95 \mathrm{~mm} / \mathrm{Hg} \text {, } \\
\text { HDL } 50 \mathrm{mg} / \mathrm{dl} \text {, TG } 147 \mathrm{mg} / \mathrm{dl}\end{array}$ & YES & NO \\
\hline $\begin{array}{l}70 \text { y/o female, LDL } 180 \text { mg/dl, BP 150/90 mm/Hg, HDL } 30 \text { mg/dl, } \\
\text { TG } 147 \text { mg/dl, FPG } 120 \text { mg/dl, non smoker }\end{array}$ & YES & $\mathrm{NO}$ \\
\hline $\begin{array}{l}55 \text { y/o male, waist circumference } 104 \mathrm{~cm}, \text { BP } 125 / 80 \mathrm{~mm} / \mathrm{Hg} \text {, HDL } \\
35 \mathrm{mg} / \mathrm{dl} \text {, TG } 152 \mathrm{mg} / \mathrm{dl} \text {, FPG } 90 \mathrm{mg} / \mathrm{dl}\end{array}$ & YES & $\mathrm{NO}$ \\
\hline
\end{tabular}

LDL - Low density lipoprotein, BP - blood pressure, HDL - high density lipoprotein, TG - triglyceride, FPG - fasting plasma glucose 


\begin{tabular}{|c|c|c|c|c|c|}
\hline $\begin{array}{l}\text { Who, in your } \\
\text { opinion, should } \\
\text { treat Metabolic } \\
\text { Syndrome } \\
\text { patients? }\end{array}$ & Internist & Cardiologist & Endocrinologist & $\begin{array}{l}\text { Family } \\
\text { physician }\end{array}$ & $\begin{array}{l}\text { Any } \\
\text { physician }\end{array}$ \\
\hline $\begin{array}{l}\text { Does Metabolic } \\
\text { Syndrome } \\
\text { influence } \\
\text { prognosis? }\end{array}$ & \multicolumn{3}{|c|}{ Yes } & \multicolumn{2}{|l|}{ No } \\
\hline $\begin{array}{l}\text { Is Metabolic } \\
\text { Syndrome } \\
\text { considered to be a } \\
\text { risk factor for } \\
\text { cancer? }\end{array}$ & \multicolumn{2}{|r|}{ Yes } & \multicolumn{3}{|c|}{ No } \\
\hline $\begin{array}{l}\text { How often do you } \\
\text { evaluate the } \\
\text { presence of } \\
\text { Metabolic } \\
\text { Syndrome in your } \\
\text { patients? } \\
\text { Never, } 5 \text { - Always) }\end{array}$ & 1 & 2 & 3 & 4 & 5 \\
\hline
\end{tabular}

\begin{tabular}{|l|l|l|l|l|l|}
\hline $\begin{array}{l}\text { Upon discharge, } \\
\text { How often do you } \\
\text { recommend for the } \\
\text { adjustment of risk } \\
\text { factors? (1- Never, }\end{array}$ & 1 & 2 & 3 & 4 & 5 \\
$5-$ Always) & & & & \\
\hline $\begin{array}{l}\text { Which of the risk } \\
\text { factors do you } \\
\text { recommend to } \\
\text { adjust most } \\
\text { commonly? }\end{array}$ & & & \\
\hline
\end{tabular}




\section{PART II [B]}

\section{Please circle the one best answer that is applicable:}

1) Which Criteria, if any, do you use most often to make diagnosis of Metabolic Syndrome?

a. National Cholesterol Education Program Adult Treatment Panel III (NCEP-ATP III)

b. World Health Organization (WHO)

c. American Academy of Clinical Endocrinologists (AACE)

d. International Diabetes Foundation (IDF)

2) Identify and circle which parameters are specific to the NCEP-ATP III guidelines:

A

\begin{tabular}{|c|c|}
\hline $\begin{array}{l}\text { Raised } \\
\quad \text { triglycerides }\end{array}$ & $\begin{array}{l}\geq 150 \mathrm{mg} / \mathrm{dL}(1.7 \mathrm{mmol} / \mathrm{L}) \text { or } \\
\text { specific treatment for this lipid } \\
\text { abnormality }\end{array}$ \\
\hline \multirow{3}{*}{$\begin{array}{l}\text { Reduced HDL } \\
\text { cholesterol }\end{array}$} & Men: $<40 \mathrm{mg} / \mathrm{dL}(1.03 \mathrm{mmol} / \mathrm{L})$ \\
\hline & Women: $<50 \mathrm{mg} / \mathrm{dL}(1.29 \mathrm{mmol} / \mathrm{L})$ \\
\hline & $\begin{array}{l}\text { Or specific treatment for this lipid } \\
\text { abnormality }\end{array}$ \\
\hline $\begin{array}{l}\text { Raised blood } \\
\text { pressure }^{\mathrm{d}}\end{array}$ & $\begin{array}{l}\geq 130 / \geq 85 \mathrm{~mm} \mathrm{Hg} \text { or treatment } \\
\text { of previously diagnosed } \\
\text { hypertension }\end{array}$ \\
\hline $\begin{array}{l}\text { Raised fasting } \\
\text { plasma glucose }\end{array}$ & $\begin{array}{l}\geq 100 \mathrm{mg} / \mathrm{dL}(5.6 \mathrm{mmol} / \mathrm{L}) \text { or } \\
\text { previously diagnosed type } 2 \\
\text { diabetes }\end{array}$ \\
\hline Central obesity & (Main component) \\
\hline
\end{tabular}

$\mathrm{B}$

$\geq 150 \mathrm{mg} / \mathrm{dL}$
$(1.7 \mathrm{mmol} / \mathrm{L})$
$\begin{aligned} & \text { Men: }<35 \mathrm{mg} / \mathrm{dL} \\ & (0.9 \mathrm{mmol} / \mathrm{L}) \\ & \text { Women: }<39 \mathrm{mg} / \mathrm{dL} \\ & (1.0 \mathrm{mmol} / \mathrm{L})\end{aligned}$
$\quad-$
$\geq 140 / 90 \mathrm{~mm} \mathrm{Hg}$


Men: waist-to-hip
ratio $>0.90$
Women: waist-to-hip
ratio $>0.85$
Or BMI $>30 \mathrm{~kg} / \mathrm{m}^{2}$
Urinary albumin
excretion rate
$\geq 20 \mu \mathrm{g} / \mathrm{min}$ or
albumin:creatinine
ratio $\geq 30 \mathrm{mg} / \mathrm{g}$

$\mathrm{C}$

$\geq 150 \mathrm{mg} / \mathrm{dL}(1.7 \mathrm{mmol} / \mathrm{L})$

Men: $<40 \mathrm{mg} / \mathrm{dL}$

$(1.03 \mathrm{mmol} / \mathrm{L})$

$(1.29 \mathrm{mmol} / \mathrm{L})$

$\geq 130 / \geq 85 \mathrm{~mm} \mathrm{Hg}$

$\geq 110 \mathrm{mg} / \mathrm{dL}(6.1 \mathrm{mmol} / \mathrm{L})$

Men: waist circumference $>102 \mathrm{~cm}$ (>40 inches) Women: waist circumference $>88 \mathrm{~cm}$ ( $>35$ inches)

3) Do you feel that metabolic syndrome is prevalent in your patient population?
a. Yes
b. No 
Please tick the one best answer that is applicable:

\begin{tabular}{|l|l|l|l|l|l|}
\hline & Never & Occassionally & Sometimes & Often & Everytime \\
\hline $\begin{array}{l}\text { 4) Do you often screen patients } \\
\text { adhering to guideline criteria for } \\
\text { Metabolic Syndrome (MetS)? }\end{array}$ & & & & & \\
\hline $\begin{array}{l}\text { 5) Do you screen for individual } \\
\text { comorbidities in isolation? }\end{array}$ & & & & & \\
\hline $\begin{array}{l}\text { 6) Do you commonly measure waist } \\
\text { circumference in your practice? }\end{array}$ & & & & & \\
\hline $\begin{array}{l}\text { 7) Do you commonly calculate Body } \\
\text { Mass Index in your practice? }\end{array}$ & & & & \\
\hline $\begin{array}{l}\text { 8) Do you routinely calculate ASCVD } \\
\text { risk score for your patients? }\end{array}$ & & & & \\
\hline $\begin{array}{l}\text { 9) Do you counsel your patients on } \\
\text { lifestyle modification? }\end{array}$ & & & & \\
\hline $\begin{array}{l}\text { 10) Do you engage patients in health } \\
\text { education regarding cardiovascular } \\
\text { risk, both modifiable and non- } \\
\text { modifiable factors? }\end{array}$ & & & & & \\
\hline $\begin{array}{l}\text { 11) Do your patients feel well } \\
\text { informed once leaving a visit about } \\
\text { their cardiovascular risk? }\end{array}$ & & & & & \\
\hline
\end{tabular}

\section{PART III}

\section{5 item Modified Metabolic Syndrome Knowledge Level Scale (MetS-KS)}

Please tick the one best answer that is applicable:

\begin{tabular}{|l|l|l|l|l|}
\hline \multicolumn{1}{|c|}{ Question/Category } & Yes & No & Not likely & Unsure \\
\hline $\begin{array}{r}\text { 1) MetS is a clinical condition with : } \\
\text { elevated blood pressure } \\
\text { impaired blood lipids } \\
\text { increased waist circumference } \\
\text { elevated blood glucose levels }\end{array}$ & & & & \\
\hline 2) MetS is a common clinical condition & & & & \\
\hline 3) MetS prevalence increases as age increases & & & & \\
\hline 4) MetS can be seen in all age groups & & & & \\
\hline $\begin{array}{l}\text { 5) When family members have heart disease, the risk } \\
\text { of MetS is reduced }\end{array}$ & & & & \\
\hline $\begin{array}{l}\text { 6) The waist circumference for MetS is different in } \\
\text { males and females }\end{array}$ & & & & \\
\hline 7) MetS is more common in females & & & & \\
\hline
\end{tabular}




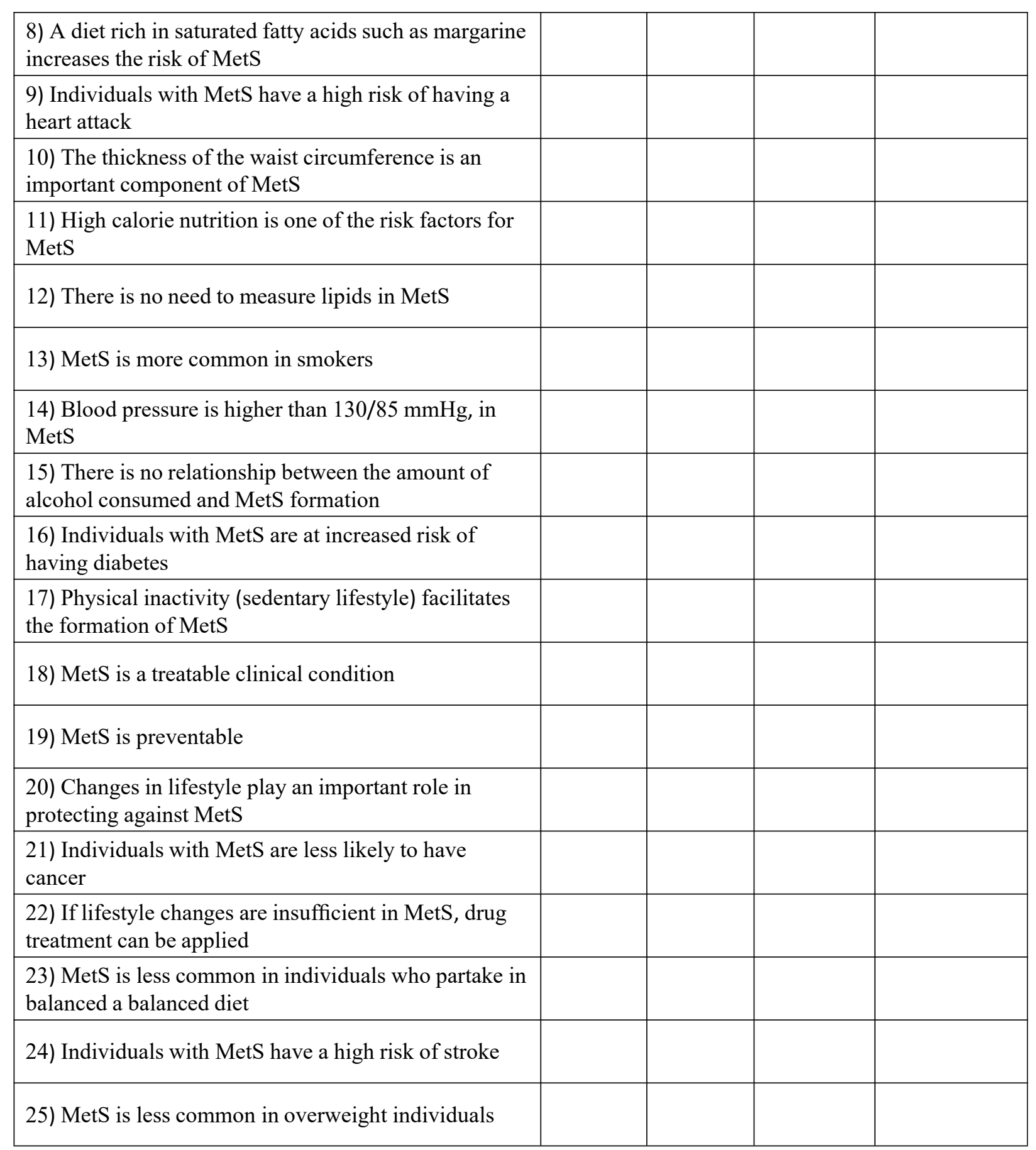




\section{APPENDIX D}

\section{QUESTIONNAIRE PERMISSION REQUESTS}

Goodday Michal Laufer Perl,

It is my esteemed honor to be able to address you today and I hope that this email finds you in good spirits. My name is Dr. Danielle Strachan-Bowleg, and I am a third year post graduate resident in the Family Medicine program at the University of the West Indies, Nassau, Bahamas campus. I am presently in the beginning stages of formulating my research project which is mandatory for my post graduate degree to obtain a DM in Family Medicine. My aim is to conduct a cross-sectional survey to assess the knowledge, perception and treatment of metabolic syndrome in a focus group of physicians. I came across your study, "The Awareness to Metabolic Syndrome among Hospital Health Providers" in my literature review, and I am writing to request permission to access a copy of the original questionnaire used as I feel its format will be beneficial to my purpose, and also permission to actually re-use a modified version of the questionnaire in my own study, of course giving you and your research team full acknowledgement. I hope you and your team will be most accommodating to my efforts to report on some of the statistics on metabolic syndrome in my country and in this region. Looking forward to hearing from you soon, with hopes of affirmative assistance in my venture. if you have any further questions about my research, please do not hesitate to contact. Thank you in advance for your time.

Kind regards,

Dr. Danielle Strachan-Bowleg B.Sc., M.B.B.S., Dip. Fam Med

Danielle Strachan <drhstrachan@yahoo.com>

\section{Goodday Dr. Gülsüm Öztürk Emiral,}

It is my esteemed honor to be able to address you today and I hope that this email finds you in good spirits. My name is Dr. Danielle Strachan-Bowleg, and I am a third year post graduate resident in the Family Medicine program at the University of the West Indies, Nassau, Bahamas campus. I am presently in the beginning stages of formulating my research project which is mandatory for my post graduate degree to obtain a DM in Family Medicine. My aim is to conduct a cross-sectional survey to assess the knowledge, perception and treatment of metabolic syndrome in a focus group of physicians. I came across your study, "DEVELOPMENT OF "METABOLIC SYNDROME KNOWLEDGE LEVEL SCALE (METS-KS)" AND ITS VALIDITY AND RELIABILITY STUDY FOR TURKEY" in my literature review, and I am writing to request permission to access a copy of the original questionnaire used as I feel its format will be beneficial to my purpose, and also permission to actually re-use a modified version of the questionnaire in my own study, of course giving you and your research team full acknowledgement. I hope you and your team will be most accommodating to my efforts to report on some of the statistics on metabolic syndrome in my country and in this region. Looking forward to hearing from you soon, with hopes of affirmative assistance in my venture. if you have any further questions about my research, please do not hesitate to contact. Thank you in advance for your time.

Kind regards,

Dr. Danielle Strachan-Bowleg B.Sc., M.B.B.S., Dip. Fam Med 
BA Burcu Atalay <burcustkn@hotmail.com>

듬 Feb 7 at 7:39 AM To: drhstrachan@yahoo.com

Dear Danielle Strachan,

I'm glad you're using "Metabolic Syndrome Knowledge Level Scale". As long as you cite, of course you can use. Good work.

Best regards. 


\section{APPENDIX E: APPROVALS}

Third \& West Terraces, Centreville Post Office Box $\mathrm{N}-8200$

Nassau, The Bahamas
Website: www.phabahamas.org

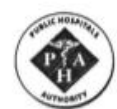

Telephone (242) 323-7750 (242) $502-1400$ : (242) 323-7744 Or: (242) 323-1422

The Public Hospitals Authority

Corporate Centre

Ref No. PHA/31/1-B-2

$29^{\text {th }}$ July, 2019

Dr. Danielle Strachan-Bowleg

Senior House Officer

Princess Margaret Hospital

Nassau, Bahamas

Dear Dr. Strachan-Bowleg,

RE: RESEARCH PROPOSAL - "Knowledge regarding Metabolic Syndrome and Adherence to NCEP.ATP III Clinical Practice Guidelines among Physicians in New Providence, The Bahamas"

The PHA/UWI Research Ethics Committee on the $25^{\text {th }}$ July, 2019 reviewed and approved your Research Proposal Study for one year in principle pending receipt of and subject to:

a. Include in the inclusion criteria "emergency medicine" epidemiologist and psychometry

b. Once identified metabolic syndrome and Adherence to NCEP.ATP III what will be done for the patient. Consider incorporating into the objective/otherwise.

c. Approval required from Director of Public Health/Chief Medical Officer, Hospital Administrators and Chairman, Medical Advisory Committee/Medical Chief of Staff of the $\mathrm{PMH}, \mathrm{SRC}$ and GBHS.

Once approvals have been granted by the above-named, the study can begin. Kindly provide a copy of your completed study to the committee.

Best Wishes.

Sincerely,

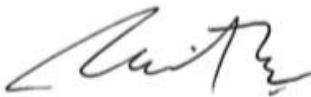

Dr. Nelson A. Clarke

Chairman

PHA/UWI Research Ethics Committee

\section{$\mathrm{JEH} / \mathrm{snmg}$}

cc. Hospital Administrators, PMH, SRC \& GBHS

Chairman, Medical Advisory Committees/Medical Chiefs of Staff, PMH, SRC

$\&$ GBHS

Director of Public Health/Chief Medical Officer, Ministry of Health

Dr. Anthony Frankson, Epidemiologist, UWI

"Working otaether for Best Oualitu Wtealthcare" 
October 14, 2019

Director of Public Health

Ministry of Health

Meeting Street

Nassau, Bahamas

\section{RE: RESEARCH PERMISSION}

Dear Ms. McMillan,

My name is Dr. Danielle Strachan-Bowleg, and I am a fourth year post graduate resident in the Family Medicine program at the University of the West Indies, Nassau, Bahamas campus. I am presently in the process of commencing my research project which is mandatory for my post graduate degree to obtain a DM in Family Medicine. My aim is to conduct a crosssectional survey to assess the knowledge, perception and treatment of metabolic syndrome in a focus group of physicians. The title of my study is "KNOWLEDGE REGARDING METABOLIC SYNDROME AND ADHERENCE TO NCEP-ATP III CLINICAL PRACTICE GUIDELINES AMONG PHYSICIANS IN NEW PROVIDENCE, THE BAHAMAS".

I am writing to request permission to be able to administer my questionnaire among the public health physicians throughout the community. This will allow my study to have a large scope of results spanning across most of the health care sector in New Providence, Bahamas. I hope you and your team will be most accommodating to my efforts to report on some of the statistics on metabolic syndrome in this region. Looking forward to hearing from you soon, with hopes of affirmative assistance in my venture. If you have any further questions about my research, please do not hesitate to contact via emaildrhstrachan@yahoo.com. Thank you in advance for your consideration.

Kind regards,

Dr. Danielle Strachan-Bowleg

B.Sc., M.B.B.S., Dip. Fam Med 
Our Ref: HEA/102/17

$21^{\text {st }}$ October, 2019

Dr. Danielle Strachan - Bowleg

Family Resident Program

University of the West Indies

Nassau, Bahamas

Dear Dr. Strachan - Bowleg,

\section{RE: PERMISSION TO CONDUCT RESEARCH ON “KNOWLEDGE REGARDING METABOLIC SYNDROME AND ADHERENCE TO NCEP - ATP II CLINICAL PRACTICE GUIDELINES AMONG PHYSICIANS IN NEW PROVIDENCE, THE BAHAMAS}

Your correspondence dated $14^{\text {th }}$ October, 2019 was received and contents noted.

Please be advised that your request to execute a research project at Department of Public Health Community Clinics using physicians as study participants has been approved. You are requested to coordinate said research with the Community Health Services Administrator, Mrs. Charlene Bain.

Additionally, you are requested to provide a copy of your research findings to the Ministry of Health upon completion.

Best regards,

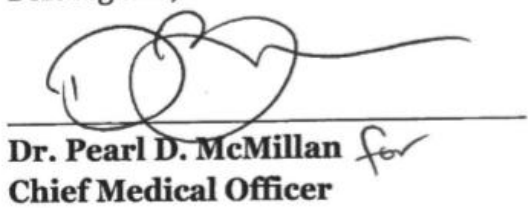

$\mathrm{PDM} / \mathrm{vabs}$

cc. Mrs. Charlene Bain - Community Health Services Administrator Dr. Jillian Bartlett - Acting Medical Staff Coordinator 
October 14, 2019

Medical Chief of Staff

Princess Margaret Hospital

Shirley Street

Nassau, Bahamas

\section{RE: RESEARCH PERMISSION}

Dear Dr. Burnett-Garroway,

My name is Dr. Danielle Strachan-Bowleg, and I am a fourth year post graduate resident in the Family Medicine program at the University of the West Indies, Nassau, Bahamas campus. I am presently in the process of commencing my research project which is mandatory for my post graduate degree to obtain a DM in Family Medicine. My aim is to conduct a crosssectional survey to assess the knowledge, perception and treatment of metabolic syndrome in a focus group of physicians. The title of my study is "KNOWLEDGE REGARDING METABOLIC SYNDROME AND ADHERENCE TO NCEP-ATP III CLINICAL PRACTICE GUIDELINES AMONG PHYSICIANS IN NEW PROVIDENCE, THE BAHAMAS".

I am writing to request permission to be able to administer my questionnaire among the physicians practicing in the hospital based setting. This will allow my study to have a large scope of results spanning across most of the health care sector in New Providence, Bahamas. I hope you and your team will be most accommodating to my efforts to report on some of the statistics on metabolic syndrome in this region. Looking forward to hearing from you soon, with hopes of affirmative assistance in my venture. If you have any further questions about my research, please do not hesitate to contact via email drhstrachan@yahoo.com. Thank you in advance for your consideration.

Kind regards, 
Dr. Danielle Strachan-Bowleg

B.Sc., M.B.B.S., Dip. Fam Med

October 14, 2019

Head of Psychiatry

Sandilands Rehabilitation Center

Fox Hill

Nassau, Bahamas

\section{RE: RESEARCH PERMISSION}

Dear Dr. Combie,

My name is Dr. Danielle Strachan-Bowleg, and I am a fourth year post graduate resident in the Family Medicine program at the University of the West Indies, Nassau, Bahamas campus. I am presently in the process of commencing my research project which is mandatory for my post graduate degree to obtain a DM in Family Medicine. My aim is to conduct a crosssectional survey to assess the knowledge, perception and treatment of metabolic syndrome in a focus group of physicians. The title of my study is "KNOWLEDGE REGARDING METABOLIC SYNDROME AND ADHERENCE TO NCEP-ATP III CLINICAL PRACTICE GUIDELINES AMONG PHYSICIANS IN NEW PROVIDENCE, THE BAHAMAS".

I am writing to request permission to be able to administer my questionnaire among the physicians practicing in the psychiatric hospital. This will allow my study to have a large scope of results spanning across most of the health care sector in New Providence, Bahamas. I hope you and your team will be most accommodating to my efforts to report on some of the statistics on metabolic syndrome in this region. Looking forward to hearing from you soon, with hopes of affirmative assistance in my venture. If you have any further questions about my research, please do not hesitate to contact via email drhstrachan@yahoo.com. Thank you in advance for your consideration. 
Kind regards,

Dr. Danielle Strachan-Bowleg

B.Sc., M.B.B.S., Dip. Fam Med

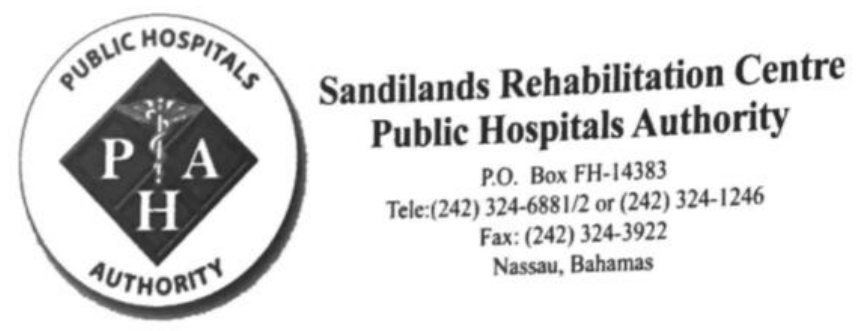

October 22, 2019

Dr. Danielle Strachan·Bowleg

Family Medicine Resident

Nassau, Bahamas

Dear Dr. Strachan-Bowleg:

I am granting approval to you to engage the physicians at the Sandilands Rehabilitation Centre in your study.

You will also have to request approval from the Hospital Administrator, Ms. Mary Walker.

Submitted for your information.

Sincerely,

Qlocmbi

Dr. Eugenia Combie Medical Chief of Staff

EC:lkt
MEDICAL CHIEF OF STAFF

OCT 222019

ADMINISTRATION DEPT. ANDILANDS REHAB, CENTRE, PHA 